\title{
NUMERICAL AND EXPERIMENTAL MODAL ANALYSIS OF MACHINE TOOL SPINDLE SYSTEMS
}

\author{
By \\ Hemachandran Sambandamurthy, B.Eng \\ Aeronautical Engineering \\ Anna University, Chennai, India, 2010

\begin{abstract}
A thesis presented to Ryerson University
In partial fulfillment of the requirements for the degree of

Master of Applied Science in the Program of

Aerospace Engineering
\end{abstract}

Toronto, Ontario, Canada, 2014

(C) Hemachandran Sambandamurthy 


\section{Author's Declaration}

\section{AUTHOR'S DECLARATION FOR ELECTRONIC SUBMISSION OF A THESIS}

I hereby declare that I am the sole author of this thesis. This is a true copy of the thesis, including any required final revisions, as accepted by my examiners.

I authorize Ryerson University to lend this thesis to other institutions or individuals for the purpose of scholarly research.

I further authorize Ryerson University to reproduce this thesis by photocopying or by other means, in total or in part, at the request of other institutions or individuals for the purpose of scholarly research.

I understand that my thesis may be made electronically available to the public. 


\begin{abstract}
The need for air transportation has increased drastically over the last few decades, to cope with these increasing demands manufacturing companies are trying to improve and speed up their machining processes. High precision in surface finish is required in aerospace industry. To achieve higher production rates, the cycle time (time required for a part or component to be machined) should be reduced. However, chatter often poses a limiting factor on the achievable productivity. One of the major parameters contributing to chatter is the fundamental frequency of the machining system. The system consists of cutting tool, tool-holder, and machine-tool spindle. Impact test is commonly used to determine frequency response function (FRF), which in turn is utilized to acquire the natural frequencies of the system. Impact testing at each stage of machining is impractical, as it will hinder production. Therefore, the study conducted in this report introduces Finite Element Analysis (using ANSYS $^{\circledR}$ ) to create an accurate model, which predicts the natural frequencies of the system. A calibrated FEM model of the spindle system, where the bearings are modelled as linear spring elements, is introduced. The spring constants are then varied such that the FEM natural frequencies match the theoretical/experimental ones. This technique is extremely useful as it reduces the downtime of the machine due to impact testing. An experimental setup of the spindle system was designed and fabricated. Impact tests were conducted on the spindle-setup and the results were used to validate the model. The proposed method could be ultimately used to incorporate the bearings degradation/aging effects into the dedicated calibrated FEM model, and to predict the system frequencies in terms of spindle age, i.e., number of in-service hours.
\end{abstract}




\section{Acknowledgement}

First and foremost, I would like to express my deepest gratitude to my supervisor, Prof. Seyed M. Hashemi for his patience, motivation, immense knowledge and enthusiasm. Without his continuous encouragement and support, this thesis would not have been completed or written.

I would like to thank Dr. Hamid Ghaemi, for his immense support and valuable time in helping me design and set up the experimental lab. Without his insight and knowledge, the lab would have been a distant dream.

I would like to thank my research colleagues Supun and Tahmaseb, my friends Partha, Siju, Simbu, Ajeesh and my roommates for their kind words during tough times and also for their moral support.

Finally, I thank my parents Dr. Sambandamurthy and Umayal, for their unconditional love, support and faith in me. My uncles Dr. Manickam and Late Dr. Selvaraj for their unquestionable support and belief in me.

This project was supported by FED-Dev ARC, Ontario, in collaboration with Centra industries Inc. (Cambridge, Ontario). Partial supports by NSERC and Ryerson University are also acknowledged. 


\section{Table of Contents}

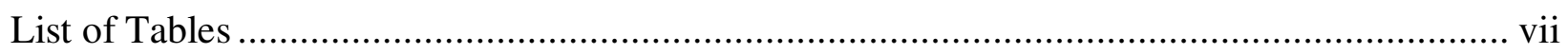

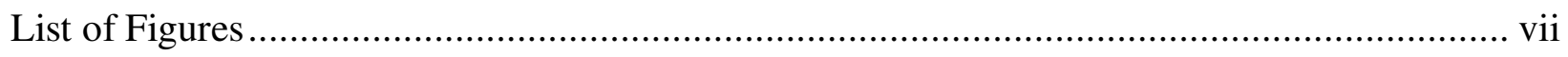

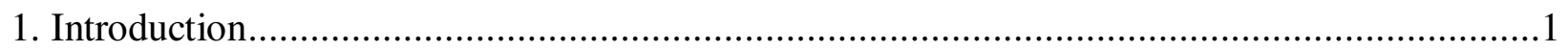

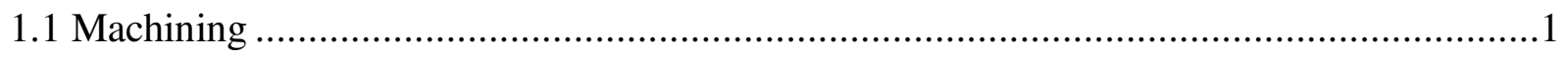

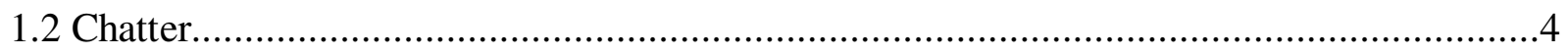

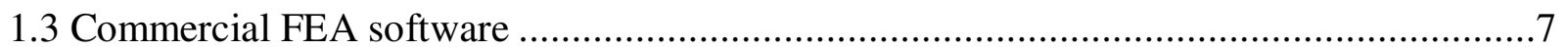

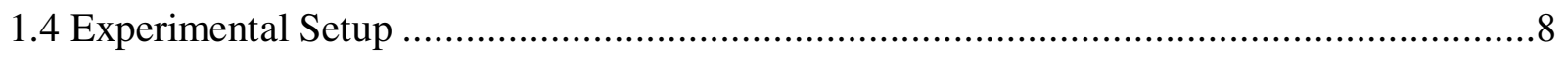

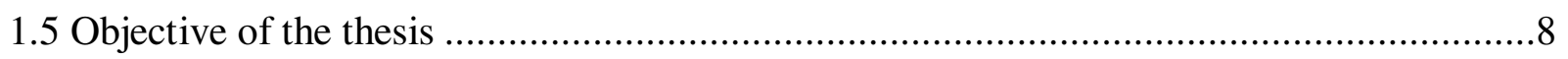

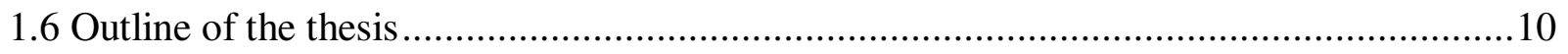

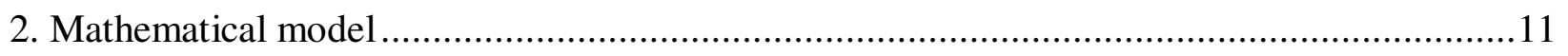

2.1 Derivation of the governing differential equations ....................................................11

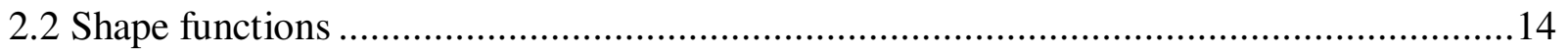

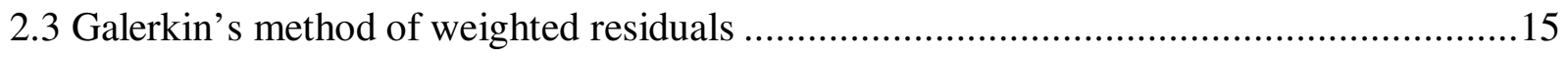

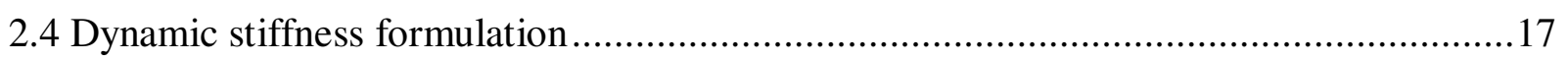

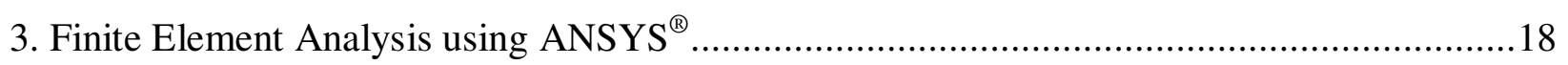

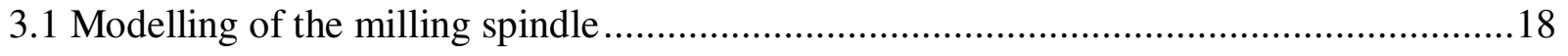

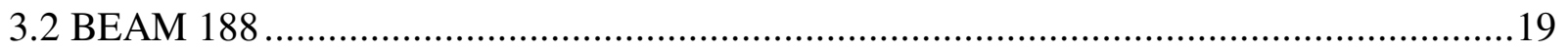

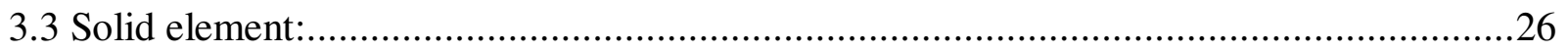

3.4 Experimental Table Setup:......................................................................................

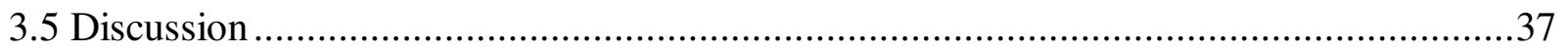

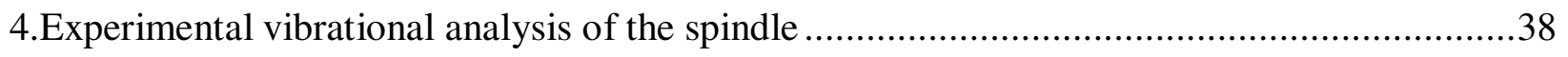

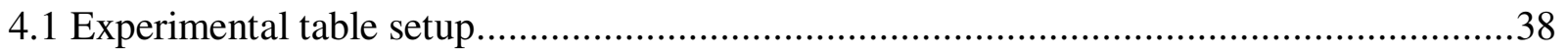

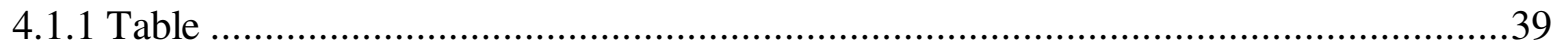

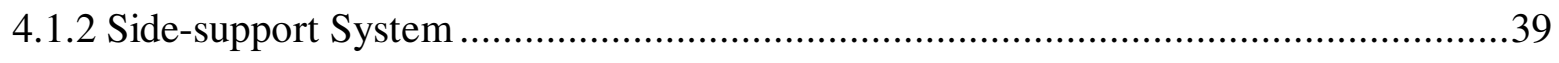

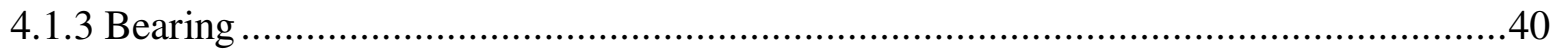

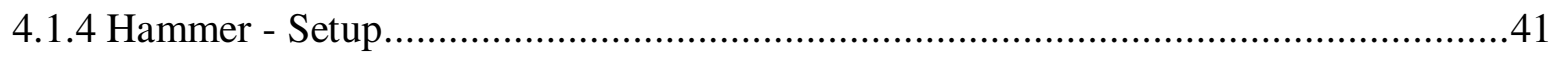

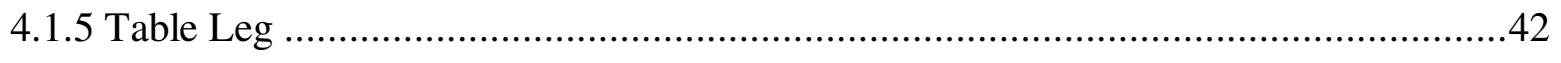

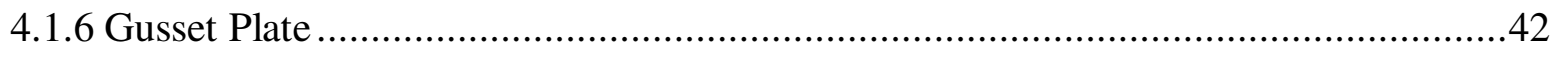




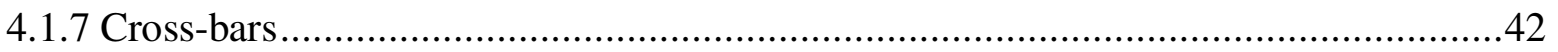

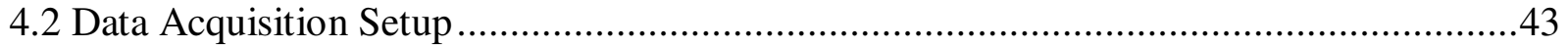

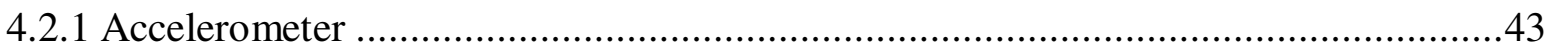

4.2.2 Data Acquisition Hardware ........................................................................44

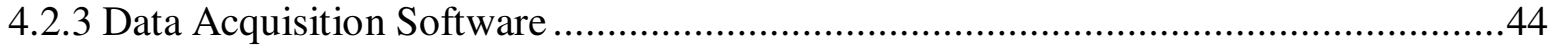

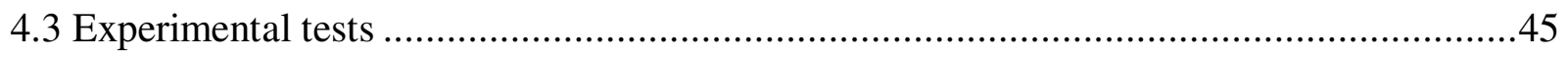

4.3.1 Impact test on the experimental table-setup.................................................46

4.3.2 Impact test on the spindle setup..............................................................49

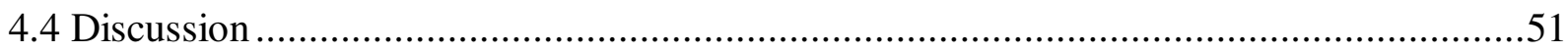

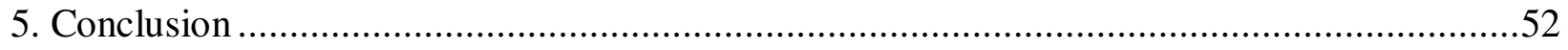

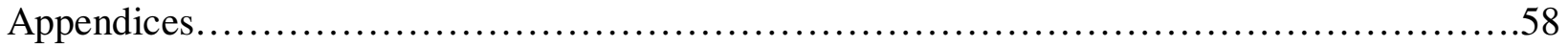

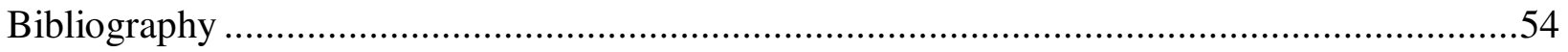




\section{List of Tables}

Table 1: Natural Frequencies of the non-spinning spindle using Beam 188 element and simple-

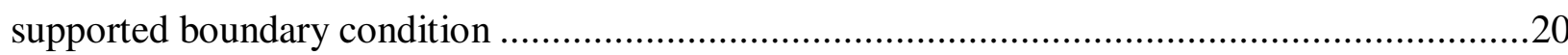

Table 2: Natural frequencies of the Beam-spindle by modifying the spring constant, k............23

Table 3: Natural frequencies of solid spindle with changing spring constant, k.....................25

Table 4: Natural frequencies of the spindle modeled by Solid elements and simply-supported

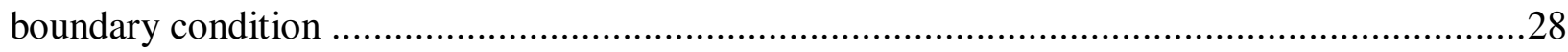

Table 5: Natural frequencies of the Solid-spindle by modifying the spring constant, k..............31

Table 6: Natural frequencies of solid spindle with changing spring constant, k......................31

Table 7: Natural frequencies of the experimental table setup modeled using Solid elements and

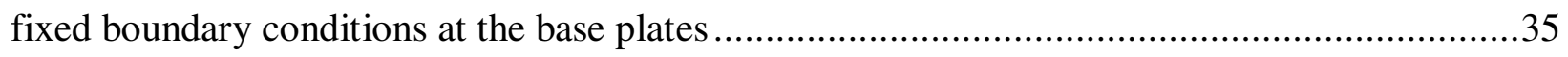

Table 8: Comparison of impact test and simulation results ...........................................51

\section{List of Figures}

Figure 1 Three dimensional spinning beam $[44]$.......................................................... 11

Figure 2: Schematic diagram of OKADA VM500 spindle [47] ...................................... 18

Figure 3: Spindle modeled in CATIA V5 .................................................................... 19

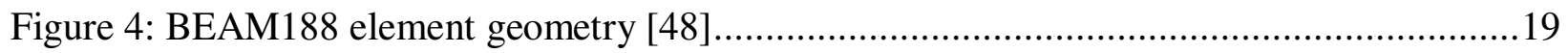

Figure 5: Beam 188 with simply supported boundary condition ....................................20

Figure 6: Convergence test for the fifth flexural frequency of the spindle system using Beam188

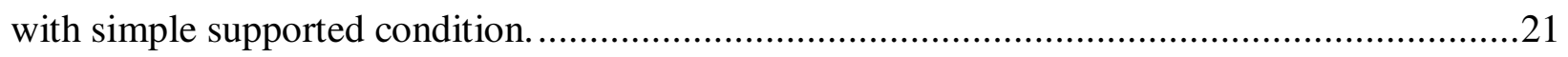

Figure 7: Mode shapes for spindle system using BEAM188 elements with SS boundary conditions .22

Figure 8: Mode shapes for spindle system using BEAM188 along with COMBIN14 elements..24 
Figure 9: Beam 188 with COMBIN element for bearings

Figure 10: Natural frequency vs Spring constant k, for beam elements ................................26

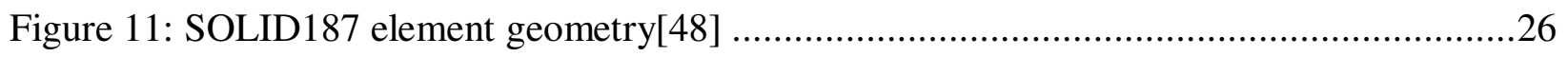

Figure 12: Solid spindle model..............................................................................27

Figure 13: Meshed Solid spindle model..............................................................27

Figure 14: Solid spindle model with Simply-supported condition ...................................28

Figure 15: Convergence test for Solid elements; first bending frequency ............................29

Figure 16: Mode shapes of spindle system using SOLID187 with SS boundary conditions........30

Figure 17: Mode Shapes for spindle system using SOLID187 and COMBIEN14 elements;

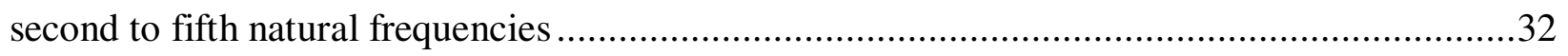

Figure 18: Mode Shapes for spindle system using SOLID187 and COMBIEN14 elements; sixth

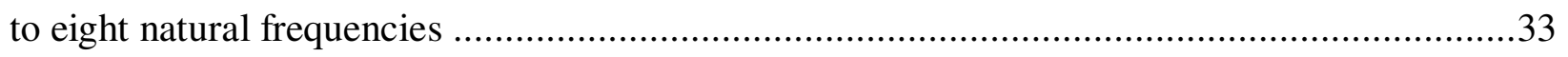

Figure 19: Solid spindle model with spring-damper boundary condition..............................34

Figure 20: Natural frequency vs Spring constant k, for solid elements ...............................34

Figure 21: Meshed experimental table setup modeled using SOLID 187 .............................36

Figure 22: Convergence test for Solid table-setup.................................................. 36

Figure 23: Schematic diagram of a typical experimental setup..........................................38

Figure 24: Experimental table-setup along with the spindle .......................................40

Figure 25: Spindle and excitation hammer-setup ................................................. 41

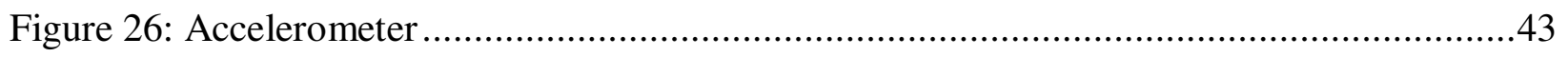

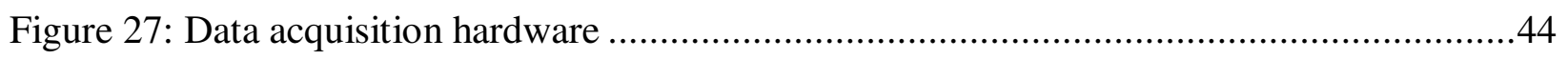

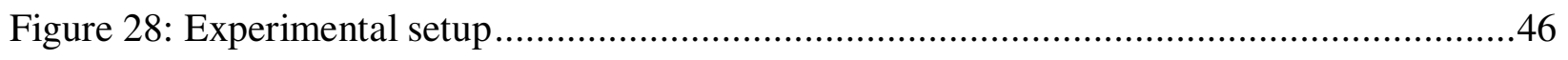

Figure 29: Location of accelerometers for impact test on experimental table-setup ..................47 
Figure 30: Time domain plot of table setup

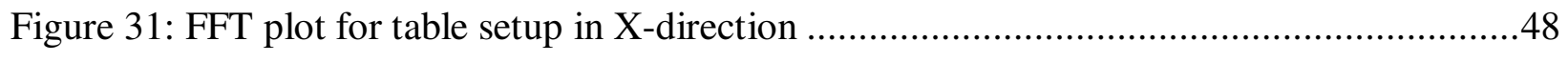

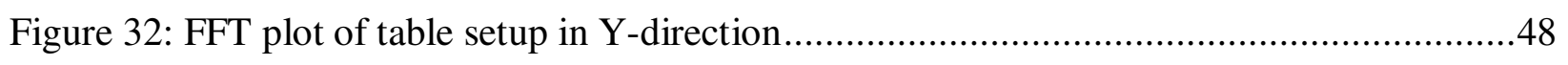

Figure 33: Location of accelerometers for impact testing on the spindle setup ......................49

Figure 34: Time domain plot of spindle setup.........................................................50

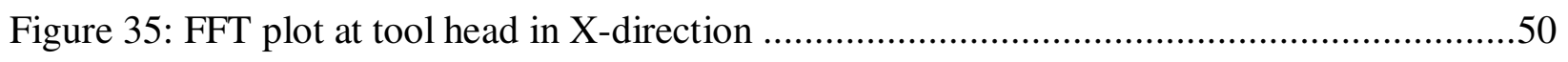

Figure 36: FFT plot at tool head in Y-direction .......................................................50 


\section{Introduction}

\subsection{Machining}

With the progress of mankind the need for materials has increased significantly. It is this need that has driven us to create or produce, which is the basis of manufacturing. Until the 18th century, humans were able to create the products they need with their hands. Those people who manufactured commodities by hand were called as artisans and craftsmen, a good example will be potters and blacksmiths.

With the increase in population the demand also increased proportionally. This led to the industrial revolution in the $19^{\text {th }}$ century, which changed the face of manufacturing industry dramatically. The introduction of machines to mass produce commodities effectively decreased the reliance on human. It also significantly decreased the production time and the cost associated with it. This period can be considered as the golden age of manufacturing industry. Ever since then, there has been a continuous demand for more goods. This has led to modification in existing manufacturing processes to meet the increasing demands.

Manufacturing sector contributed about 16 percent of the global GDP (Gross Domestic Product) in 2010, the valve was at $\$ 7.5$ trillion in 2010 from $\$ 5.7$ trillion in 2000 [1]. A major portion of the manufacturing sector comprises of engineering production. These include components manufactured for transportation, power generation, aerospace and other industries. The engineering section of the manufacturing sector can be broadly classified into chip-removal production process and chip-less production process.

Casting, moulding, joining and 3-D printing or additive manufacturing are the chip-less production processes in which material is added at a controlled manner to get the desired profile. These processes have the advantage of less use of materials, especially when it comes to mass production. Heavier components and complex structures can be manufactured with much ease. Even though efforts have been made to improve dimensional accuracy and smooth surface finish of these processes, they are not up to the standard for certain industries like aerospace, where high tolerance and surface finish are required. 
The chip-removal production process is commonly known as machining process or subtractive manufacturing, in which unwanted material is removed to obtain the desired shape. A finished product is obtained from a raw work piece after a number of machining operations have been performed on it. These machining operations can be categorised into following groups:

\section{i. Traditional or conventional machining process \\ ii. Non-traditional machining process.}

The emergence of new technologies like electrical discharge machining (EDM), ultrasonic machining and electron beam machining (EBM) have changed the face of traditional machining operations. These constitute the non-traditional machining processes. Hard materials like titanium aluminide ( $\mathrm{TiAl})$ and brittle materials like diamond, which were once considered impossible to machine, are a reality now because of these new technologies [2].

Traditional or conventional machining is defined as any process in which small chips of material are removed from the work piece with the use of cutting tool. Operations such as drilling, milling and turning fall under this category. These processes are based on the rotary or reciprocating principle of operation. There should be a relative motion between the cutting tool and work piece for the chip removal process to take place. In some cases, the tool is fixed and work piece rotates as in lathe machine. In others, the work piece is fixed and tool rotates, as in milling machines [3] .

Machining is a vital manufacturing process for industries like automobile and aerospace, where good surface finish and dimensional tolerance are necessary. Competition from other manufacturers and the need to produce quality products in less time are increasing with every passing year. One way to cope with the increase in demand is to increase the number of manufacturing units, which will result in additional setting up cost. The other way is to increase the number of components that can be made in a given time, thereby reducing the production time. The latter method is viable as it increases the efficiency of the process.

This has led companies to look for various means to improve their machining process. The time taken to machine a certain component or part is called the cycle time. It is this cycle time which the companies are looking to reduce in order to maximize their production rate. The cycle time depends upon the following two parameters [3]: 
- Spindle speed

- Material removal rate (MRR)

\section{Spindle speed rate}

It is the rate at which the machine spindle rotates, generally measured in revolution per minute (rpm). The spindle holds either the material or the tool. Increasing the speed increases the rate at which material is removed.

\section{Material removal rate}

The amount of material removed per unit second is the material removal rate. This depends upon the relative motion between the tool and work namely the cutting speed and feed rate furthermore; the penetration of the tool known as the depth of cut also affects the material removal rate [3].

It was long believed that these factors posed a limiting effect on optimizing the machining process. It was later found that chatter, the vibration which occurs during the machining activity, places a major constrain on the cycle time. Even with the advances in technology, chatter for the past fifty years has placed a limitation on quality of parts and production output in machining operation [2].

The lack of dynamic stiffness of one or more elements of the machine can lead to three types of vibrations, namely free vibrations, forced vibrations and self-excited vibrations. The machine system comprises of the work piece, the tool holder, the cutting tool and the machine tool. Free vibrations occur when the system is allowed to vibrate freely. External harmonic excitations cause forced vibration in a mechanical system. If the cause of vibration is identified then free and forced vibrations can be reduced or eliminated. Of the three vibrations self-excited vibration is the least controllable and the most undesirable that causes instability to the system [2]. 


\subsection{Chatter}

In machining process self-excited vibration caused by the interaction of the cutting tool and the part due to chip removal process is known as chatter. Chatter causes instability to the system and therefore it is undesirable in machining process, because of the following negative effects [2]:

- Poor surface finish

- Accelerate tool wear

- Damage to machine tool

- Reduction in metal removal rate

- Increased production time

- Waste of energy and materials

In certain industries like the aerospace and automotive manufacturing sectors, where tight surface tolerance are required, additional manual operations has to be done to achieve the desired output because of chatter. Additional manufacturing processes will increase production cost and time.

Chatter is commonly classified into two categories namely, (i) primary chatter (generated by the cutting process itself) and (ii) secondary chatter (generated by the regeneration of waviness on the workpiece surface). Depending on the self-exciting mechanism that causes the vibration, chatter can be classified into the following types [4]:

1. Frictional chatter

2. Thermo-mechanical chatter

3. Mode-coupling chatter

4. Regenerative chatter

In 1906 Taylor [3] conducted experiments on machining process and was the first to talk about chatter as an obscure problem for a machinist. He observed the effect of chatter depends on the spindle speed and also that of chip thickness. Schmidt [5] suggested that self-induced and forced vibration in machining can be caused due to periodic shearing of the metal chips. Arnold 
[6] in early 1940's developed a broad theory for chatter vibration. He conducted extensive experimental research on turning process and concluded that chatter occurs due to the decrease in cutting force which happens as a result of increase in spindle speed. As the tool wear increases this effect becomes more prominent.

Tobias and Fishwick [7] introduced the idea of instability in cutting process as a reason for chatter. They noted that varied chip thickness affects the cutting force, which in turn changes the amplitude of vibration causing regenerative chatter. Eisele [8] stated machining as a continuous, dynamic process with forces in the tool tip constantly changing, as opposed to the previous perception of steady state, discrete process. This idea was taken forward by Tobias [9] who considered machining as a dynamic process, in which the cutting speed, chip thickness, feed rate and cutting angle can vary independent of each other. The concept of stability lobes, a plot between axial depth of cut and spindle speed, was proposed by Tobias to identify regions of stable cutting without chatter. This was in agreement with the view given by Tlusty and Polacek [10] stating that the stability limits based on dynamics of the system can be created. Tlusty and Polacek showed when depth of cut passes beyond the limit, instability arises. This primarily is due to increase in oscillation leading to chatter. A graphical method representing the dynamic characteristics of the machine was presented by Tobias and Gurney [11]. They modeled the machine tools as a series of simple mass-spring systems and put forward the theory that regenerative chatter is traced as a wave pattern on the work piece because of the relative vibration between the tool and work piece. The amplification in the tool head is governed by the shift in phase between the preceding and current wave being traced on the work piece.

Most research papers on chatter during 1960's were focused on turning, which is the simplest of machining processes. Furthermore, the theory proposed by Tobias, Tlusty and Polacek [9, 10] were based on one-dimensional system, which in reality is multi-dimensional. Complex machining process, like milling, required a modified approach from the earlier proposed models. During milling process not all cutter teeth are in contact with the surface at the same time. In fact only a portion of each teeth comes into contact with the surface during tool revolution. Each tooth comes in contact with the wave left over by the previous tooth during cutting. The first comprehensive mathematical model for milling was proposed by Sridhar et al. 
[12], where they developed a stability theroy based on numerical method. A similar approach was also presented by Optiz and Bernardi [13]. These models were based on the fact that each tooth will remain in contact with the work piece during the entire length of the arc to be machined. This is the case for linear approach in chatter modeling [14]. In practice, the contact between the tool and work piece is lost when the amplitude increases beyond the stability limit. One of the first researchers to address this non-linearity were Tlustly and Ismail [15]. They put forward a widely accepted theory that vibration stabilises after a point of time, which is the basis of their non-linear chatter concept. Chatter does not grow indefinitely, it grows till the tool is in contact with the work piece and after that diminshes. As the amplitude of vibration increases, the tool starts oscillating due to phase shift between the preceeding waves on the surface and reaches a point were it loses contact with work piece. Yoshitaka et al. [16] proved the above theory with an experimental setup, where current was passed through work piece and machine during the machining process. Whenever there was chatter, they noticed a drop in current at the toolmachine contact point. This indicated the presence of an open circuit as tool lost contact with work peice, which proved the theory. They assumed the presence of a resitive force induced by the tool as it moves forward along the cut. At lower spindle speeds, the resistive force considered in their equation resulted in wider region of stability. This effect was also observed experimentally. Tlusty and Ismail [17] took into account the periodic forces and teeth in contact during milling process and proposed a new model. They used time domain digital simulation to show the dynamic behaviour. Altintas and Budak [18] took into account the chip thickness, interaction with the structure, and time varying directional factors in developing an analytical method for predicting stability limits in milling process. Recent researches have also taken into account the tool wear in calculating the stability of the machining process. Like all components, the tool is also fragile and can be subjected to change in size and shape over a period of time, affecting the stability of the system [19]. At low spindle speeds, the stability of the system increases with tool wear [20], due to the effect of process damping. Generally, tool wear is undesirable as it reduces the tool life and should also be taken into account. 


\subsection{Commercial FEA software}

With the invention of powerful computers, solving complex numerical problems has become relatively easy. These computational techniques have helped to save a lot of time, leading to the introduction of a new field in engineering namely, Finite Element Analysis. This technique has been widely used in the modelling of material removal and cutting process in machining, tool wear and failure and specific dynamic maching process [21]. Wang and Cleghorn [22] studied the stability of a spinning stepped shaft-workpeice, using Timoshenko beam finite element model. Until then, Euler-Bernoulli beam theory was used which neglects shear and rotary inertia effects. The non-rotating conditions resulted in considerable error. Baker and Rouch [23] took into account the flexibility of the tool and work piece without accessing the dynamics of cutting process model. The effectiveness in using Timoshenko beam theory was well documented by Budak et al. [24]. Due to low length to diameter ratio of machine components, Euler-Bernoulli beam theory can be inaccurate in calculation of modal frequency. Further studies conducted by the Budak et al. [25] reported both Euler-Bernoulli beam and Timoshenko beam theories do not have considerable difference at low frequency region, but Euler-Bernoulli beam theory gave inaccurate results at high frequency. The variation of tool, spindle, bearing location stiffness and operational parameters and their effects on the frequency of the system was also studied by them [26]. They found that the damping values of bearing do not affect the natural frequency of the system and the bearing stiffness affects only the first two rigid body modes of the system [27]. For performing finite element analysis, the ANSYS ${ }^{\circledR}$ commercial software is widely used [28-30]. The spindle and tool assembly setup is mostly modelled using beam elements as its evident from the studies of Budak et al. [24-27] and studies carried out by Zhang et al. [28] and Weiguang et al. [29]. Deping et al. [30] and Zhang et al. [28] used solid elements to model machine structure and the spindle assembly. COMBIN element, which is a spring-damper element is used to model the bearing and the bearing contact points [28-30]. The natural frequency of the system can be found using modal analysis in ANSYS $^{\circledR}$. Zhang et al. [28] used subspace mode exraction method for modal analysis. Block lanczos method was used by Weiguang et al. [29], the reason being the high convergence rate it has over subspace method. In the present study, the spindle is modeled using both BEAM188 and SOLID187 elements. The COMBIN14 elements are used for modeling bearing contact points. 


\subsection{Experimental works}

Starting from the ground breaking work of Taylor [3], experiments carried out on the machine system has played a vital role in understanding chatter. Hahn [31] suggested that the chatter vibration frequency depends on the natural frequency of the system. The natural frequency of the system can be found by conducting dynamic test on the spindle system. Usually modal analysis is carried out to find the frequency of the machine system. For this, the machine setup has to be excited. This excitation is provided by vibration shaker table, where the entire system is placed and the excitation is provided by the shaking table. On the other hand, impact test is the most widely used method of excitation to find the natural frequency of a system. Impact testing uses an impact hammer which provides the necessary energy to excite the system. Once the excitation is given to the system, the response has to be monitored in order to obtain the dynamic behaviour of the machine system. There are several methods to observe the output. The dynamic cutting force can be collected by dynamometers [32-35]. Microphones can also be used to calculate the response of the system, based on the sound coming from the interaction between the tool and work piece [36-38]. The most commonly used instrument to measure the dynamics of the system is the accelerometer, which measures the displacement of the body [39-41]. Computer algorithms are used to convert the data obtained from the accelerometer into desired outputs like displacement and frequency spectrum. In recent years combination of all the three methods were also used for dynamic real-time prediction of chatter, as done by Siddhpura and Paurobally [42]. The stability lobes, which give an accurate prediction of the region of chatter, depends on the dynamics of the entire system. Therefore, the natural frequency of the system has to be identified properly for better prediction of chatter. Altintas and Cao [43] experimentally proved that for accurate prediction of the machine dynamics the mounting joints which support the spindle system should also be included during analysis.

\subsection{Objective of the thesis}

Engineering manufacturing companies all over the world are trying to increase their production rate. In aerospace sector, machining of hard metals (e.g., titanium, molybdenum and tungsten) requires proper prediction of chatter, linked to the machine tool dynamic. The dimensional tolerance and surface finish required for these industries are relatively high, which 
further emphasises the need to forecast and control chatter. Since, it is not convenient and profitable to test the machine frequently to find changes in its dynamics, the calibrated spindle model developed in this research will be helpful in predicting these changes without interfering or stopping the production.

The first step in developing a stability lobe diagram involves the prediction of the natural frequency of the machine. To the best of author's knowledge, a stability lobe diagram has not been made publically available for OKADA VM500 milling machine, which is one of the oldest and widely used milling machines in the manufacturing industry. The objective of this thesis is to develop a numerical spindle model using ANSYS ${ }^{\circledR}$ software for the OKADA VM500 milling machine, which resembles the actual spindle and to validate it by conducting impact test on the actual spindle.

In what follows, the mathematical model of the spindle idealized as an assembly of uniform beam segments, and modeled using the classical finite element method, is developed. The spindle model is developed using BEAM188 and SOLID187 elements, using commercially available ANSYS $^{\circledR}$ software. The bearing boundary conditions are first applied as simple supports, and were then be modified to COMBIN14 elements. The spring constant value is modified to tune the natural frequency of the spindle to develop a calibrated model, which results in the system nominal characteristics. Impact test is carried out on the actual spindle, placed on a specifically designed table, which mimics the actual machine setup. Subsequently, the natural frequency is obtained from the simulations and the experimental tests conducted on the setup are compared.

The ANSYS ${ }^{\circledR}$ model takes into account the spindle, bearing, tool-holder and the tool in evaluating the natural frequency of the system. It is very important to take into account these components, as the dynamics of the machine system plays a vital role in developing the stability lobe diagram, which in turn, is crucial in prediction and avoidance of chatter. The model validated with experimental test results can also be extended to study the effects of bearing life and its effect on the natural frequency of the spindle. Thus, the ANSYS ${ }^{\circledR}$ model developed will be helpful in simulation of these scenarios, which otherwise require frequent vibration testing of the actual setup, resulting in loss of valuable production time. 


\subsection{Outline of the thesis}

In chapter 2, the mathematical spindle model along with the tool is modelled as a series of beam element with varying cross-section. The model is based on the works of Banerjee [44] and Martin [45]. In section 2.1, the governing differential equation is obtained using Hamilton's principle. The shape functions for the model is defined in section 2.2, which is followed by the application of Galerkin's method of weighted residuals to differential equation in section 2.3. Finally in section 2.4 , the general dynamic equation of the spindle is formulated.

In chapter 3, numerical model of the spindle using commercially available software ANSYS $^{\circledR}$ is developed and modal analysis was performed. In section 3.1, the modelling of the spindle along with the tool system is explained. BEAM188 and SOLID187 elements are used to create the model individually. In sections 3.2 and 3.3, simply supported boundary conditions are applied first at the bearing locations and they are later modified to spring-damper elements for tuning the model's natural frequency. In section 3.4, the modal analysis is performed for the experimental table setup designed for conducting impact test. The chapter ends with a brief discussion in section 3.5.

The experimental vibrational analysis of the spindle used for validation of the numerical model developed in previous chapter is discussed in chapter 4. The experimental setup design is discussed in section 4.1. The data acquisition setup used for the testing is briefed in section 4.2. In section 4.3, the impact test carried out on the spindle and the experimental table setup is discussed in detail. A brief discussion is presented in section 4.4

Finally, conclusions and recommendations for the future research work are presented in final chapter. 


\section{Mathematical model}

Classical finite element method was used to derive the mathematical model of the spindle system. The spindle along with the tool was modelled as a series of spinning beam element with varying cross-section. The mathematical model was profoundly based on the works of Banerjee [44] and Martin [45]. The elements transverse bending displacement behaviour was simulated based on Euler-Bernoulli beam formulations. For the purpose of creating a general element, bending-torsion coupling based on laminar theory was included. It also follows linear torsion gradient based on torsion theories. The Hamilton's Principle was used to derive the governing differential equation. This was followed by the application of Galerkin's residual method to obtain characteristic matrices, which was then used to formulate the general dynamic equation of the system.

\subsection{Derivation of the governing differential equations}

Consider a right-handed Cartesian coordinate system with a uniform spinning beam of length $\mathrm{L}$ as shown in Fig 1. The beam element is aligned along $\mathrm{z}$-axis and was considered rotating at a constant angular velocity $\Omega$, with mass per unit length $\mu$ and polar mass moment of inertia per unit length $\mathrm{J} . \mathrm{EI}_{\mathrm{xx}}$ and $\mathrm{EI}_{\mathrm{yy}}$ were the principal axis bending rigidities, GJ was the torsional rigidity and $\mathrm{K}$ was the bending- torsion coupling rigidity.

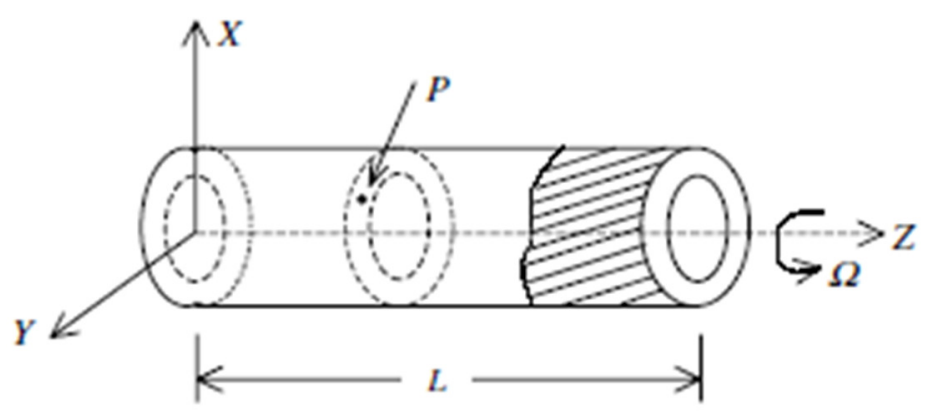

Figure 1 Three dimensional spinning beam [44]

Consider a point $\mathrm{P}$ at a cross-section $\mathrm{z}$ from the origin $\mathrm{O}$ of the beam. The position vector of the point is given by 


$$
\mathrm{P}=\mathrm{x} \hat{\imath}+\mathrm{y} \hat{\jmath}+\mathrm{z} \hat{k}
$$

where $\hat{\imath}, \hat{\jmath}$ and $\hat{k}$ are unit vectors along $\mathrm{X}, \mathrm{Y}$ and $\mathrm{Z}$ directions respectively.

Let $u$ and $v$ be the displacement of the point in $\mathrm{X}$ and $\mathrm{Y}$ direction respectively. The cross-section is allowed to rotate or twist about $\mathrm{OZ}$ by $\phi$. The position vector $\mathrm{r}$ of the generic point $\mathrm{P}$ after deformation is given by

$$
r=(u-\phi y) \hat{\imath}+(v+\phi x)
$$

The velocity of the point $\mathrm{P}$ is given by

$$
v=\dot{r}+\Omega \times r=[\dot{u}-\dot{\phi} y-\Omega(v+\phi x)] \hat{\imath}+[\dot{v}+\dot{\phi} x+\Omega(u-\phi y)] \hat{\jmath}
$$

where $\Omega=\Omega k$

The kinetic energy is defined as the energy stored in an object during motion. The general definition of kinetic energy of the beam is given by,

$$
T=\frac{1}{2} \int_{0}^{L}|v|^{2} d m
$$

Substituting equation (3) in (4) gives the kinetic energy of the system. Since the beam has doubly symmetric cross section, $\int y d A=0, \int x d A=0$ and $J=\int\left(x^{2}+y^{2}\right) d A$.

$$
T=\frac{1}{2} \rho A \int_{0}^{L}\left[\left(\dot{u}^{2}+\dot{v}^{2}\right)+2 \Omega(u \dot{v}-\dot{u} v)+\Omega^{2}\left(u^{2}+v^{2}\right)\right] d z+\frac{1}{2} \int_{0}^{L}\left[\Omega^{2} \phi^{2}+\dot{\phi}^{2}\right] d z
$$

If we consider the elastic deformation of the beam due to the applied force, then the beam will tend to return to its original position when the applied force is removed. The work done by the resistive force across the beam deformation is the strain potential energy. The total potential energy of this element is the sum of bending strain energy and torsional strain energy.

$$
U=\frac{E I_{y y}}{2} \int_{0}^{L}\left(u^{\prime \prime}\right)^{2} d z+\frac{E I_{x x}}{2} \int_{0}^{L}\left(v^{\prime \prime}\right)^{2} d z+\frac{G J}{2} \int\left(\phi^{\prime}\right)^{2} d z
$$

The derivative with respect to the length of the beam and time are represented by a prime (') and a dot (.) respectively.

Using the Hamilton's principle in the usual state 


$$
\delta \int_{t_{1}}^{t_{2}}(T-U) d t=0
$$

where $\delta$ is variational operator and $t_{1}$ and $t_{2}$ are time intervals in the dynamic trajectory. Substituting the potential and kinetic energy obtained into the Hamilton's principle and by collecting like terms and integrating by parts gives the following set of equations.

$$
\begin{aligned}
& E I_{y y} u^{\prime \prime \prime \prime}-\mu \Omega^{2} u+\mu \ddot{u}-2 \mu \Omega \dot{v}+\mathrm{k} \phi^{\prime \prime \prime}=0 \\
& E I_{x x} v^{\prime \prime \prime \prime}-\mu \Omega^{2} v+\mu \ddot{v}+2 \mu \Omega \dot{\mathrm{u}}+\mathrm{k} \phi^{\prime \prime \prime}=0 \\
& \mathrm{ku}^{\prime \prime \prime}+\mathrm{kv}^{\prime \prime \prime}+\mathrm{GJ} \phi^{\prime \prime}-\rho \mathrm{J} \ddot{\phi}+\rho \mathrm{J} \Omega^{2} \phi=0
\end{aligned}
$$

However in the spindle modeled at hand there is no material coupling; $\mathrm{k}=0$. As a result, the equation (10) representing the torsional behavior becomes uncoupled from the bending equation which are coupled through the spinning speed, $\Omega$. Therefore equation (8) and (9) can be reduced to,

$$
\begin{aligned}
& E I_{y y} u^{\prime \prime \prime \prime}-\mu \Omega^{2} u+\mu \ddot{u}-2 \mu \Omega \dot{v}=0 \\
& E I_{x x} v^{\prime \prime \prime}-\mu \Omega^{2} v+\mu \ddot{v}+2 \mu \Omega \dot{u}=0
\end{aligned}
$$

Assuming simple harmonic oscillation with the deformation, we have

$$
\begin{aligned}
& u(z, t)=U(z) \cdot e^{i \omega t} \\
& v(z, t)=V(z) \cdot e^{i \omega t}
\end{aligned}
$$

The time dependencies are separated by substituting equations (13-14) in equations (8-9)

$$
\begin{aligned}
& {\left[E I_{y y} U^{\prime \prime \prime}-\mu\left(\Omega^{2}+\omega^{2}\right) \cdot U(z)-2 i \mu \Omega \omega \cdot \mathrm{V}(\mathrm{z})\right] \cdot e^{i \omega t}=0} \\
& {\left[E I_{x x} V^{\prime \prime \prime}-\mu\left(\Omega^{2}+\omega^{2}\right) \cdot V(z)+2 i \mu \Omega \omega \cdot \mathrm{U}(\mathrm{z})\right] \cdot e^{i \omega t}=0}
\end{aligned}
$$

In this current study, non-spinning condition is considered; $\Omega=0$. Therefore, the equations (15) and (16) becomes uncoupled. 


\subsection{Shape functions}

Shape functions are the mathematical functions chosen to represent the deformed shape of the element. Usually polynomials are used to represent the shape functions [46]. Based on Euler-Bernoulli beam theory we assume that $\mathrm{U}$ and $\mathrm{V}$ variables follow fourth order polynomial function for bending along the beam.

The general form of the displacement function is

$$
\begin{aligned}
& U(z)=a_{1} z^{3}+a_{2} z^{2}+a_{3} z+a_{4} \\
& V(z)=b_{1} z^{3}+b_{2} z^{2}+b_{3} z+b_{4}
\end{aligned}
$$

After applying the necessary boundary conditions, the displacement functions are of the following form

$$
\begin{gathered}
U(z)=\left(\frac{2}{L^{3}}\left(\hat{d}_{1 x}-\hat{d}_{2 x}\right)+\frac{1}{L^{2}}\left(\hat{\phi}_{1 y}+\hat{\phi}_{2 y}\right)\right) \hat{z}^{3}+\left(-\frac{3}{L^{2}}\left(\hat{d}_{1 x}-\hat{d}_{2 x}\right)-\frac{1}{L}\left(2 \hat{\phi}_{1 y}+\hat{\phi}_{2 y}\right)\right) \hat{z}^{2}+ \\
\hat{\phi}_{1 y} \hat{z}+\hat{d}_{1 x} \\
V(z)=\left(\frac{2}{L^{3}}\left(\hat{d}_{1 y}-\hat{d}_{2 y}\right)+\frac{1}{L^{2}}\left(\hat{\phi}_{1 x}+\hat{\phi}_{2 x}\right)\right) \hat{z}^{3}+\left(-\frac{3}{L^{2}}\left(\hat{d}_{1 y}-\hat{d}_{2 y}\right)-\frac{1}{L}\left(2 \hat{\phi}_{1 x}+\hat{\phi}_{2 x}\right)\right) \hat{z}^{2}+ \\
\hat{\phi}_{1 y} \hat{z}+\hat{d}_{1 x}
\end{gathered}
$$

The equations (19-20) are rearranged of the form,

$$
\begin{aligned}
& U(z)=N_{u 1} d_{1 x}+N_{u 2} \phi_{1 y}+N_{u 3} d_{2 x}+N_{u 4} \phi_{2 y} \\
& V(z)=N_{v 1} d_{1 y}+N_{v 2} \phi_{1 x}+N_{v 3} d_{2 y}+N_{v 4} \phi_{2 x}
\end{aligned}
$$

The equations (21-22) can be re-written in matrix notation as follows

$$
U(z)=\left[N_{u}\right]\left\{d_{u}\right\}
$$

where,

$$
\left\{d_{u}\right\}=\left\{\begin{array}{l}
d_{1 x} \\
\phi_{1 y} \\
d_{2 x} \\
\phi_{2 y}
\end{array}\right\}
$$


and

$$
\left[N_{u}\right]=\left[\begin{array}{llll}
N_{u 1} & N_{u 2} & N_{u 3} & N_{u 4}
\end{array}\right]
$$

where $N_{u}$ is the shape function of the displacement function $\mathrm{U}$, in which the individual terms are

$$
\begin{array}{lc}
N_{u 1}=\frac{1}{L^{3}}\left(2 z^{3}-3 z^{2} L+L^{3}\right) & N_{u 2}=\frac{1}{L^{3}}\left(z^{3} L-2 z^{2} L^{2}+z L^{3}\right) \\
N_{u 3}=\frac{1}{L^{3}}\left(-2 z^{3}+3 z^{2} L\right) & N_{u 4}=\frac{1}{L^{3}}\left(z^{3} L-z^{2} L^{2}\right)
\end{array}
$$

The shape functions for the displacement function $\mathrm{V}$ are similar to $N_{u}$ except for the obvious change of the subscripts as both of them use similar displacement function equation.

$$
\left[N_{u}\right]=\left[N_{v}\right]
$$

\subsection{Galerkin's method of weighted residuals}

To formulate the beam stiffness, there are many methods and Galerkin's method of weighted residuals is the most popular among them. The general integral form of this is as follows.

$$
\iiint R W d V=0
$$

where $R$ is the residuals and the governing equations (15-16) will be used here. Based on the Galerkin condition, the shape functions should be used as weighting functions. The shape functions obtained earlier are applied here. This results in a complicated five term integral functions, which for simplicity is calculated individually in Appendix A. According to EulerBernoulli theory, the first term represents the bending behaviour of the beam and is as follows,

$$
\int_{0}^{L}\left(E I_{y y} U^{\prime \prime}\right)\left[N_{u}\right] d z=0
$$

this results in the following form for the element static stiffness matrix (refer to Appendix A)

$$
\frac{E I_{y y}}{L^{3}}\left[\begin{array}{cccc}
12 & 6 L & -12 & 6 L \\
6 L & 4 L^{2} & -6 L & 2 L^{2} \\
-12 & -6 L & 12 & -6 L \\
6 L & 2 L^{2} & -6 L & 4 L^{2}
\end{array}\right]\left\{\begin{array}{l}
d_{1 x} \\
\phi_{1 y} \\
d_{2 x} \\
\phi_{2 y}
\end{array}\right\}=0
$$


this square matrix is the stiffness matrix for the beam in bending. The same procedure is followed for the rest of the terms. The second term yields

$$
\begin{gathered}
\int_{0}^{L}\left[N_{u}\right]^{T}\left(-\mu\left(\Omega^{2}+\omega^{2}\right)\right)\left[N_{u}\right] d z\left\{d_{u}\right\}=0 \\
-\left(\Omega^{2}+\omega^{2}\right) \frac{\mu L}{420}\left[\begin{array}{cccc}
156 & 22 L & 54 & -13 L \\
22 L & 4 L^{2} & 13 L & -3 L^{2} \\
54 & 13 L & 156 & -22 L \\
6 L & -3 L^{2} & -22 L & 4 L^{2}
\end{array}\right]\left\{\begin{array}{l}
d_{1 x} \\
\phi_{1 y} \\
d_{2 x} \\
\phi_{2 y}
\end{array}\right\}=0
\end{gathered}
$$

The matrix in equation (32) is commonly called as inertial matrix. Third term results in dampening matrix.

$$
\begin{gathered}
\int_{0}^{L}\left[N_{u}\right]^{T}(-2 i \mu \Omega \omega)\left[N_{v}\right] d z\left\{d_{v}\right\}=0 \\
-2 i \Omega \omega \frac{\mu L}{420}\left[\begin{array}{cccc}
156 & 22 L & 54 & -13 L \\
22 L & 4 L^{2} & 13 L & -3 L^{2} \\
54 & 13 L & 156 & -22 L \\
6 L & -3 L^{2} & -22 L & 4 L^{2}
\end{array}\right]\left\{\begin{array}{c}
d_{1 y} \\
\phi_{1 x} \\
d_{2 y} \\
\phi_{2 x}
\end{array}\right\}=0
\end{gathered}
$$

Equation (16) is evaluated using the same procedure as the previous terms. This results in the following forms,

$$
\begin{gathered}
\frac{E I_{x x}}{L^{3}}\left[\begin{array}{cccc}
12 & 6 L & -12 & 6 L \\
6 L & 4 L^{2} & -6 L & 2 L^{2} \\
-12 & -6 L & 12 & -6 L \\
6 L & 2 L^{2} & -6 L & 4 L^{2}
\end{array}\right]\left\{\begin{array}{l}
d_{1 y} \\
\phi_{1 x} \\
d_{2 y} \\
\phi_{2 x}
\end{array}\right\}=0 \\
-\left(\Omega^{2}+\omega^{2}\right) \frac{\mu L}{420}\left[\begin{array}{cccc}
156 & 22 L & 54 & -13 L \\
22 L & 4 L^{2} & 13 L & -3 L^{2} \\
54 & 13 L & 156 & -22 L \\
-13 L & -3 L^{2} & -22 L & 4 L^{2}
\end{array}\right]\left\{\begin{array}{l}
d_{1 y} \\
\phi_{1 x} \\
d_{2 y} \\
\phi_{2 x}
\end{array}\right\}=0 \\
2 i \Omega \omega \frac{\mu L}{420}\left[\begin{array}{cccc}
156 & 22 L & 54 & -13 L \\
22 L & 4 L^{2} & 13 L & -3 L^{2} \\
54 & 13 L & 156 & -22 L \\
-13 L & -3 L^{2} & -22 L & 4 L^{2}
\end{array}\right]\left\{\begin{array}{l}
d_{1 x} \\
\phi_{1 y} \\
d_{2 x} \\
\phi_{2 y}
\end{array}\right\}=0
\end{gathered}
$$

these matrices are very similar to equations $(30,32,34)$ because of the usage of similar shape functions. 


\subsection{Dynamic stiffness formulation}

The matrices resulting from the previous sections are put together. The general dynamic equation of the following form is obtained.

$$
e^{i \omega t}\left(\omega^{2} \boldsymbol{M}+\omega \boldsymbol{G}+\boldsymbol{K}\right)\{d\}=0
$$

where $\{d\}$ is defined by,

$$
\{d\}=\left[\begin{array}{llllllllll}
d_{1 x} & d_{1 y} & \phi_{1 x} & \phi_{1 y} & \phi_{1 z} & d_{2 x} & d_{2 y} & \phi_{2 x} & \phi_{2 y} & \phi_{2 z}
\end{array}\right]^{T}
$$

The stiffness, inertial and gyroscopic matrices of the three dimensional spinning beam is assembled, the detail is provided in Appendix B. This provides the components required for solving the general dynamic equation. The only possible way that equation (38) can be true is, if the determinate of the matrix sum is 0 .

$$
\left|\omega^{2} \boldsymbol{M}+\omega \boldsymbol{G}+\boldsymbol{K}\right|=0
$$

The non-trivial solution of the three dimensional rotating beam will result in the natural frequencies. 


\section{Finite Element Analysis using ANSYS ${ }^{\circledR}$}

ANSYS $^{\circledR}$ is one of the widely used commercial analytical software for performing finite element analysis. The spindle was modelled in CATIA ${ }^{\circledR}$ V5 and imported to ANSYS ${ }^{\circledR}$ Academic Research, Release 14.5. After importing the model, the desired boundary conditions were applied and the model was meshed. This was followed by modal analysis which gives the natural frequency of the system. In modal analysis, the model was constraint and zero-bound (absence of external load) was the only load condition. In this analysis, simply supported boundary conditions were first applied at the bearing locations and they were later modified to COMBIN14 elements. Beam elements and solid elements were used to model the spindle individually.

\subsection{Modelling of the milling spindle}

The spindle of the OKADA VM 500, which is a vertical milling machine, was modelled using CATIA ${ }^{\circledR}$ V5. The schematic structure of the spindle is shown in Figure 2. The spindle has a total of 10 bearings, with four sets of angular contact bearings and two other ball-bearings. Apart from that, it has two belt assemblies, which provides the necessary driving force from the spindle motor. The dimensions of the spindle were measured and recorded, as shown in Appendix B. For the sake of modelling convenience, the tapered and curved areas of the spindle and tool were modelled as uniform areas. The spindle along with the tool holder and tool were modelled as a single rigid system as shown in Figure 3.

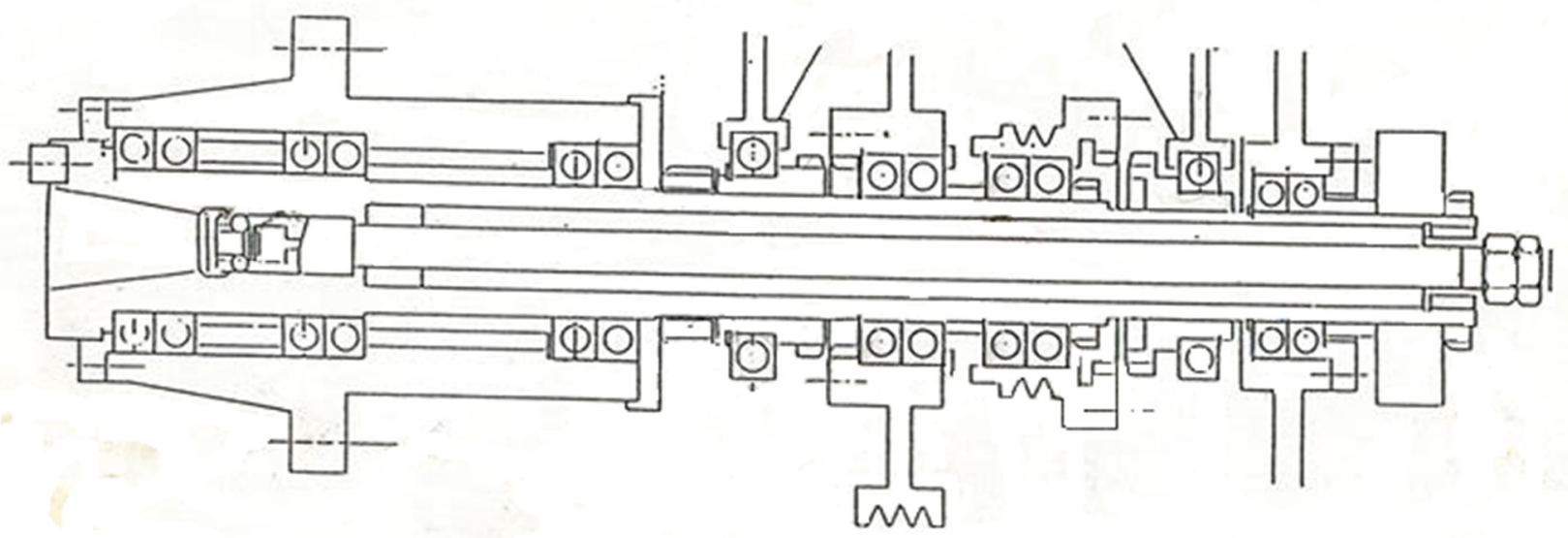

Figure 2: Schematic diagram of OKADA VM500 spindle [47] 


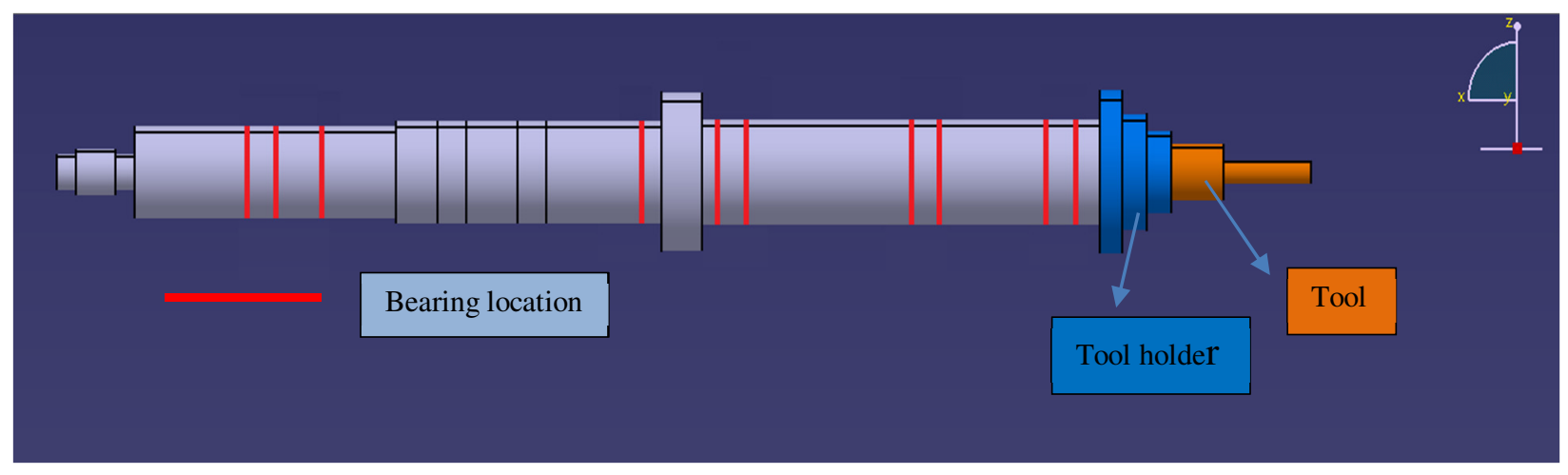

Figure 3: Spindle modeled in CATIA ${ }^{\circledR}$ V5

\subsection{BEAM 188}

The spindle was modelled using beam elements [23-26], as it is the most effective way of representing the spindle. The BEAM188 element has 2 nodes and 6 degrees-of-freedom (3 translational and 3 rotational), as shown in Figure 4. The BEAM188 element is one-dimensional line element in space and requires cross-sectional details for modelling [48], which for this case is provided in Appendix C. The material property of tool steel was used in the model. The young's modulus, $\mathrm{E}=210 \mathrm{GPa}$ and density, $\rho=7850 \mathrm{Kg} / \mathrm{m}^{3}$ was applied. At first, simply supported boundary condition was applied at the bearing locations, as shown in Fig 5. Modal analysis was carried out and the first six natural frequencies of the spindle system are tabulated in Table 1.

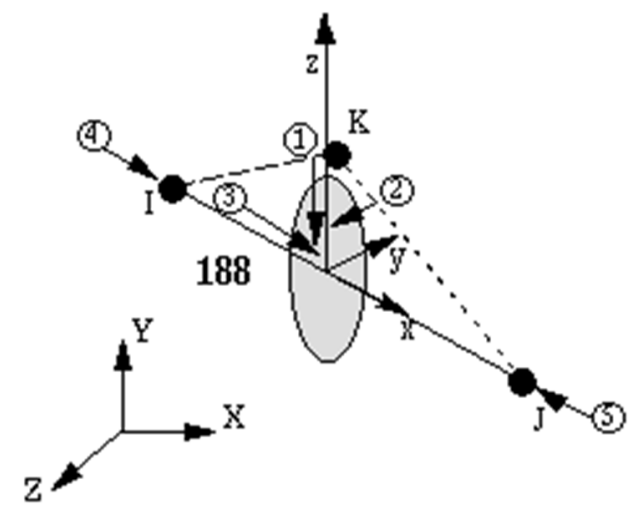

Figure 4: BEAM188 element geometry [48] 


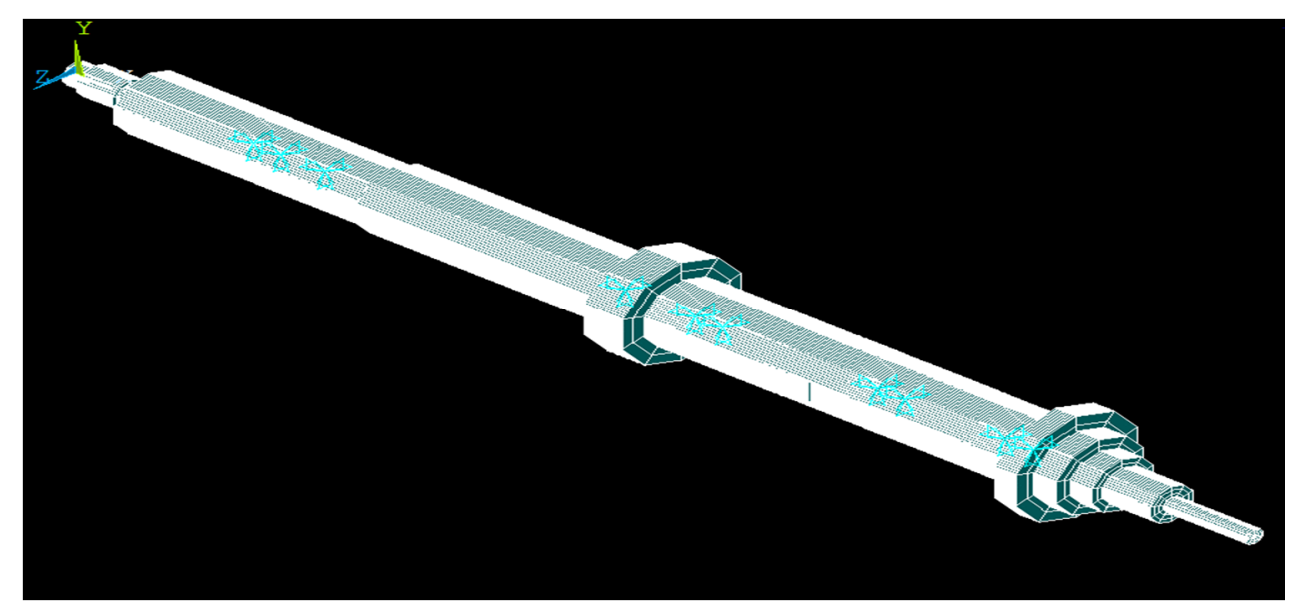

Figure 5: Beam 188 with simply supported boundary condition

Table 1: Natural Frequencies of the non-spinning spindle using Beam 188 element and simplesupported boundary condition

\begin{tabular}{|c|l|l|l|l|l|l|l|}
\hline Nodes & 23 & 45 & 67 & 89 & 111 & 133 & 155 \\
\hline Elements & 22 & 44 & 66 & 88 & 110 & 132 & 154 \\
\hline Frequency & \multicolumn{7}{|c|}{ Natural Frequencies (Hz) } \\
\hline 1 & 2367.3 & 2367.3 & 2367.3 & 2367.3 & 2367.3 & 2367.3 & 2367.3 \\
\hline 2 & 2367.3 & 2367.3 & 2367.3 & 2367.3 & 2367.3 & 2367.3 & 2367.3 \\
\hline 3 & 2790.2 & 2790.2 & 2790.2 & 2790.2 & 2790.2 & 2790.2 & 2790.2 \\
\hline 4 & 2790.2 & 2790.2 & 2790.2 & 2790.2 & 2790.2 & 2790.2 & 2790.2 \\
\hline 5 & 3802.5 & 3781.1 & 3780.8 & 3780.8 & 3780.8 & 3780.8 & 3780.8 \\
\hline 6 & 3802.5 & 3781.1 & 3780.8 & 3780.8 & 3780.8 & 3780.8 & 3780.8 \\
\hline
\end{tabular}


From Table 1 it can be seen that the first/second, third/fourth and fifth/sixth natural frequencies are similar. They are mutually orthogonal and constitute the bending lateral vibrations along Y and $\mathrm{Z}$ axes, as shown in Figure 7. Convergence study was conducted to find the least number of elements needed to obtain acceptable results, as shown in Figure 6. The model was meshed finer each time and the results obtained were recorded. From Table 1 , it can be seen that the $5^{\text {th }}$ natural frequency remains at $3780.8 \mathrm{~Hz}$ after 66 elements and does not change even after 154 elements. Therefore, the appropriate number of elements required to obtain the result was considered to be 66 elements.

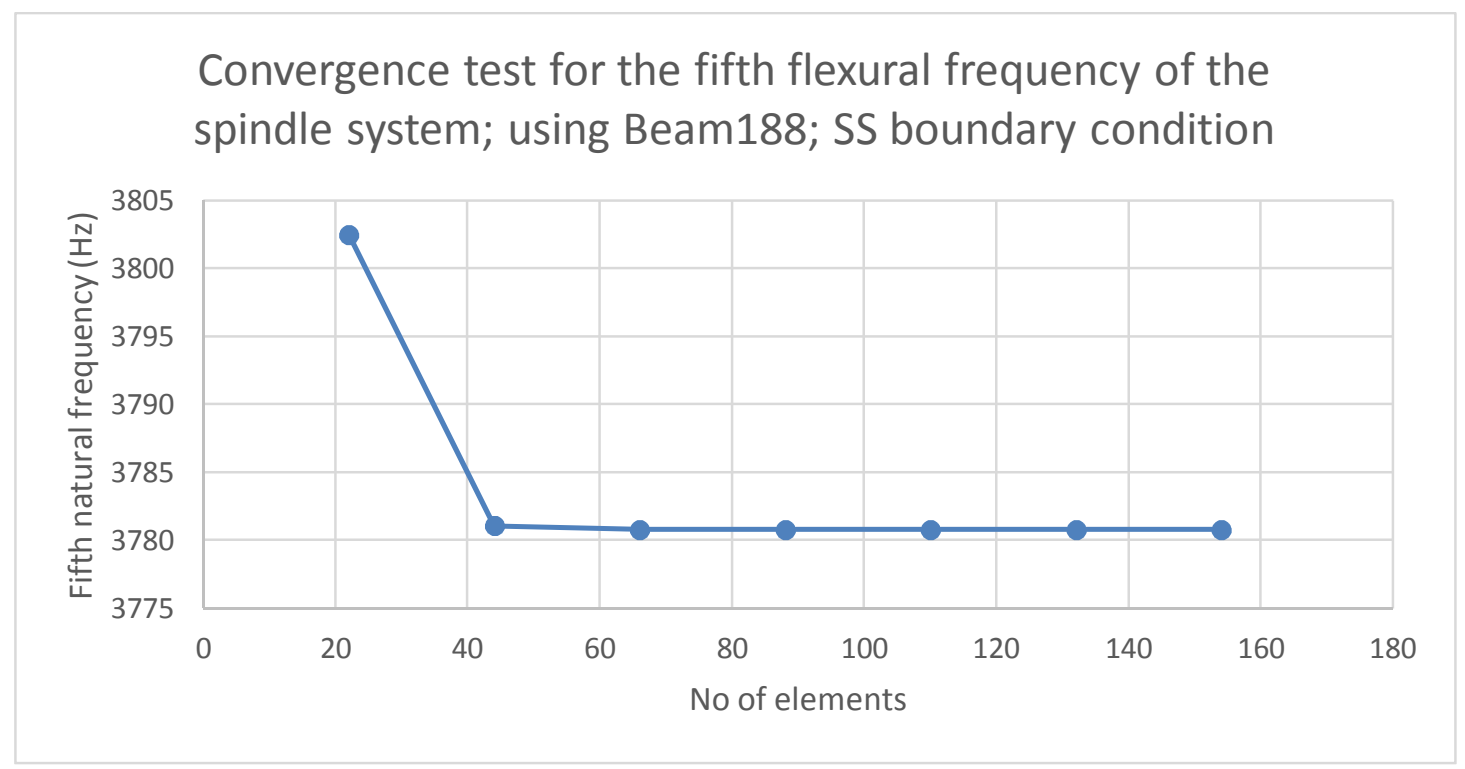

Figure 6: Convergence test for the fifth flexural frequency of the spindle system using Beam188 with simple supported condition. 


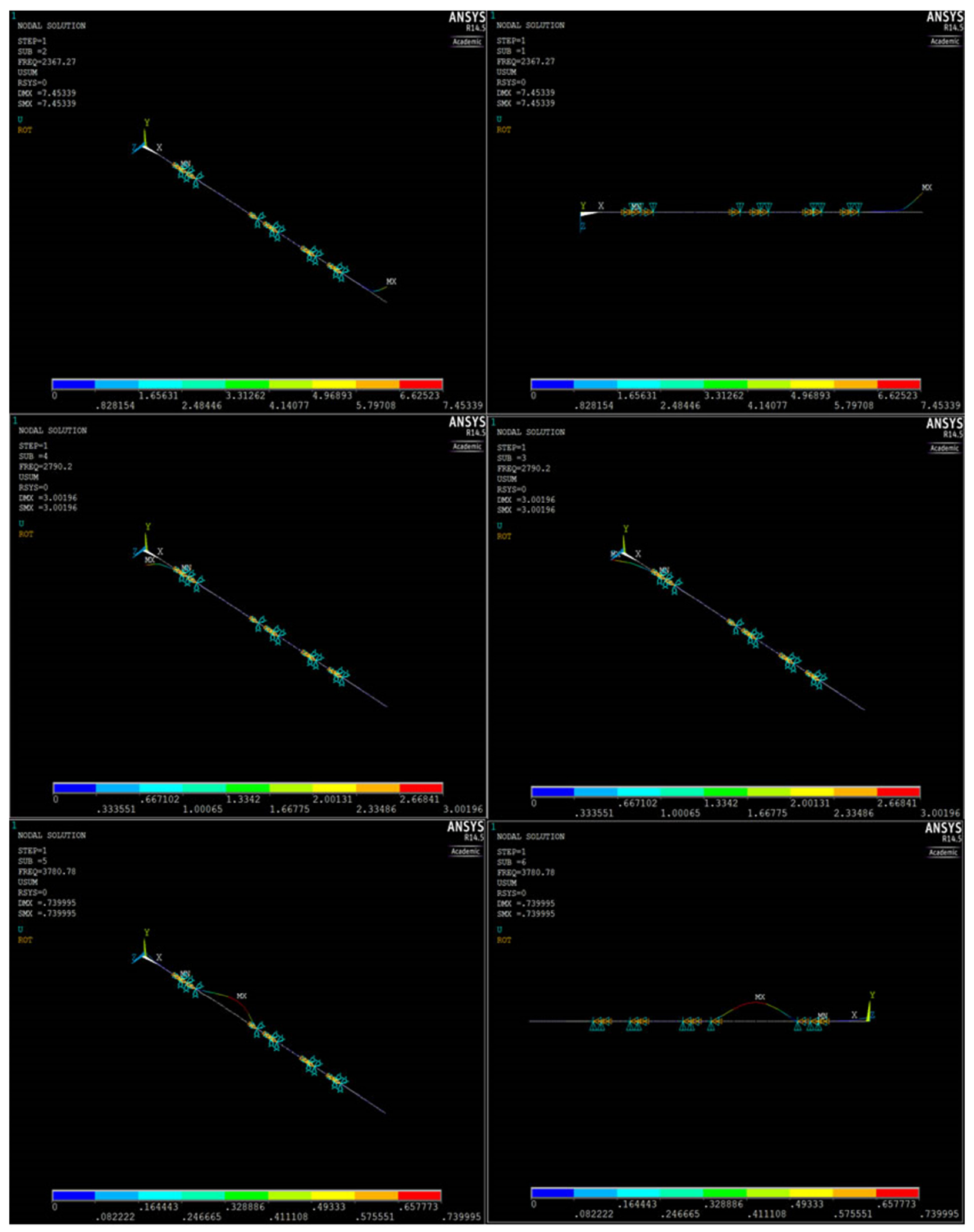

Figure 7: Mode shapes for spindle system using BEAM188 elements with SS boundary conditions 
The boundary condition at the bearing locations were then modified from simplysupported to spring-damper COMBIN14 element [27-29], where the spring constant value, ' $\mathrm{k}$ ' can be modified (Table 2). By changing the spring constant value, the spindle model was tuned to its nominal natural frequency. Four spring-damper elements were used in every bearing location. At the bearing location, the rotational and translational degree of freedom along the Y and Z-axis was constrained by the spring-damper element. The various values of the spring constant leading to the natural frequency of the spindle are given in Table 2 . At $\mathrm{k}=1.5 \times 10^{8}$ $\mathrm{N} / \mathrm{m}$, the natural frequency reported by the manufacturer was obtained. It was observed that as the spring stiffness value increases, the natural frequency also increases. The spindle was not constrained along its longitudinal translational direction and also along its axis of rotation. This translational and rotational freedom was the reason for the first and second natural frequencies in Table 2 for being close to zero, i.e., rigid body modes. The third and fourth frequencies represent spindle bending, as shown in Figure 8. From Table 3, it can be inferred that the natural frequency increases with the increase in spring constant, k, value. Figure 10 shows that the natural frequency after certain value of spring constant levels out, as the spring starts behaving like a simple support for greater values of spring constant, $\mathrm{k}$.

Table 2: Natural frequencies of the Beam-spindle by modifying the spring constant, $\mathrm{k}$

\begin{tabular}{|c|l|l|l|l|}
\hline $\begin{array}{l}\text { Spring constant, } \\
\mathrm{k}(\mathrm{N} / \mathrm{m})\end{array}$ & $0.75 \mathrm{E}+08$ & $1.00 \mathrm{E}+08$ & $1.35 \mathrm{E}+08$ & $1.5 \mathrm{E}+08$ \\
\hline Frequency & \multicolumn{4}{|c|}{ Natural Frequencies (Hz) } \\
\hline 1 & 0 & 0 & 0 & 0 \\
\hline 2 & $1.10 \mathrm{E}-03$ & $1.09 \mathrm{E}-03$ & $2.61 \mathrm{E}-04$ & 0 \\
\hline 3 & 1347.9 & 1376.3 & 1450.1 & 1482 \\
\hline 4 & 1350 & 1378.7 & 1480.9 & 1510 \\
\hline 5 & 1490.8 & 1532.6 & 1515.6 & 1560 \\
\hline 6 & 1493.9 & 1536 & 1518.5 & 1563.9 \\
\hline
\end{tabular}




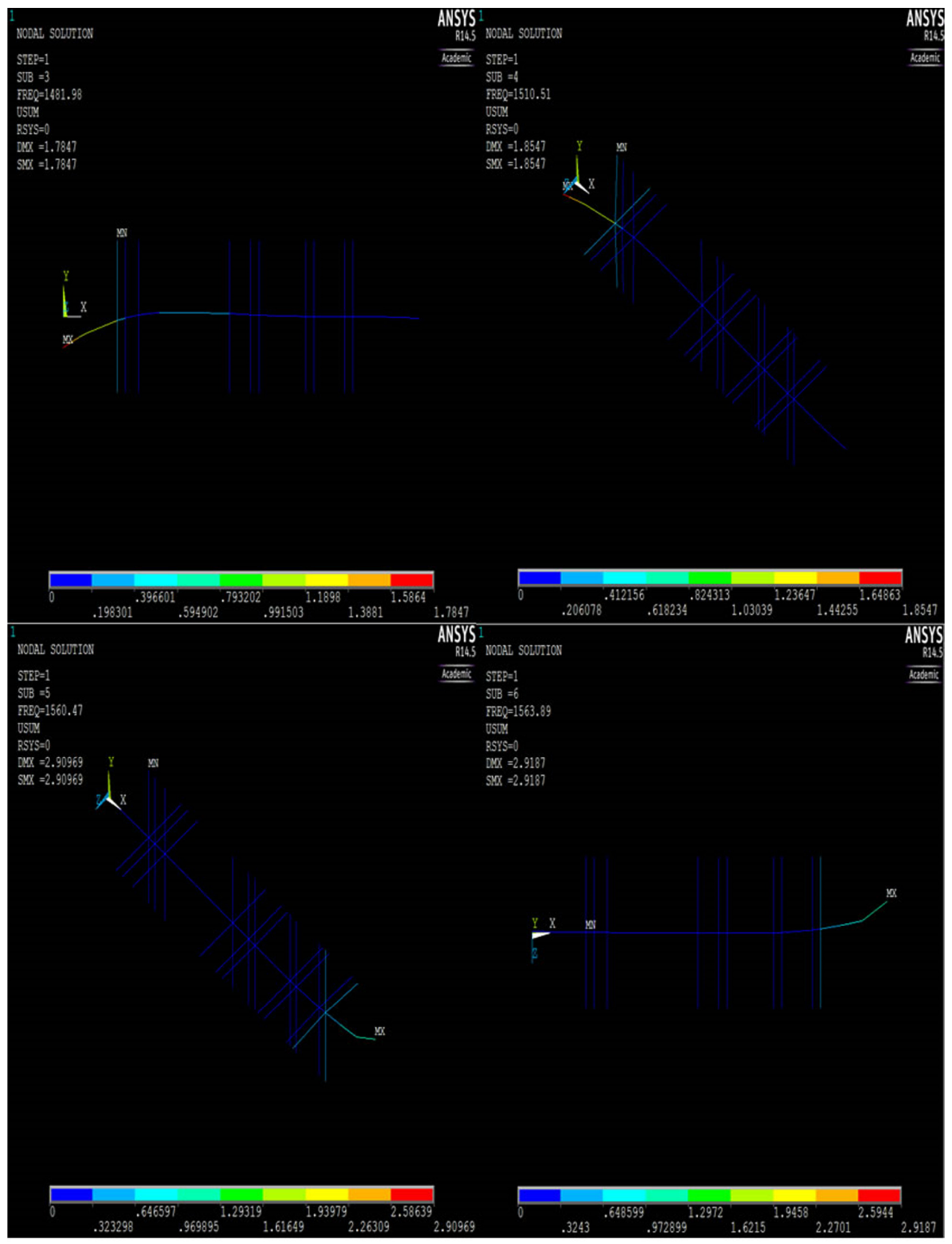

Figure 8: Mode shapes for spindle system using BEAM188 along with COMBIN14 elements. 


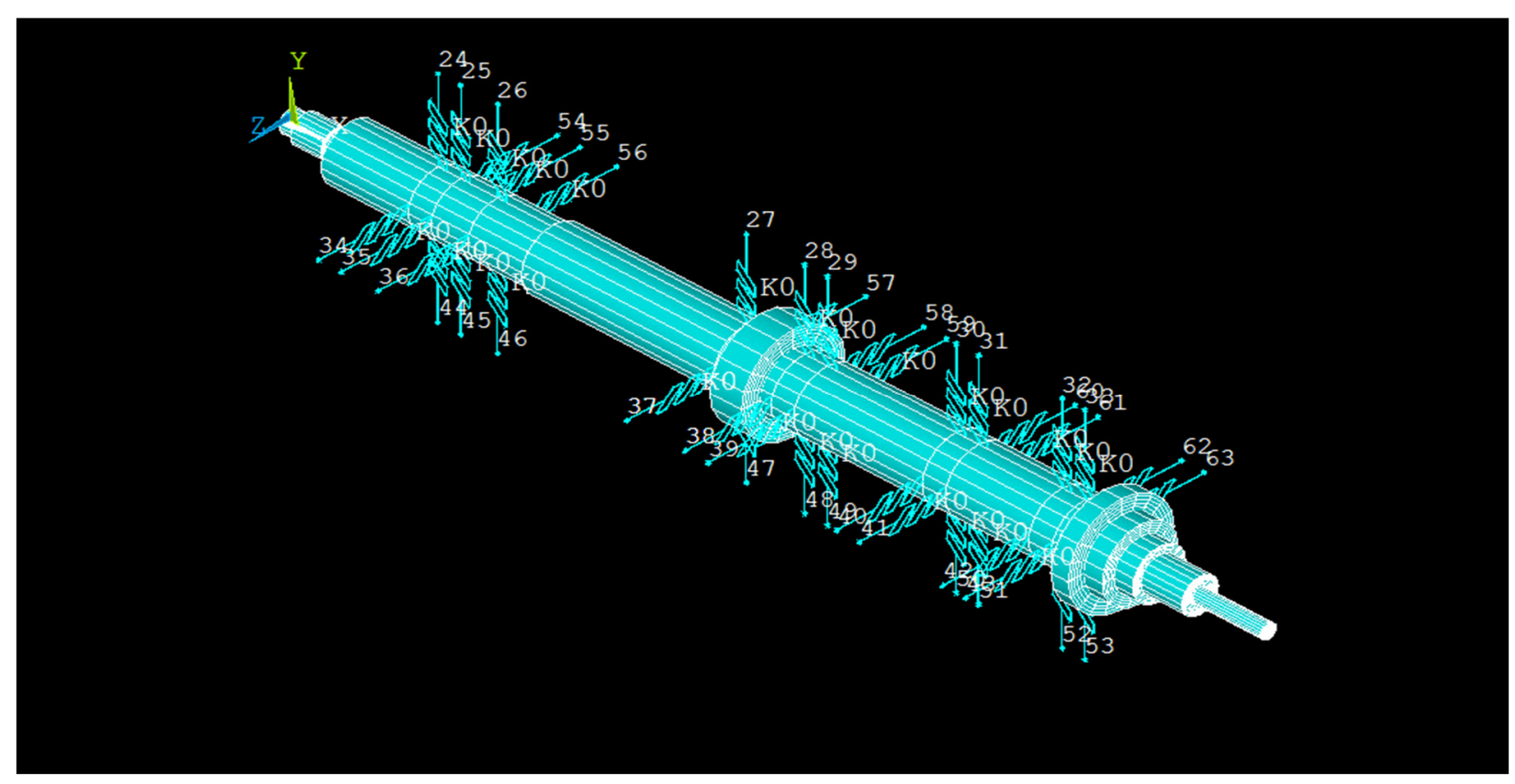

Figure 9: Beam 188 with COMBIN element for bearings

Table 3: Natural frequencies of solid spindle with changing spring constant, $\mathrm{k}$

\begin{tabular}{|c|c|c|c|c|c|c|c|c|c|c|c|}
\hline $\begin{array}{l}\text { Spring } \\
\text { constant, } \\
k(N / m)\end{array}$ & $\begin{array}{l}1.5 \\
E+05\end{array}$ & $\begin{array}{l}1.5 \\
E+06\end{array}$ & $\begin{array}{l}1.5 \\
E+07\end{array}$ & $\begin{array}{l}1.5 \\
E+08\end{array}$ & $\begin{array}{l}1.5 \\
E+09\end{array}$ & $\begin{array}{l}1.5 \\
E+10\end{array}$ & $\begin{array}{l}1.5 \\
E+11\end{array}$ & $\begin{array}{l}1.5 \\
E+12\end{array}$ & $\begin{array}{l}1.5 \\
E+13\end{array}$ & $\begin{array}{l}1.5 \\
E+14\end{array}$ & $\begin{array}{l}1.5 \\
E+15\end{array}$ \\
\hline Frequency & \multicolumn{11}{|c|}{ Natural frequencies $(\mathrm{Hz})$} \\
\hline 1 & 0 & 0 & 0 & 0 & 0 & 0 & 0 & 0 & 0 & 0 & 0 \\
\hline 2 & 0 & 0 & 0 & 0 & 0 & 0 & 0 & 0 & 0 & 0 & 0 \\
\hline 3 & 73.082 & 229.78 & 678.28 & 1482 & 2157.2 & 2356.1 & 2365.5 & 2365.4 & 2365.4 & 2365.4 & 2365.4 \\
\hline 4 & 73.139 & 229.96 & 680.89 & 1510.5 & 2157.2 & 2356.1 & 2365.5 & 2365.4 & 2365.4 & 2365.4 & 2365.4 \\
\hline 5 & 73.588 & 232.4 & 725.25 & 1560.5 & 2226.4 & 2688 & 2695.9 & 2695.9 & 2695.9 & 2695.9 & 2695.9 \\
\hline 6 & 77.18 & 243.57 & 752.8 & 1563.9 & 2229.7 & 2688 & 2796.3 & 2810.3 & 2811 & 2811.9 & 2811.9 \\
\hline
\end{tabular}




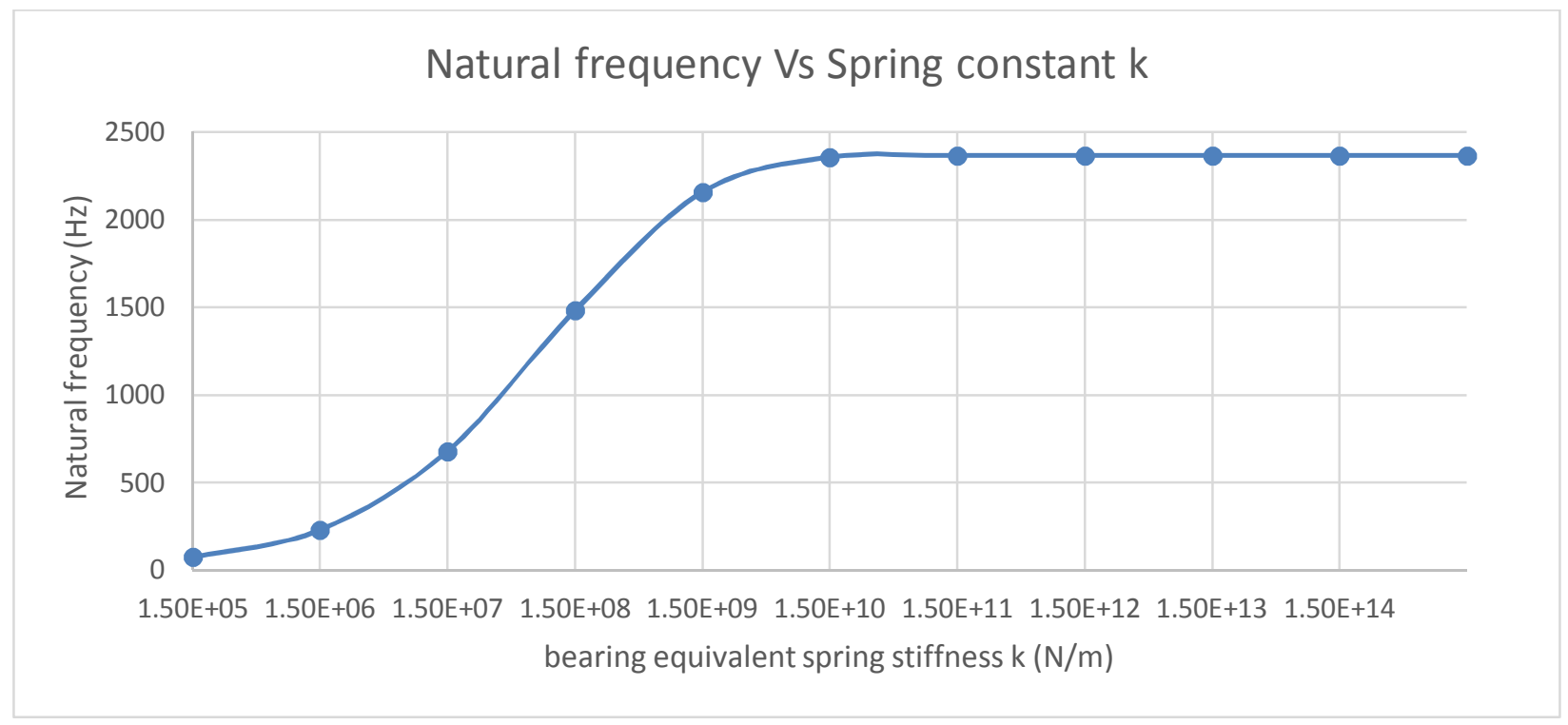

Figure 10: Natural frequency vs Spring constant k, for beam elements

\subsection{Solid element:}

The spindle was also modeled using SOLID187 elements (Figure 11). These are 10-node elements having three degrees of freedom in each node, translation along $\mathrm{x}, \mathrm{y}$ and z-axis and are well suited for modeling irregular mesh [48]. The spindle modeled in CATIA ${ }^{\circledR}$ V5 was imported to ANSYS $^{\circledR}$, as shown in Figure 12. The material property of tool steel was used in the model. The young's modulus, $\mathrm{E}=210 \mathrm{GPa}$ and density, $\rho=7850 \mathrm{Kg} / \mathrm{m}^{3}$ was applied. The model was then meshed using solid elements, as shown in Figure 13. Following the procedure similar to section 3.1, the bearings were first modeled as simply-supported boundary condition as shown in Figure 14. Modal analysis was carried out on the spindle model, where seven mesh sizes were used, and the first six natural frequencies of the system are shown in Table 4.

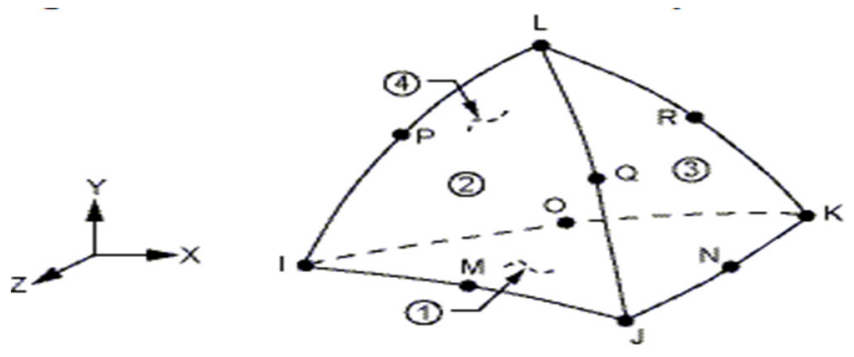

Figure 11: SOLID187 element geometry [48] 


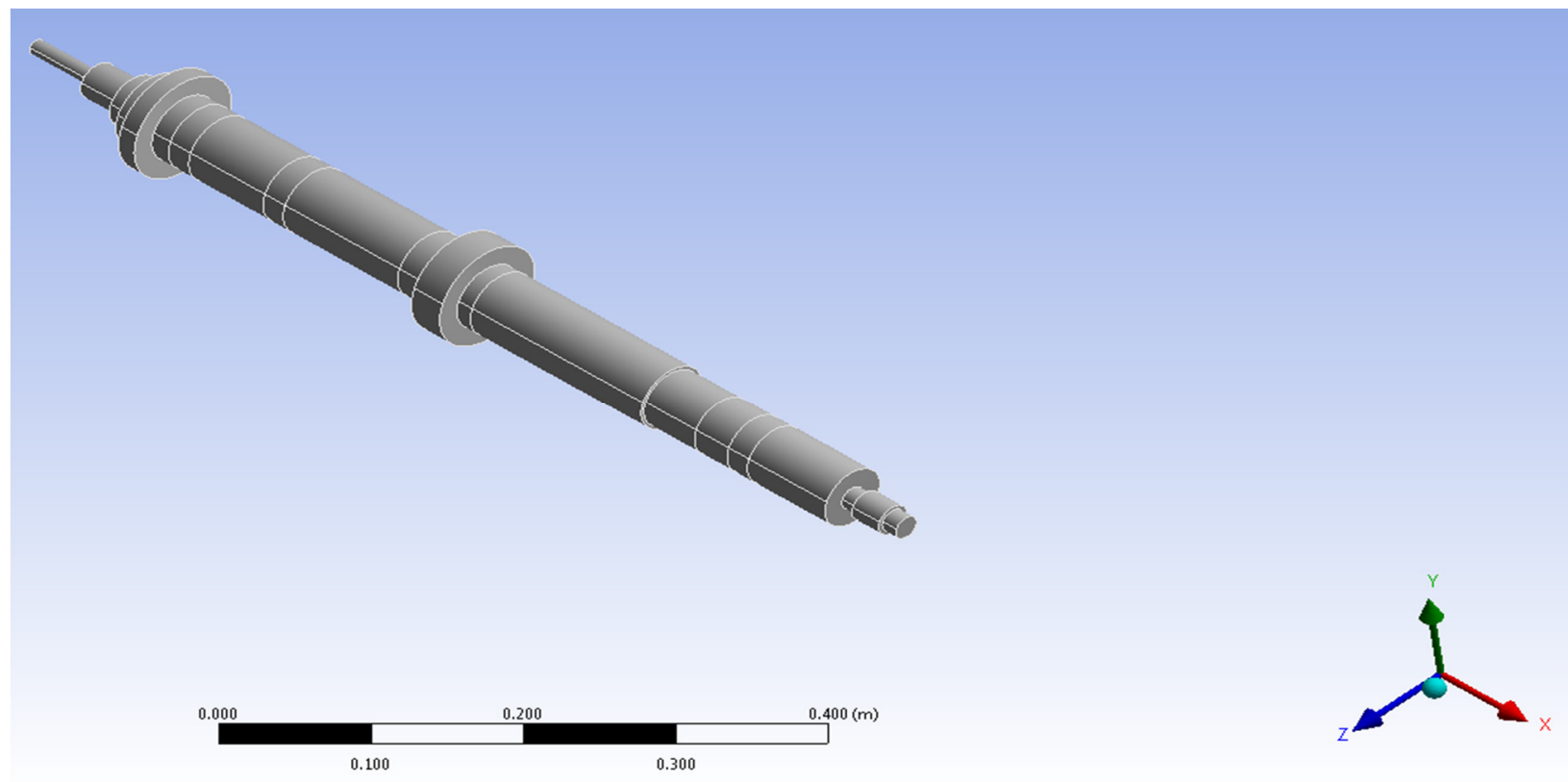

Figure 12: Solid spindle model
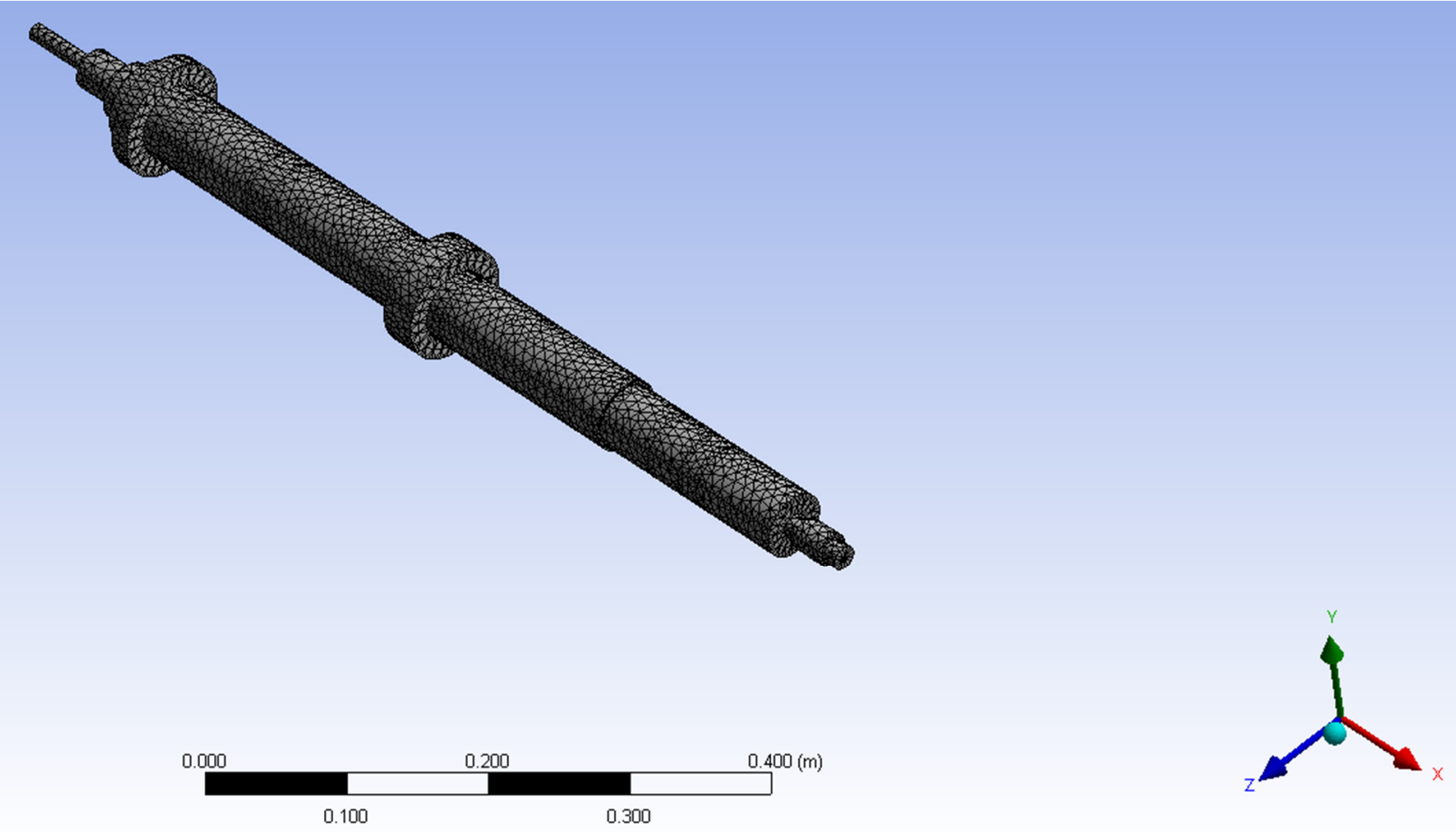

Figure 13: Meshed Solid spindle model 


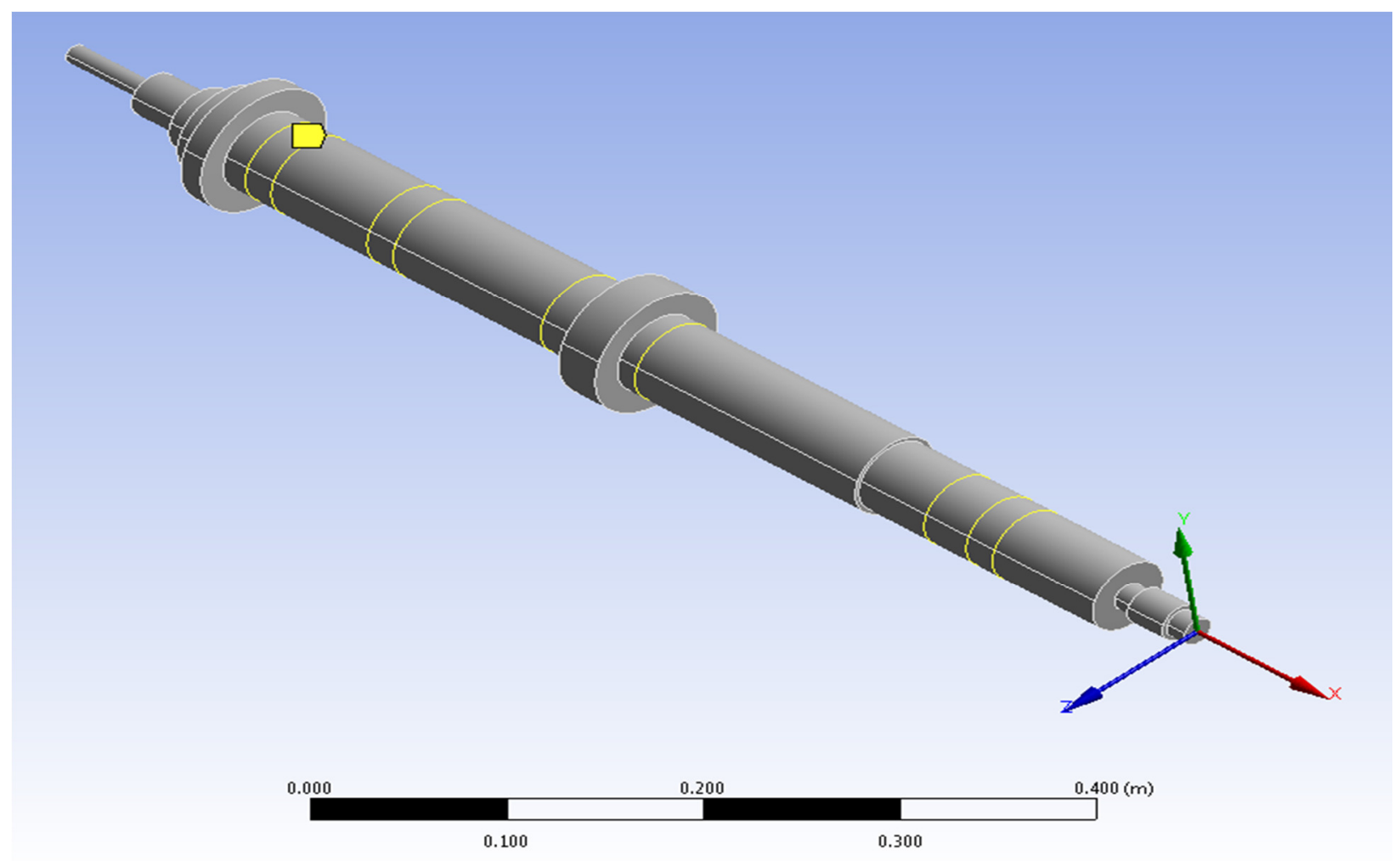

Figure 14: Solid spindle model with Simply-supported condition

Table 4: Natural frequencies of the spindle modeled by Solid elements and simply-supported boundary condition

\begin{tabular}{|c|l|l|l|l|l|l|l|}
\hline Elements & 3755 & 8022 & 9830 & 12626 & 16965 & 17651 & 18256 \\
\hline Frequency & \multicolumn{7}{|c|}{ Natural Frequencies (Hz) } \\
\hline 1 & 2306.4 & 2248.6 & 2246.2 & 2245.4 & 2244.3 & 2244.3 & 2244.3 \\
\hline 2 & 2316.5 & 2255.1 & 2247.1 & 2246.1 & 2244.9 & 2244.9 & 2244.9 \\
\hline 3 & 3029.3 & 2979 & 2968.2 & 2953.7 & 2951.9 & 2951.9 & 2951.9 \\
\hline 4 & 3038.1 & 2987 & 2969.4 & 2955.5 & 2954.8 & 2954.8 & 2954.8 \\
\hline 5 & 4206.2 & 4118.3 & 4101.7 & 4094 & 4092.4 & 4092.4 & 4092.4 \\
\hline 6 & 4239.5 & 4132.3 & 4108.3 & 4100.3 & 4098.9 & 4098.9 & 4098.9 \\
\hline
\end{tabular}


The first/second, fourth/third and sixth/fifth natural frequencies represent the bending vibration along the Y/Z direction respectively, as shown in Figure 16. Convergence test was conducted for the model. Figure 15 clearly states the first bending natural frequency starts converging at around 16965 elements, which was taken as the minimum number of required elements needed for calculating acceptable results.

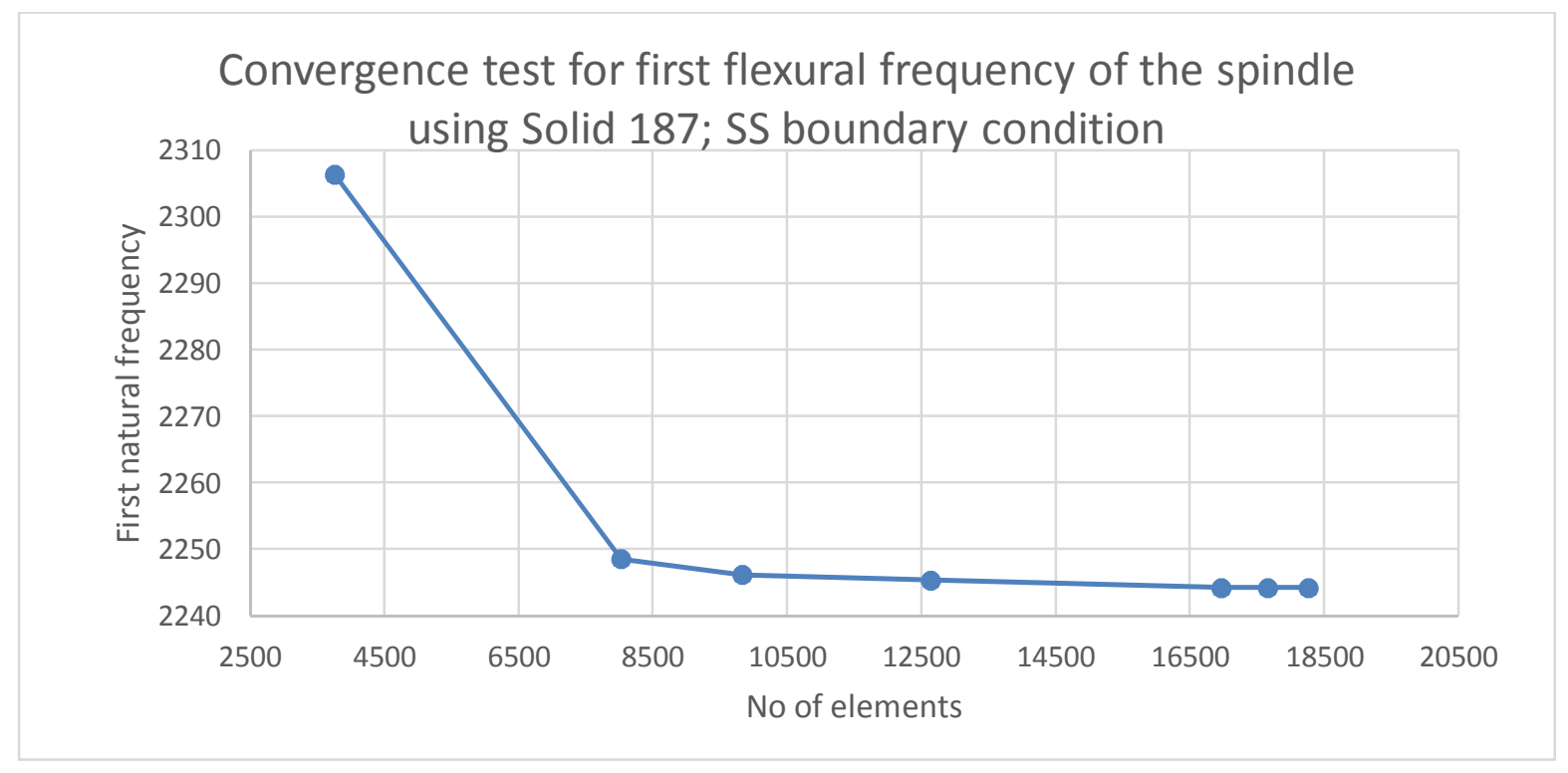

Figure 15: Convergence test for Solid elements; first bending frequency

Once again, the boundary conditions at the bearing points were then modified from simply-supported to COMBIN14 elements. The spring constant value, $\mathrm{k}$ was modified and the corresponding modal analysis result was found as shown in Table 5. It depicts, as the spring constant valve increases the natural frequency also increases. Each bearing location was replaced by four spring-damper elements as shown in Figure 19. The values of k were tuned to get the required natural frequency reported by the manufacturer, which was attained when $\mathrm{k}=2.25 \times 10^{8}$ $\mathrm{N} / \mathrm{m}$. The spindle was not constrained along the longitudinal translational direction, which results in zero for the first natural frequency. The second/third, fourth/fifth and sixth/seventh natural frequencies represent the bending of the spindle in $\mathrm{Z} / \mathrm{Y}$ directions respectively, as shown in Figure17. The eighth natural frequency represents the torsional vibration of the spindle, as shown in Figure 18. A parametric study was then carried out to study the role of the spring constant on the natural frequency of the spindle was studied as shown in Table 6. After reaching a certain value the natural frequencies of the spindle levels out and starts behaving like simple support for higher values of k, as shown in Figure 20. 

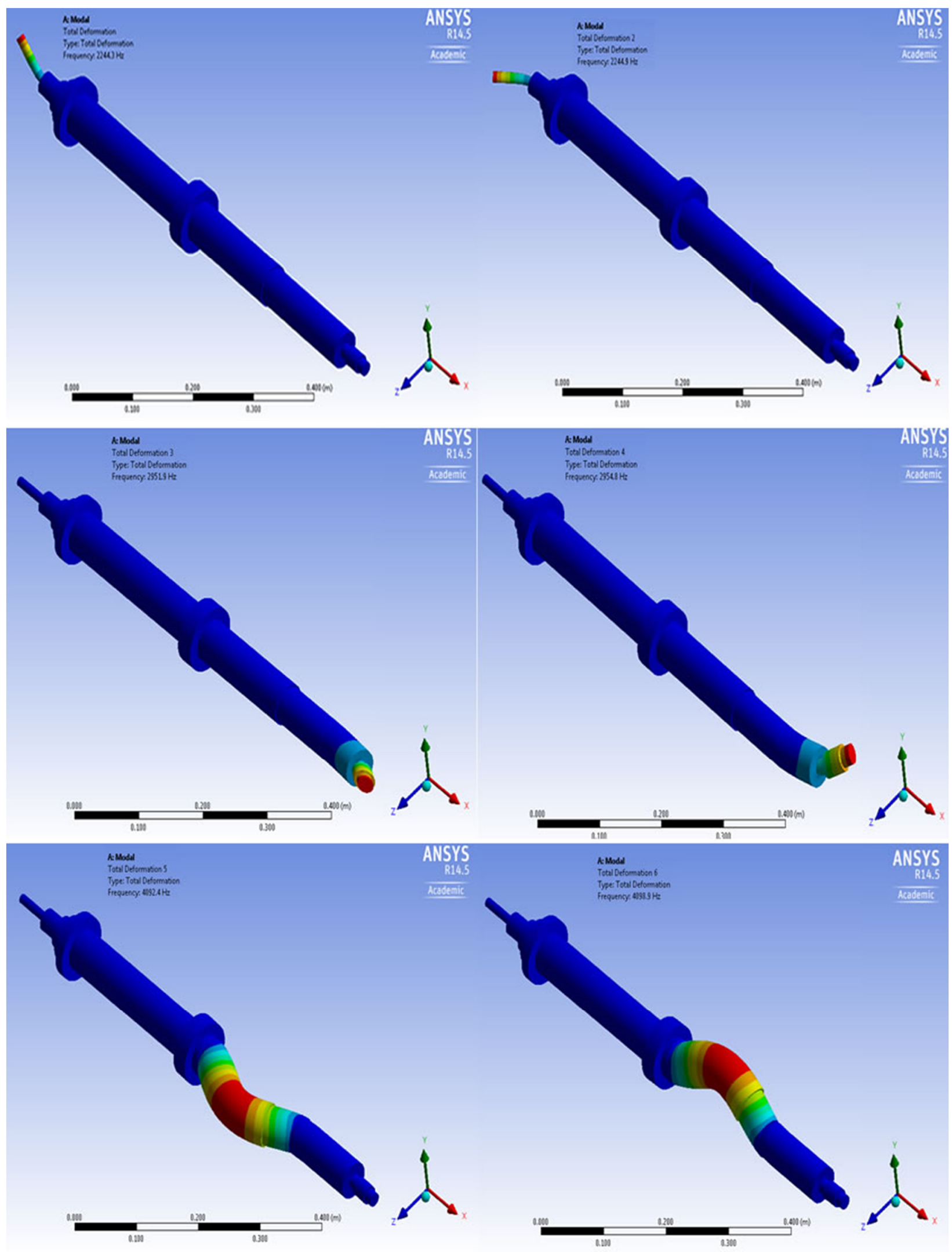

Figure 16: Mode shapes of spindle system using SOLID187 with SS boundary conditions 
Table 5: Natural frequencies of the Solid-spindle by modifying the spring constant, $\mathrm{k}$

\begin{tabular}{|c|l|l|l|l|l|l|l|}
\hline $\begin{array}{l}\text { Spring } \\
\text { constant, } \\
(\mathrm{x} \mathrm{10} \times\end{array}$ & 1.35 & 1.5 & 1.6 & 1.65 & 1.75 & 2.1 & 2.25 \\
\hline Frequency & \multicolumn{7}{|c|}{ Natural Frequencies (Hz) } \\
\hline 1 & 0 & 0 & 0 & 0 & 0 & 0 & 0 \\
\hline 2 & 1348.5 & 1376.3 & 1393.3 & 1401.5 & 1417.2 & 1466.6 & 1485.7 \\
\hline 3 & 1350.6 & 1378.7 & 1395.9 & 1404.2 & 1420 & 1470.2 & 1489.6 \\
\hline 4 & 1491.7 & 1532.6 & 1557.4 & 1569.1 & 1591.4 & 1658.2 & 1682.5 \\
\hline 5 & 1494.8 & 1536 & 1561 & 1572.8 & 1595.2 & 1662.6 & 1687 \\
\hline 6 & 1805.9 & 1865.4 & 1901.6 & 1918.8 & 1951.4 & 2050.7 & 2087.4 \\
\hline 7 & 1810.8 & 1870.8 & 1907.3 & 1924.7 & 1957.6 & 2058 & 2095 \\
\hline 8 & 1884.5 & 1981.5 & 2043 & 2073 & 2131.3 & 2321.4 & 2396.9 \\
\hline
\end{tabular}

Table 6: Natural frequencies of solid spindle with changing spring constant, $\mathrm{k}$

\begin{tabular}{|c|l|l|l|l|l|l|l|l|l|l|l|l|l|}
\hline $\begin{array}{l}\text { Spring } \\
\text { constant, } \\
\mathrm{k}(\mathrm{N} / \mathrm{m})\end{array}$ & $\begin{array}{l}2.25 \\
\mathrm{E}+05\end{array}$ & $\begin{array}{l}2.25 \\
\mathrm{E}+06\end{array}$ & $\begin{array}{l}2.25 \\
\mathrm{E}+07\end{array}$ & $\begin{array}{l}2.25 \\
\mathrm{E}+08\end{array}$ & $\begin{array}{l}2.25 \\
\mathrm{E}+09\end{array}$ & $\begin{array}{l}2.25 \\
\mathrm{E}+10\end{array}$ & $\begin{array}{l}2.25 \\
\mathrm{E}+11\end{array}$ & $\begin{array}{l}2.25 \\
\mathrm{E}+12\end{array}$ & $\begin{array}{l}2.25 \\
\mathrm{E}+13\end{array}$ & $\begin{array}{l}2.25 \\
\mathrm{E}+14\end{array}$ & \begin{tabular}{l}
$\mathrm{E}+15$ \\
\hline Frequency
\end{tabular} \\
\hline 1 & 0 & 0 & 0 & 0 & 0 & 0 & 0 & 0 & 0 & 0 & 0 \\
\hline 2 & 78.749 & 248.93 & 783.22 & 1485.7 & 2084.5 & 2144.9 & 2153.4 & 2154.2 & 2154.3 & 2154.3 & 2154.3 \\
\hline 3 & 89.475 & 280.21 & 783.63 & 1489.6 & 2090.7 & 2157.3 & 2168.1 & 2169.3 & 2169.4 & 2169.4 & 2169.4 \\
\hline 4 & 89.476 & 280.23 & 784.37 & 1682.5 & 2174.2 & 2440 & 2476 & 2479.8 & 2480.2 & 2480.2 & 2480.2 \\
\hline 5 & 90.107 & 284.02 & 861.77 & 1687 & 2211.2 & 2504.7 & 2547.9 & 2552.5 & 2553 & 2553 & 2553 \\
\hline 6 & 90.107 & 284.04 & 862.34 & 2087.4 & 2976.8 & 3338.1 & 3394.6 & 3400.6 & 3401.2 & 3401.3 & 3401.3 \\
\hline 7 & 501.21 & 548.03 & 914.12 & 2095 & 3022.8 & 3443.9 & 3513.1 & 3520.5 & 3521.3 & 3521.3 & 3521.3 \\
\hline 8 & 501.83 & 548.03 & 914.61 & 2396.9 & 3280.4 & 3629.3 & 3693.3 & 3700.4 & 3701.2 & 3701.2 & 3701.2 \\
\hline
\end{tabular}




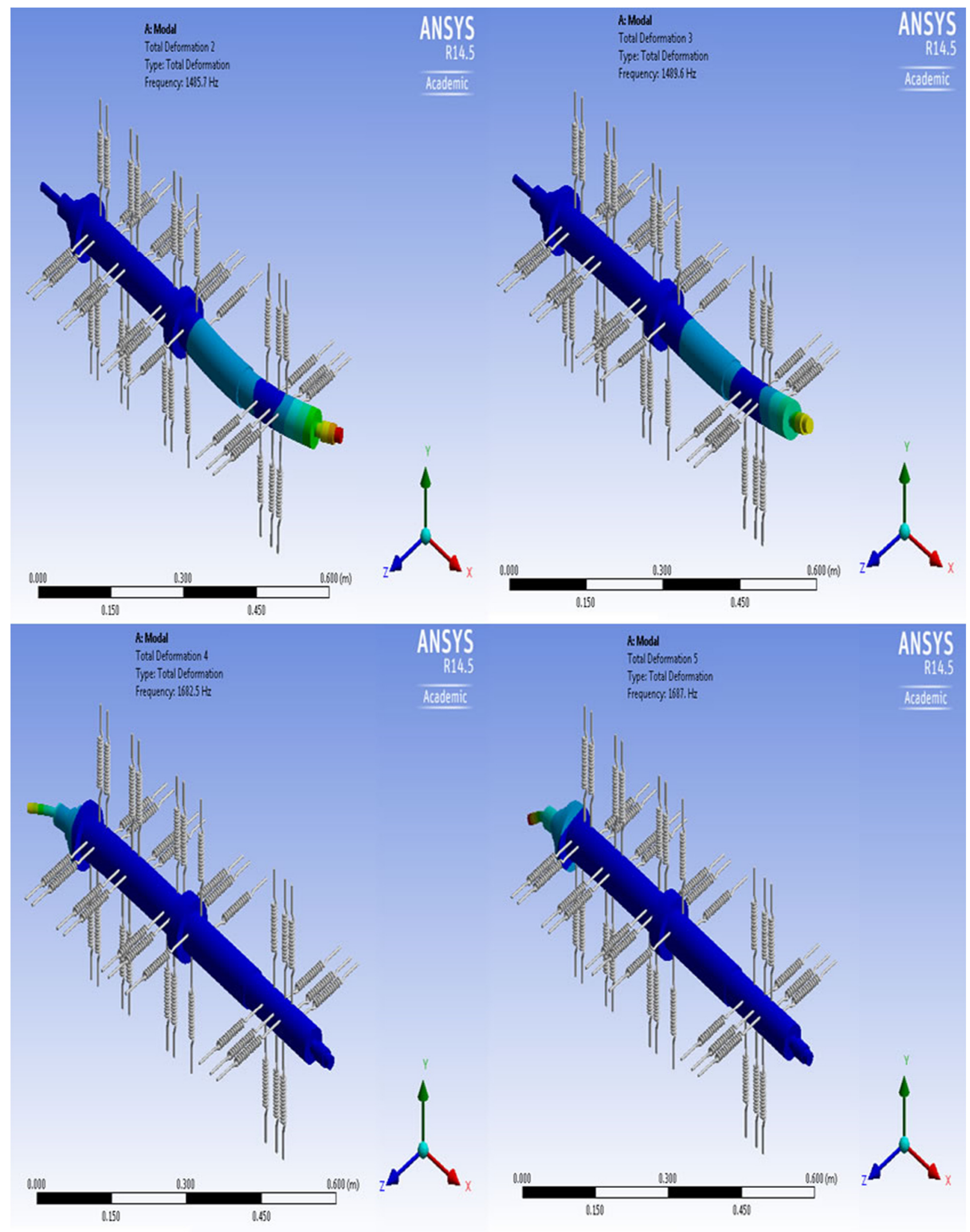

Figure 17: Mode Shapes for spindle system using SOLID187 and COMBIEN14 elements; second to fifth natural frequencies 

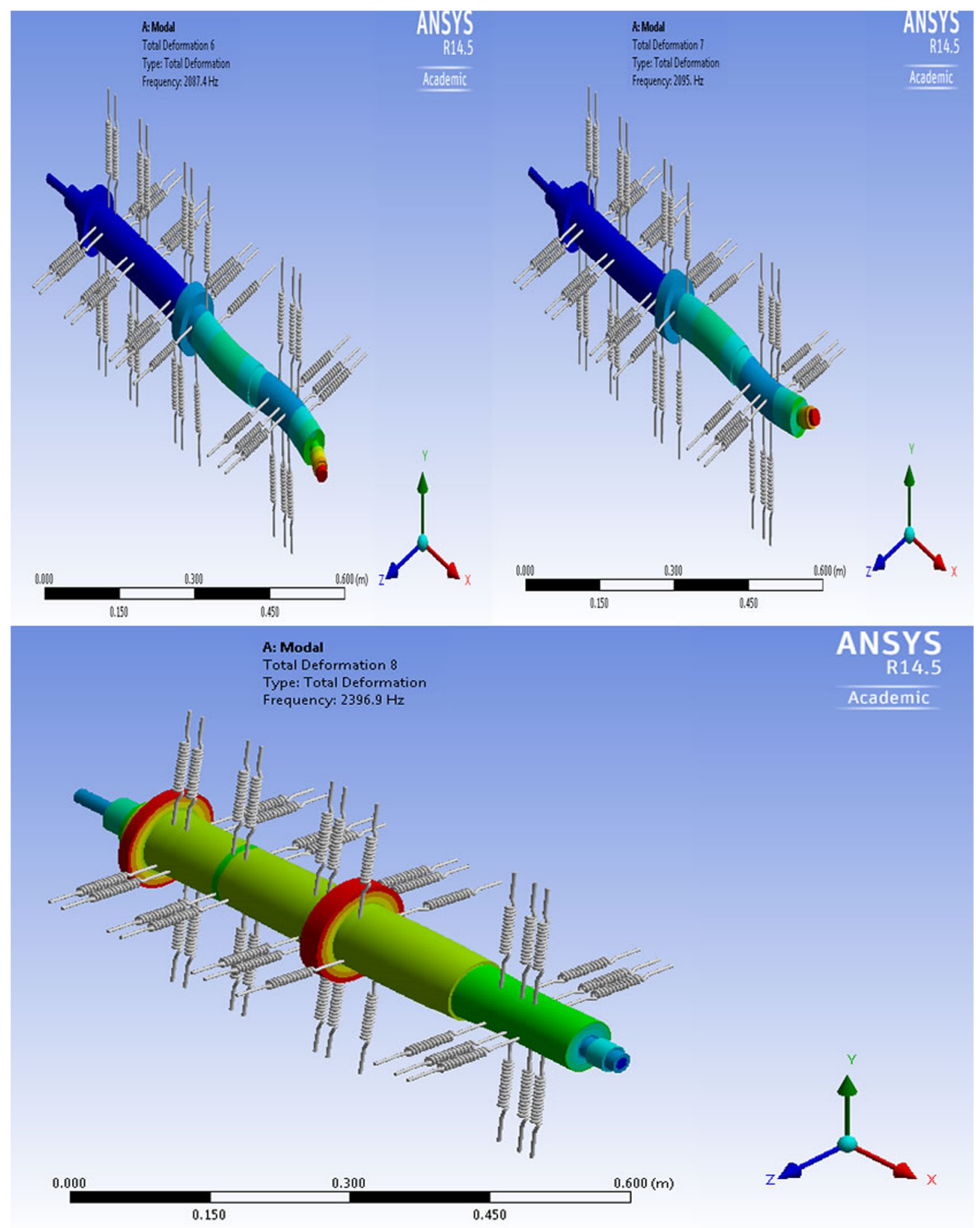

Figure 18: Mode Shapes for spindle system using SOLID187 and COMBIEN14 elements; sixth to eight natural frequencies 


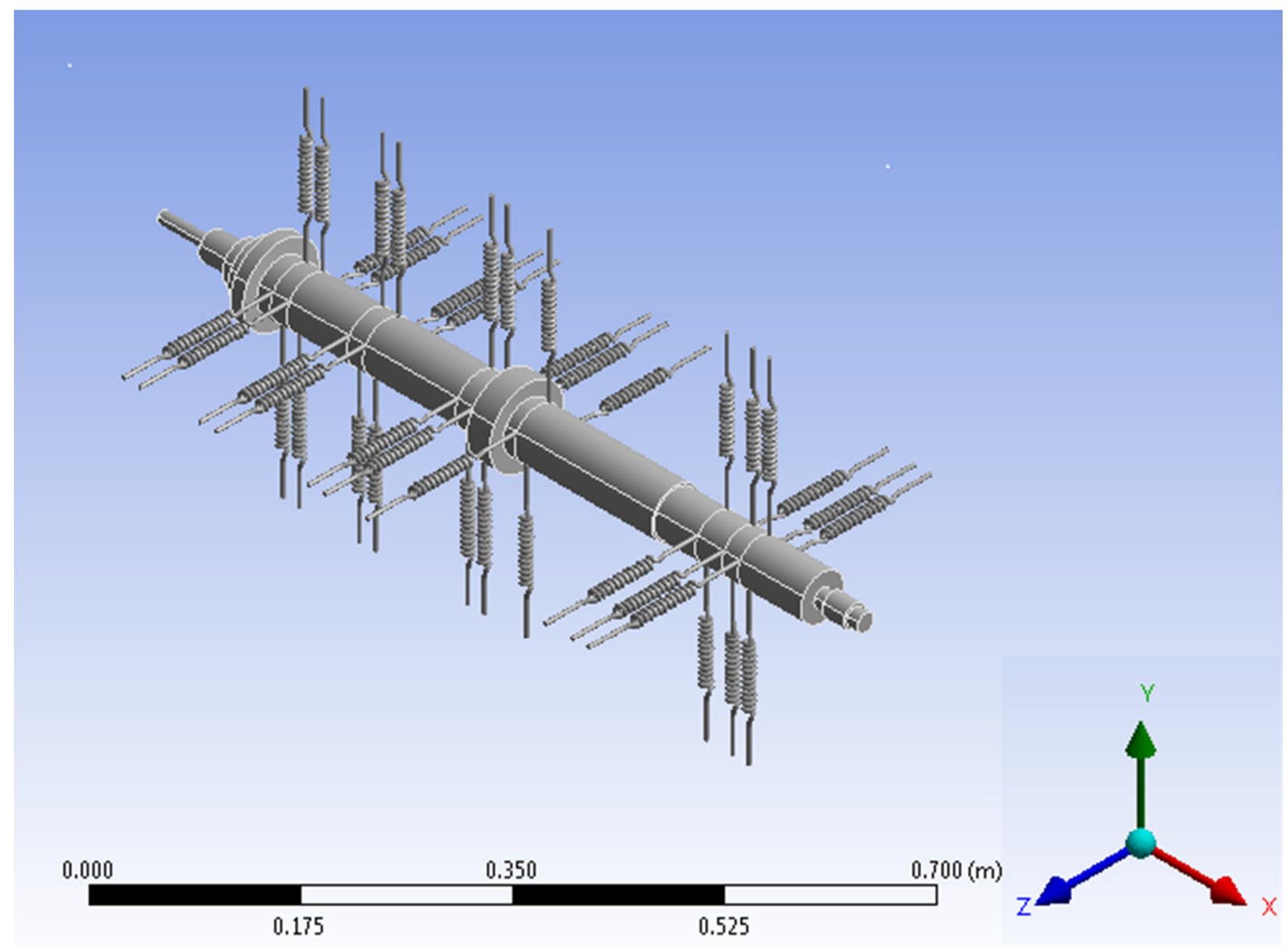

Figure 19: Solid spindle model with spring-damper boundary condition

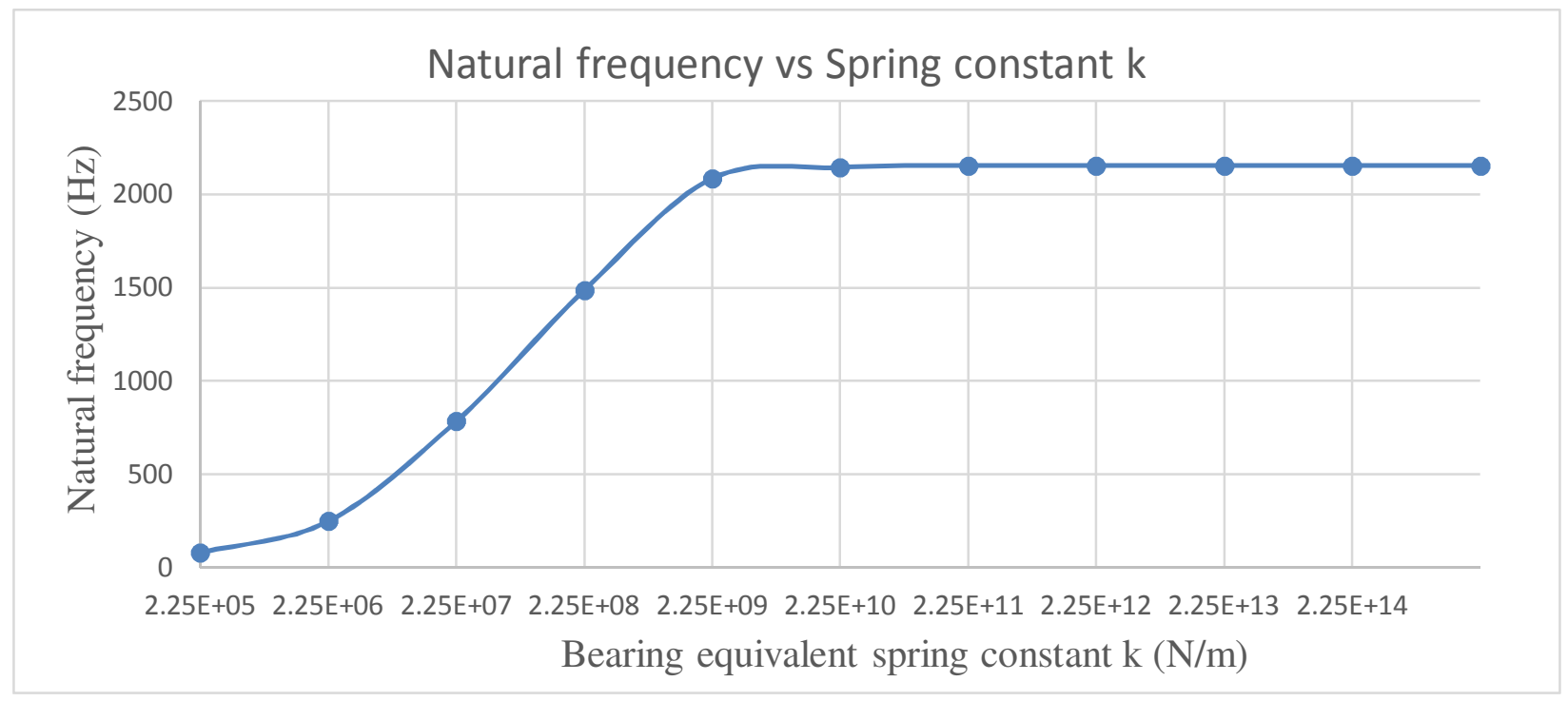

Figure 20: Natural frequency vs Spring constant k, for solid elements 


\subsection{Experimental Table Setup:}

The test setup for the experimental analysis consists of a table, which holds the spindle in place. There are also two supporting arms from the table, which holds the bearings in their respective locations. The experimental table design has been discussed elaborately in Chapter 4. The setup was modelled in CATIA $^{\circledR}$ V5 and imported to ANSYS ${ }^{\circledR}$ workbench. SOLID187 element was used in this analysis as shown in Figure 21. The connection between the table and side support arms were considered as bonded. For meshing convenience, the holes in the table and slots in the side support arms were neglected. For modal analysis, the model has to be constrained. So, the base plate of the table was fixed in all degrees of freedom. Table 5 shows the resulting natural frequencies from the analysis. The first and second natural frequencies constitute the bending mode. The third natural frequency represents the torsional vibrational mode of the setup. Convergence test was conducted and as shown in Figure 22, the first natural frequency converged at 3923 elements. From the modal analysis, the natural frequency of the table-setup was found to be $35.2 \mathrm{~Hz}$.

Table 7: Natural frequencies of the experimental table setup modeled using Solid elements and fixed boundary conditions at the base plates

\begin{tabular}{|c|l|l|l|l|l|l|l|l|l|}
\hline Elements & 2344 & 2663 & 2914 & 3116 & 3610 & 3923 & 4164 & 4402 & 4548 \\
\hline Nodes & 15466 & 17845 & 19674 & 21487 & 24549 & 26783 & 28129 & 30212 & 31584 \\
\hline Frequency & \multicolumn{7}{|c|}{ Natural Frequencies (Hz) } \\
\hline 1 & 35.67 & 35.64 & 35.58 & 35.53 & 35.32 & 35.2 & 35.2 & 35.2 & 35.2 \\
\hline 2 & 50.166 & 50.132 & 49.957 & 49.876 & 49.431 & 49.359 & 49.357 & 49.356 & 49.356 \\
\hline 3 & 65.335 & 65.157 & 65.142 & 65.13 & 64.44 & 64.345 & 64.339 & 64.331 & 64.33 \\
\hline 4 & 69.471 & 69.216 & 69.102 & 68.728 & 68.687 & 68.64 & 68.638 & 68.637 & 68.636 \\
\hline 5 & 72.002 & 71.934 & 71.82 & 71.86 & 71.216 & 71.203 & 71.198 & 71.198 & 71.198 \\
\hline 6 & 77.226 & 77.067 & 77.057 & 77.031 & 76.116 & 76.038 & 76.032 & 76.03 & 76.03 \\
\hline
\end{tabular}



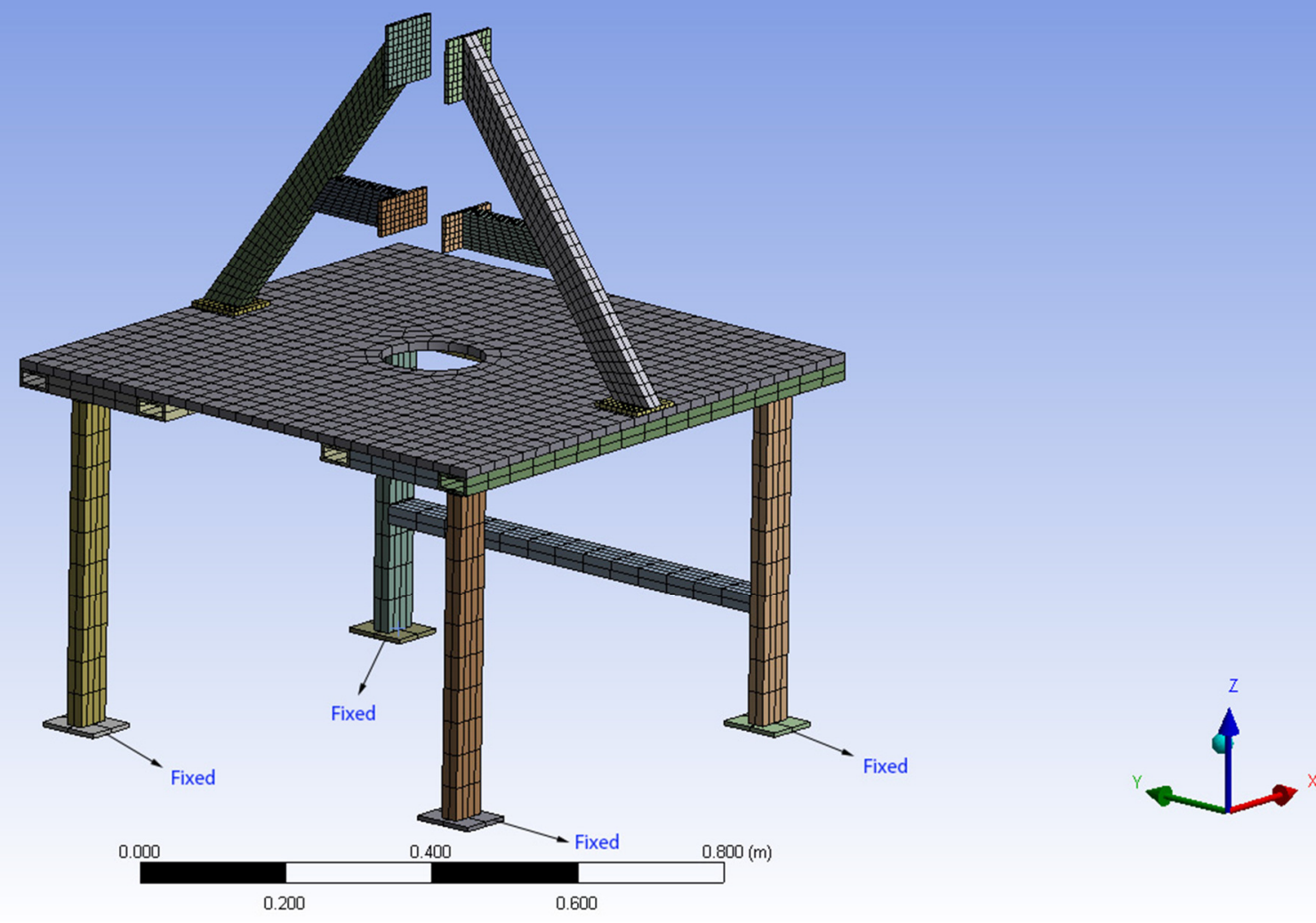

Figure 21: Meshed experimental table setup modeled using SOLID 187

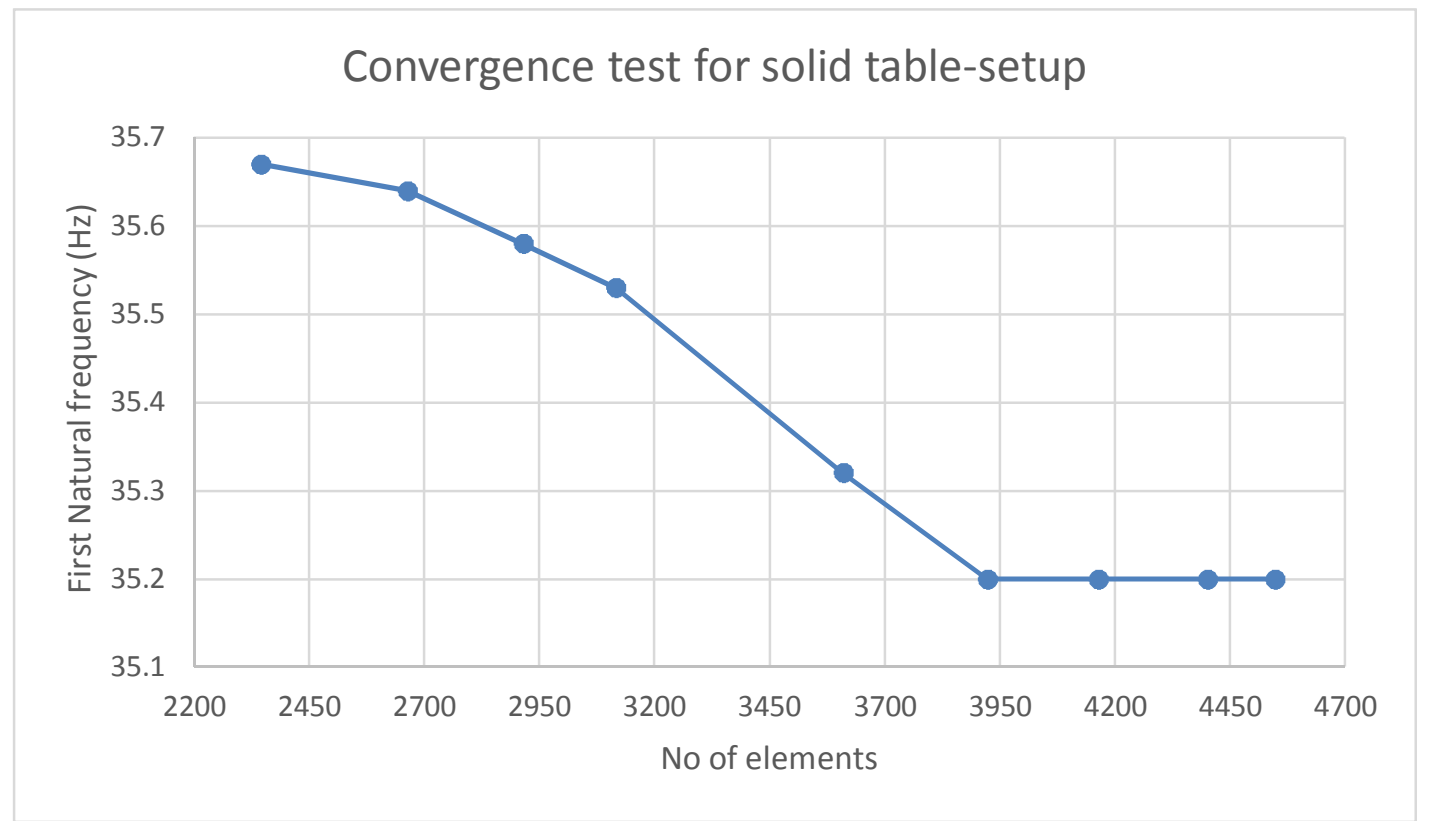

Figure 22: Convergence test for Solid table-setup 


\subsection{Discussion}

Numerical modeling and analysis of the spindle was carried out using commercially available analysis software ANSYS ${ }^{\circledR}$ Academic Research, Release 14.5. The spindle was modeled using BEAM188 and SOLID187 elements. The bearings were modelled initially as simple supports and later are modified to COMBIN14 elements. By changing the spring constant value, the spindle was tuned to the natural frequency reported by the manufacturer. Numerical analysis was also carried out for the experimental setup using SOLID187 element.

From section 3.2 and 3.3, it is observed that the BEAM188 requires relatively lesser number of elements to converge than the SOLID187. This could be attributed to the properties of BEAM188. Therefore, the BEAM188 are able to capture the displacement more precisely than the SOLID187, with fewer elements. The frequencies resulting from solid element model were found to be about 5\% lower than those obtained from the beam element model. The variation is due to the fact that SOLID187 elements take into account the shear and rotary inertia effects, which are neglected in BEAM188 elements.

The natural frequency of the spindle increases with the increase in spring constant value. The increase in natural frequency levels out after reaching a certain value of spring constant. This happens as a result of the springs starting to act like simple supports at higher values of spring constants.

SOLID187 may require more elements to converge for a solution than BEAM188, but they are well suited for structures with irregular shapes. Since BEAM188 can be applied only to simple beam structures, they cannot be used in modelling complex geometries. 


\section{Experimental vibrational analysis of the spindle}

In this chapter, the experimental setup, designed to carry out the vibrational analysis of the spindle, will be discussed. The developed numerical model has to be validated, to carry out further analysis in the future. The focus of the proceeding sections will be on the design of the experimental setup, data acquisition (DAQ) system and software used, tests carried out on the spindle, and the results obtained. The experimental setup was set up and the tests were carried out at the lab in Ryerson University. Impact tests were conducted to obtain the natural frequencies of the spindle system. The experimental unit consists of two parts, namely the table setup to hold the spindle in place, and the data acquisition system to collect and process the data obtained. A schematic diagram of a typical experimental setup is shown in Figure 23.

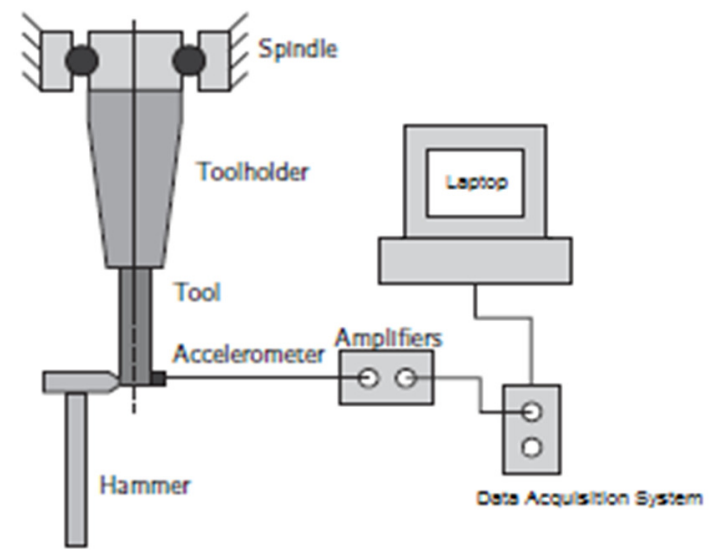

Figure 23: Schematic diagram of a typical experimental setup

\subsection{Experimental table setup}

To carry out an experimental modal analysis, one requires a proper and rigid support system. The main objective of the experimental analysis was to mimic the actual working conditions of the spindle system. Therefore, the table for this experiment has to be rigid enough to mimic the machine tool head, holding the spindle rigidly in place, and the spindle has to be held in a vertical position so as to replicate the actual working setup and the bearings have to be placed at correct locations on the spindle. The experimental table setup consists of (i) a table for the spindle to rest, (ii) side-supports to hold the bearings along with the spindle and (iii) hammersetup to excite the spindle. 


\subsubsection{Table}

The purpose of the table is to hold the spindle in place and to provide a rigid support for the entire setup. The material chosen for the table is steel. Steel is strong and has nominal modulus of elasticity and ultimate tensile strength. A table of $.5^{\prime \prime}$ thickness is made to hold the setup. This thickness is adequate enough to hold the entire weight of the spindle and the side supports for the bearings. A 5.75" hole is made at the centre of the table to insert the spindle into it. The tool holder and tool section of the spindle lies below the table. The spindle is held in position with the help of six .5" machine bolts fastened to the table.

\subsubsection{Side-support System}

The side-support setup was required to hold the bearings in their respective locations. The structure has to be light-weight and also strong enough to resist bending moments caused by the forces acting on the spindle during testing. The structure best suited for this purpose was hollow structural section (HSS) with rectangular cross-section, 2" X 1" X 3/16" tube steel was used for this purpose. The side-support has to be provided from two opposite directions to hold the bearing in proper position. There are three locations on the spindle above the table, where the bearings are placed.

The important part of this side-support design is that they have to accommodate for the change in diameter along the length of the spindle. A slant side-support design was well suited, because of less use of material along with better support to the bearings. The bottom part of the side-support was fillet welded on all sides to a plate which is fastened to the table with four 5/16" bolts. The top part of the side-support was fillet welded to a quarter inch plate to which two bearings were attached. Towards the central part of the main support, another HSS arm extends to hold the other bearing in place. This HSS arm was also welded to the main side-support. The plates welded to the main HSS, are all provided with slots in them so that the position of the bearing can be changed if necessary. The side-support along with the bearing blocks are shown in Figure 24. 


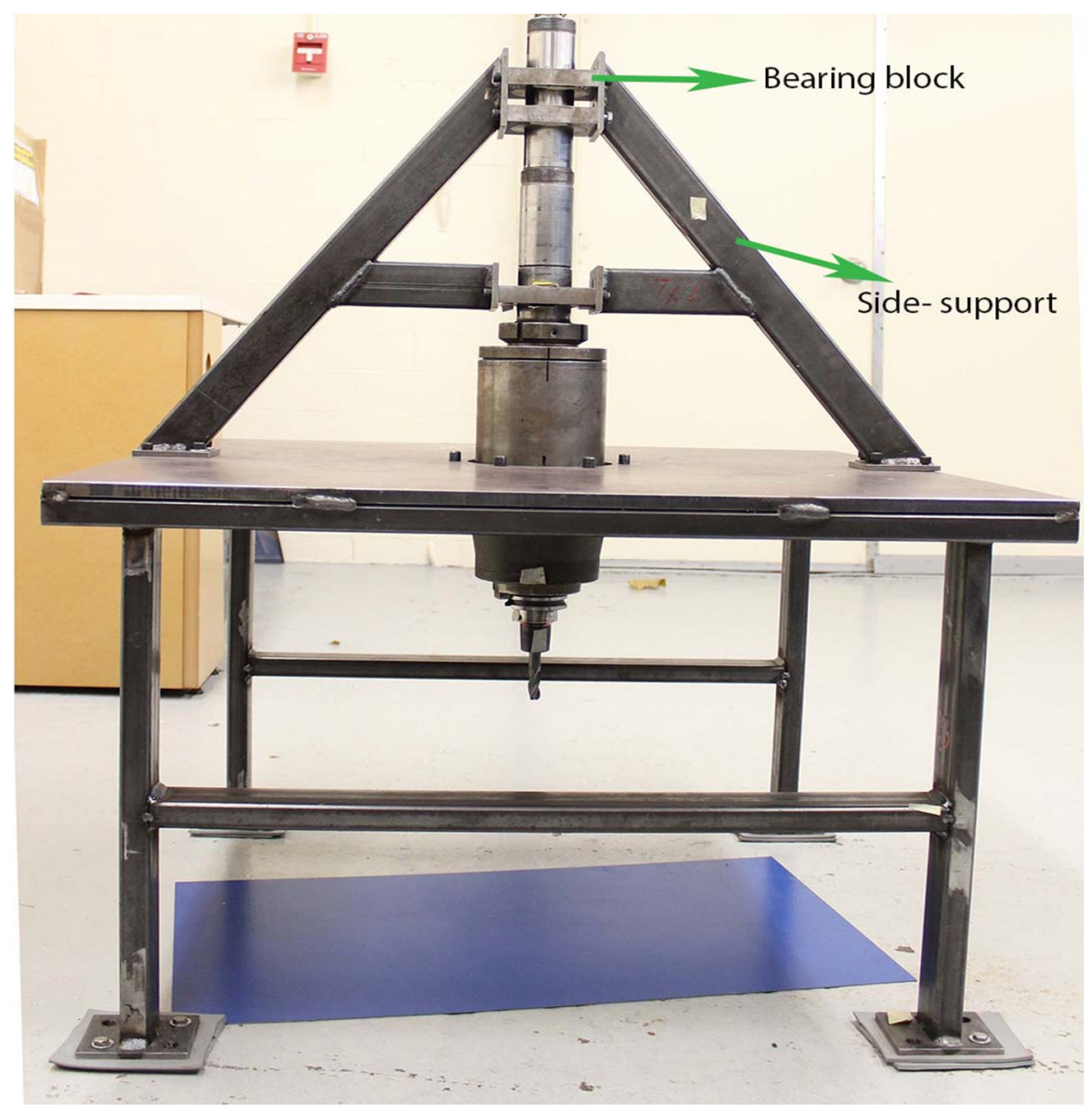

Figure 24: Experimental table-setup along with the spindle

\subsubsection{Bearing}

The other vital part of the experimental setup was the bearings. The spindle has six bearings in it all together, of which three sets are located within the spindle cover, which holds the spindle. The spindle cover is fastened to the table. The other three are located outside the spindle cover and are above the table. Circular steel blocks were used to replace and mimic the effects of the actual bearings. These blocks are of the same thickness as the bearing and are of Class RC-6 fit to the spindle. The bearing blocks are well oiled to maintain the same effect as the bearing over the spindle.

These bearings are held in position with the help of rectangular blocks with circular opening in the middle to accommodate the spindle along with the bearing. These are given a tight clearance fit so that they are held in place. Holes of 5/16" diameter with half an inch depth 
are drilled on the sides of these rectangular blocks. These blocks are held against the side-support plates with the help of socket screws.

\subsubsection{Hammer - Setup}

The purpose of the hammer-setup was to excite the spindle system. The excitation setup consists of a hammer attached to the base of the table, as shown in Figure 25. The hammer has to be placed such that it does not interfere with the spindle tool post when it swings to hit the toolholder. A 24-oz hammer was used for this purpose; a U-clamp was attached to the base of the spindle cover. A revolute joint was made to the top of the hammer, held in place by the U-clamp. In order to measure the vibration accurately, the test has to be carried out at two spots that are $90^{\circ}$ from each other. The distance of the hammer from the centre to these spots has to be same. The other spot has an L-shaped plate to which the U-clamp and the hammer were attached and it has been designed in such a way that the distance of the hammer is same as the previous case. The length of the hammer has been modified so that the hammer hits at about $7.5 \mathrm{~cm}$ above the tool end. This spot was chosen as the damage to tool can be avoided in this region.

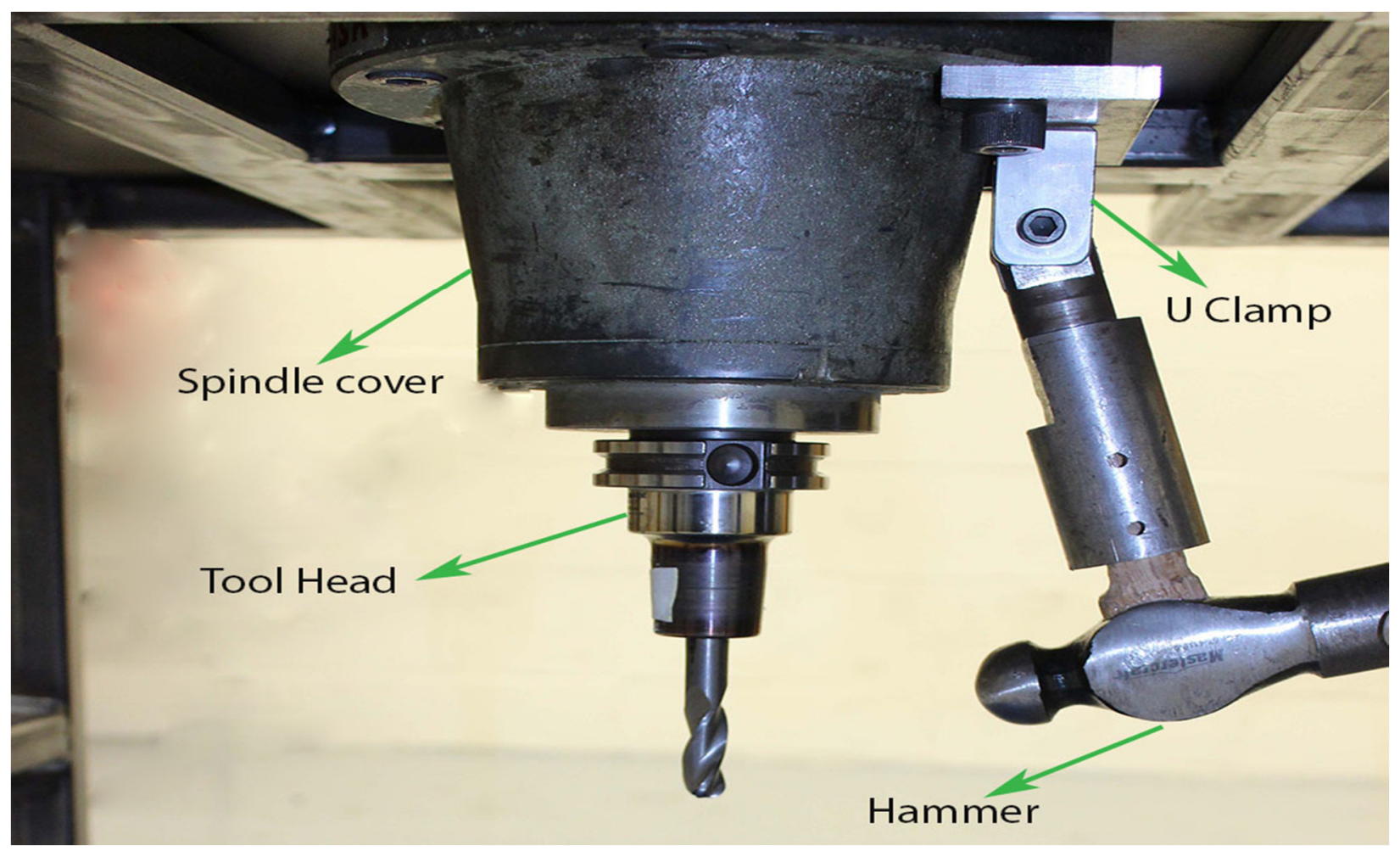

Figure 25: Spindle and excitation hammer-setup 


\subsubsection{Table Leg}

The legs of the table are made up of HSS with rectangular cross-section. These steel structures are not only light in weight, but also offer good resistance against torsional loads and bending moments. The length of the legs is kept to be minimal so that they stay close to the ground and offer better support to the entire setup. The legs are welded to the base of the table by fillet weld with half an inch thickness. They are located inward to provide better support as most of the load is concentrated at the centre. Steel structures run from one leg to the other as shown in Figure 24, providing support to the structure and prevent buckling of the legs. These steel supports are welded to the legs of the table.

\subsubsection{Gusset Plate}

Gusset plates were welded to the end of the table legs. These plates are rectangular in shape and are about quarter of an inch thick. They have a hole of .5" in diameter in each corner. The table legs have to be firmly rooted to the ground in order to avoid unwanted movement of the table. The gusset plates help to attain that purpose. The table has to be placed in level ground and in order to ensure that, two layers of aircraft grade rubber mats are placed below the gusset plate to compensate for unevenness in the ground. Holes of about 1.5" in depth were made in the ground and were in line with the holes from the gusset plate. Expansion anchor bolts were used to anchor the gusset plates to the ground. These bolts fix the legs firmly to the ground.

\subsubsection{Cross-bars}

The table has to be strong enough to hold the enormous weight of the spindle and the side support. The ways in which the table of sufficient strength can be obtained is either by having a table of substantial thickness or strengthening it by cross-bars. The former method, although effective, will significantly increase the weight of the setup thereby causing excessive stress on the legs of the table. The latter method is much more convenient and cost-effective with less weight. Since significant amount of load is concentrated at the centre, that section has to be strengthened against buckling. Two HSS steel structures were placed perpendicularly on either side of the centre hole on bottom of the table and two more along the edges, they run along entire length of the table. These steel structures were intermittently welded to the table, with weld length of $2 "$ and pitch of 4". There are two horizontal supports to the two long HSS tubes near 
the centre. These horizontal cross-bars were also intermittently welded with the same dimension. Thus these cross-bars provide sufficient strength to the table.

\subsection{Data Acquisition Setup}

The data acquisition setup helps to collect real physical quantities like temperature, pressure, displacement and convert them into digital signals, which are interpreted and processed by computers. In simple terms, they help to visualize complex physical phenomena happening in a system. A general data acquisition setup comprises of a sensor/transducer to collect the physical information and convert them into electrical signals. These electrical signals are collected and processed by the data acquisition hardware for the computers to interpret. The data acquisition software helps to analyse the digital input and visualize the results.

\subsubsection{Accelerometer}

Accelerometers are sensors, as shown in Figure 26, used to measure the dynamic acceleration of the physical device. In this case, they are used to sense the displacement of the spindle. The 7104A-0050 IEPE accelerometers used convert physical displacement into electrical signals using piezoelectric effect. Internal Electronic Piezoelectric (IEPE) type accelerometers do not require external amplifiers, as they have built-in charge amplifiers. The accelerometers have a range of up to $50 \mathrm{~g}$ and an operating temperature range of -50 to $125{ }^{\circ} \mathrm{C}$. They require external current to power the built-in amplifier. The amplified electrical signals from the accelerometers are sent to the DAQ hardware through a coaxial cable.

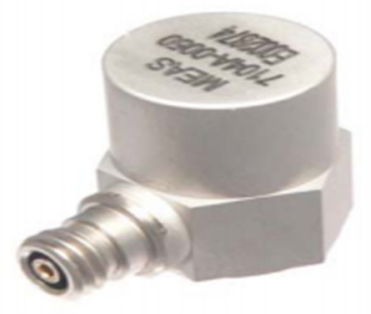

Figure 26: Accelerometer 


\subsubsection{Data Acquisition Hardware}

The DAQ hardware is the interface between the signal acquired from the sensor and the computer. In the DAQ hardware, the electrical signal obtained from the amplifier is converted to digital signal using analog to digital convertor. The digital signal is then sent to the computer, where the analysis and storage of data takes place. The DAQ hardware used is the commercially available QuantumX® MX440A model from HBM Instruments. It has dedicated 4-channel configurable inputs, which are electrically isolated, a data rate of up to $19,200 \mathrm{~Hz}$ as well as support Transducer Electronic Data Sheet (TEDS). The digital signal from the DAQ hardware is sent to the computer through Ethernet connection. The data acquisition hardware used in testing is shown in Figure 27.

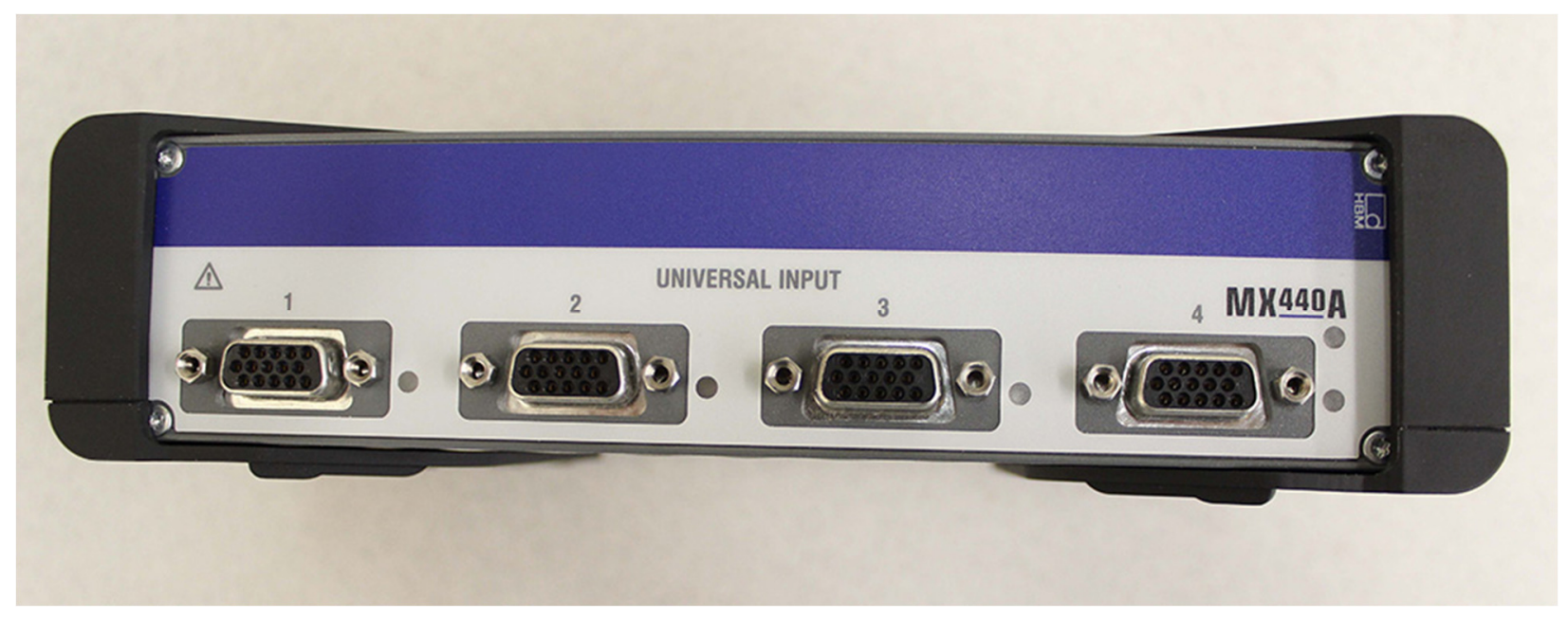

Figure 27: Data acquisition hardware

\subsubsection{Data Acquisition Software}

The digital signal received from the DAQ hardware has to be analysed, which is done by the DAQ software. There are many commercially available software for performing the analysis, catman ${ }^{\circledR}$ Easy/AP version 3.3 is used in these experimental analysis. The data obtained can be analysed in real-time, while the test is being carried out on the setup. The catman ${ }^{\circledR}$ Easy/AP has three sections, namely DAQ channels, DAQ jobs, and visualization.

\section{DAQ channels:}

The channels in the DAQ hardware were assigned their respective accelerometers through this section. The accelerometers power requirement along with the sensitivity data, were 
entered into the sensor database. The accelerometers can be enabled/disabled through DAQ channels, which can be identified from the indicator sign.

DAQ jobs:

In the DAQ jobs section, the sampling rate for the test was entered. The ideal sample rate is usually taken ten times the maximum frequency measured, in order to avoid alias effect. Therefore, for the test conducted, the sampling frequency was taken as 19,200 Hz. There are DAQ start and stop functions, which specify the conditions for data collection. A particular channel can be set as trigger channel under trigger mode. When the channel reaches the specified value, the data collection might start or stop. The post-trigger option gives the command to collect data till a specified time, after the channel has reached an indicated value.

\section{Visualization:}

The digital signal sent by the hardware to the computer has to be interpreted in a meaningful way, which is done with the help of visualization option. It has real-time graph, analog meter, digital indicator and frequency spectrum functions. These functions are plotted in real-time. The Fast Fourier Transform (FFT) converts the sample function (displacement-time function) from its original time domain to the frequency domain using computer algorithms. From FFT, the frequency plot is obtained. The collected information from the sensors, along with the analysis can be stored in different formats using DAQ software.

\subsection{Experimental tests}

In order to verify the numerical models developed in Chapter 3, impact tests were performed on both the spindle and the experimental table-setup. The impact force was provided by the hammer and the vibrations of the system were captured using the accelerometers. The electrical signals from the sensor were relayed to the DAQ hardware, which converts them into digital signals. These were processed and analysed by the data acquisition software and the final FFT graphs were plotted. The FFT graphs provide the natural frequencies of the system under test. Two sets of experiments were carried out; the first one was intended to find the natural frequency of the experimental table-setup and the second was to evaluate the natural frequency of the spindle. The complete experimental setup used during testing is shown in Figure 28. The accelerometer calibration setup was used to calibrate the accelerometers. An acceleration of $1 \mathrm{~g}$ 
was given to the accelerometer and the time domain plot was verified for the output, which showed $1 \mathrm{~g}$ acceleration along the $\mathrm{y}$-axis of the plot. A test was also conducted on a beam with known natural frequency to find the accuracy of the setup used and was found to be within agreeable limits.

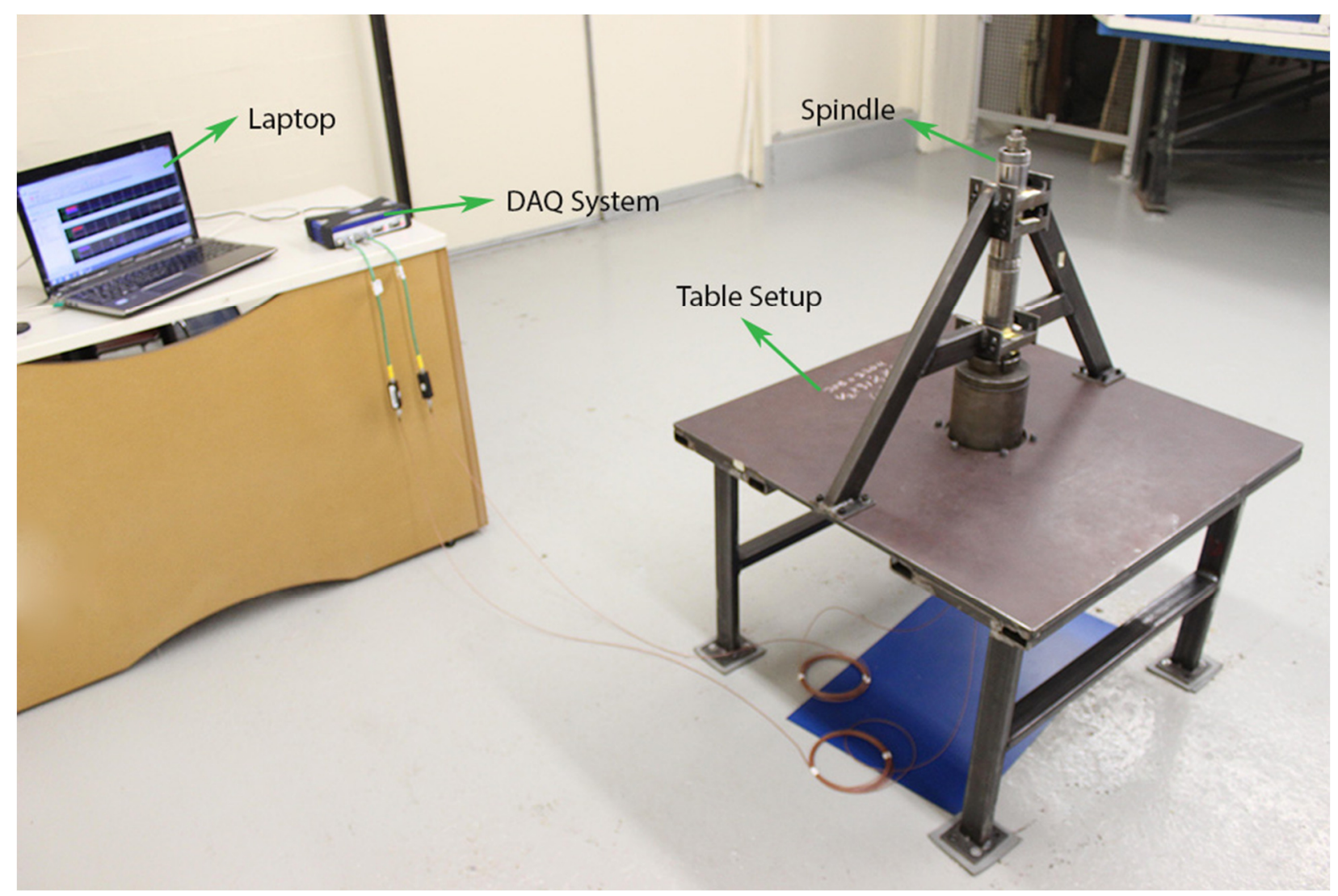

Figure 28: Experimental setup

\subsubsection{Impact test on the experimental table-setup}

The impact test was conducted on the table setup, as shown in Figure 29. The spindle along with the bearing blocks were removed from the setup, leaving just the table and the two side supports. Two accelerometers were used to collect the physical data from the table. The first accelerometer was placed in-line with the point of impact of the hammer along the X-axis, as the displacement being maximum in that area. The other accelerometer was placed perpendicular to the first accelerometer along the Y-axis. The accelerometers were connected to DAQ hardware, connected in turn to the laptop running DAQ analysis software and the required initial setup, as mentioned in the previous section 4.2, were performed. The time domain graph, as shown in 
Figure 30 and FFT graph were displayed in the computer screen. About 15 impact tests were conducted on the table and the natural frequency of $32.5 \mathrm{~Hz}$ was recorded from the FFT graph as shown in Figure 31. Next the impact point was along the Y-axis and the accelerometer along Yaxis measured the displacement and the Figure 32 shows the resulting FFT graph. Both the FFT graphs obtained show the natural frequency of the table setup to be $32.5 \mathrm{~Hz}$.

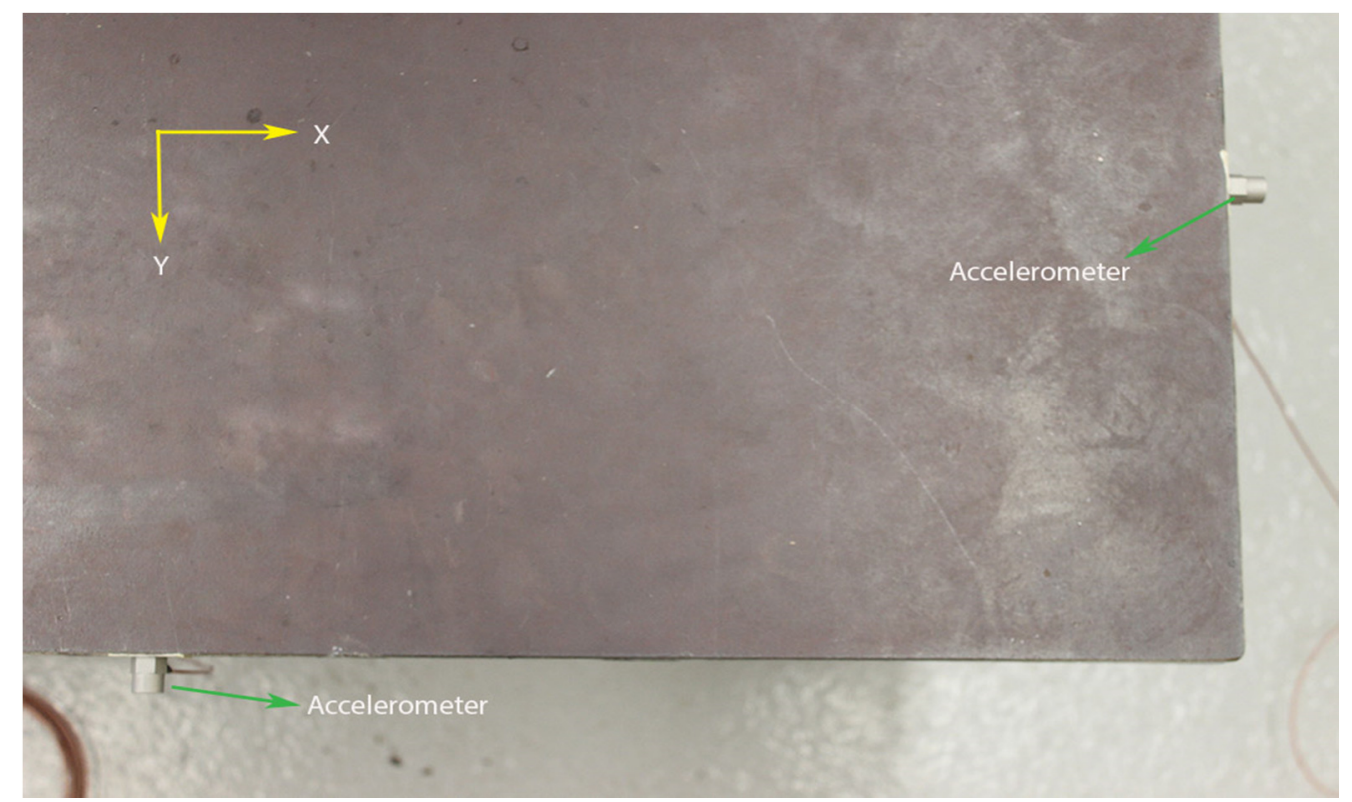

Figure 29: Location of accelerometers for impact test on experimental table-setup

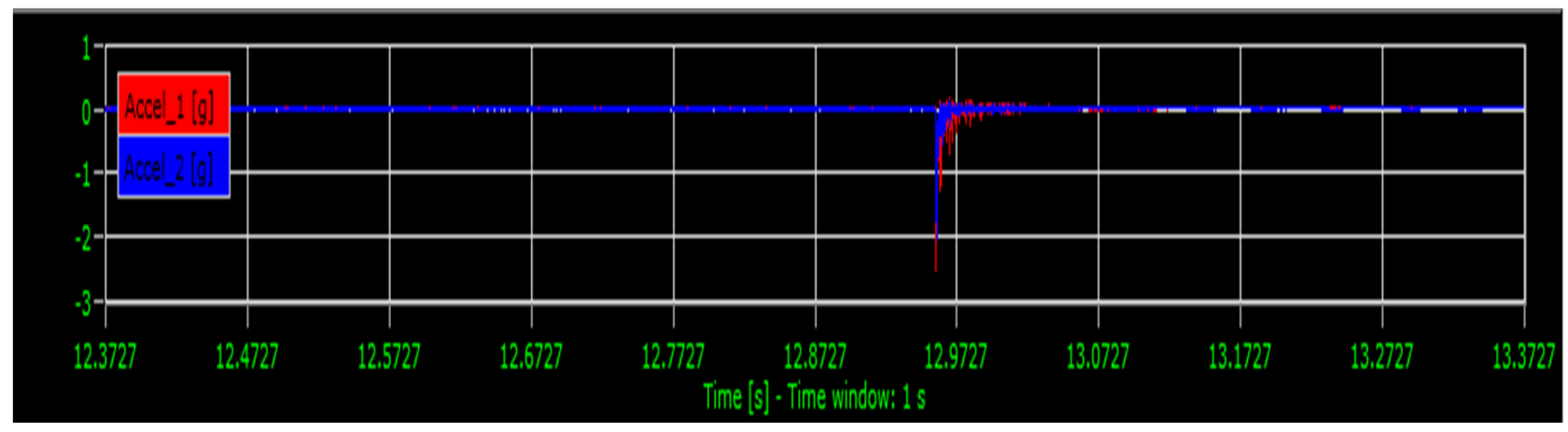

Figure 30: Time domain plot of table setup 


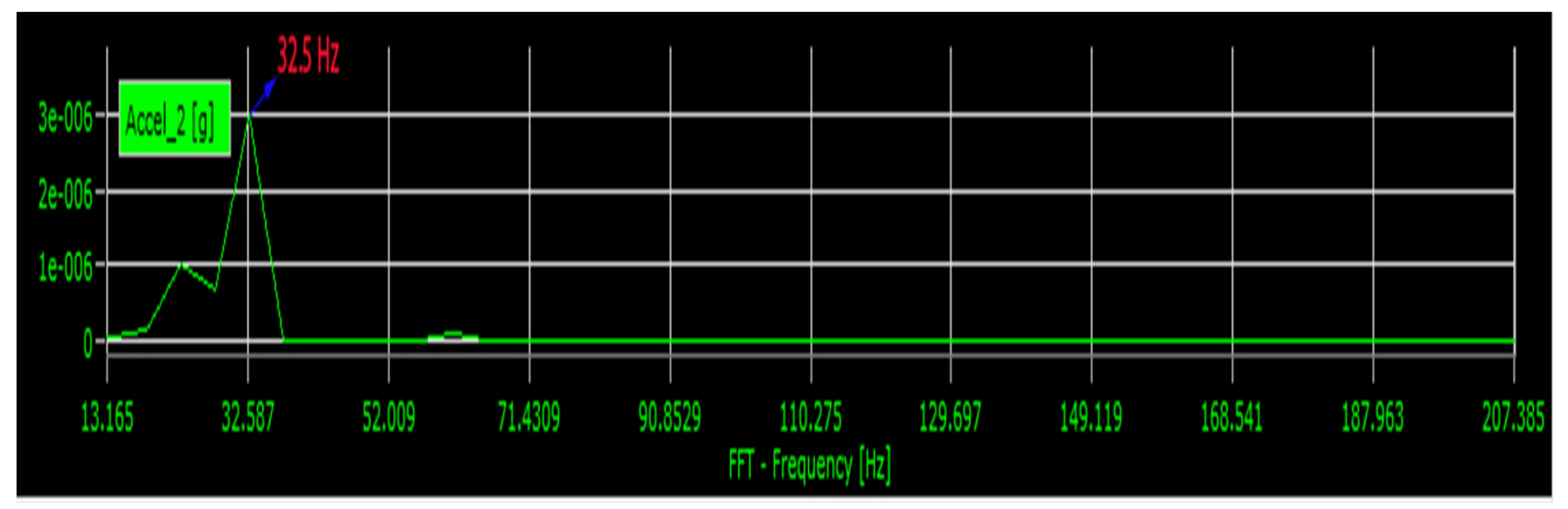

Figure 31: FFT plot for table setup in X-direction

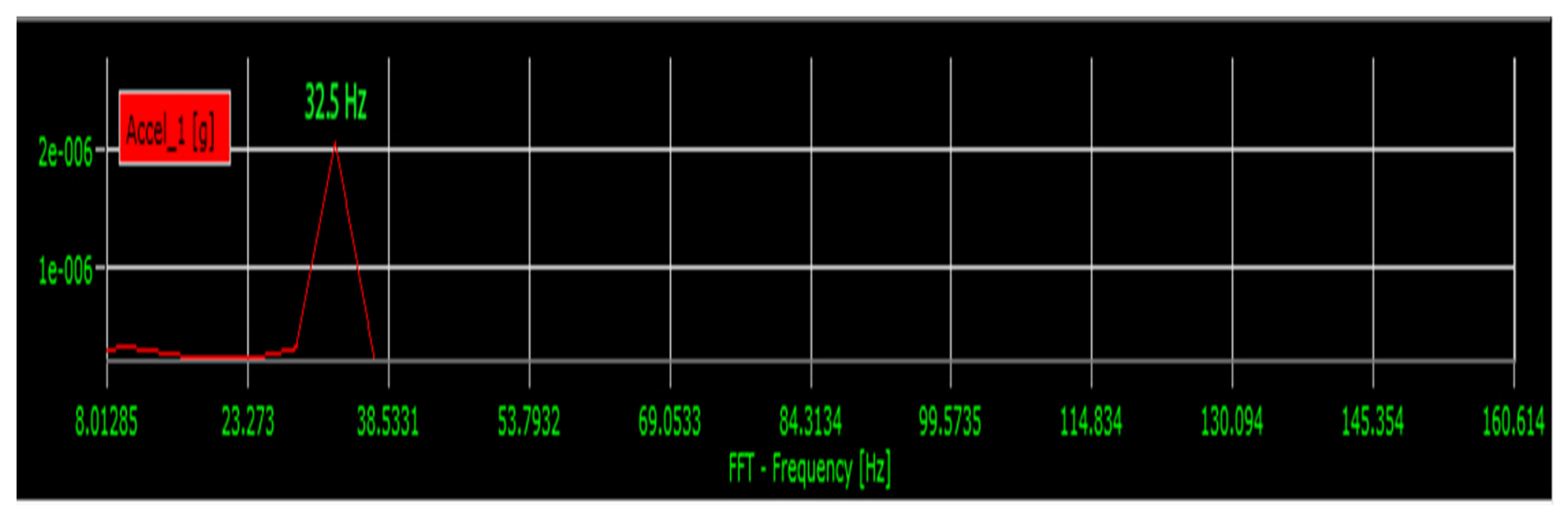

Figure 32: FFT plot of table setup in Y-direction 


\subsubsection{Impact test on the spindle setup}

The impact test for the spindle setup was then performed, as shown in Figure 33. For this, the spindle was placed on the table and secured tightly. The bearing blocks were placed in their respective locations and tightened along with the side supports. The hammer setup was fixed to the base of the spindle cover. Accelerometers should be placed on flat surfaces to better capture the displacements. Therefore, in this case they were placed on the tool head as it had almost a flat surface. The procedure similar to section 4.3.1 was also conducted for this test. Figure 34 shows the displacement function of the spindle setup. At first, the impact was made in line with the Xaxis and the accelerometer along that direction was used to measure the displacement. The FFT graph obtained for that procedure is shown in Figure 35. Then, the impact was made along the Y-axis and the accelerometer placed along Y-axis was activated to collect the data. Figure 31 shows the FFT for the impact along Y-axis. In both the cases, the frequency at $1471 \mathrm{~Hz}$ was observed to be dominant. 15 impact tests were conducted on the spindle setup, the resulting natural frequencies had a maximum value of $1471 \mathrm{~Hz}$ and a minimum of $1436 \mathrm{~Hz}$. For the purpose of comparison, the average between these values, which is $1453.5 \mathrm{~Hz}$ was taken as the natural frequency of the spindle-setup.

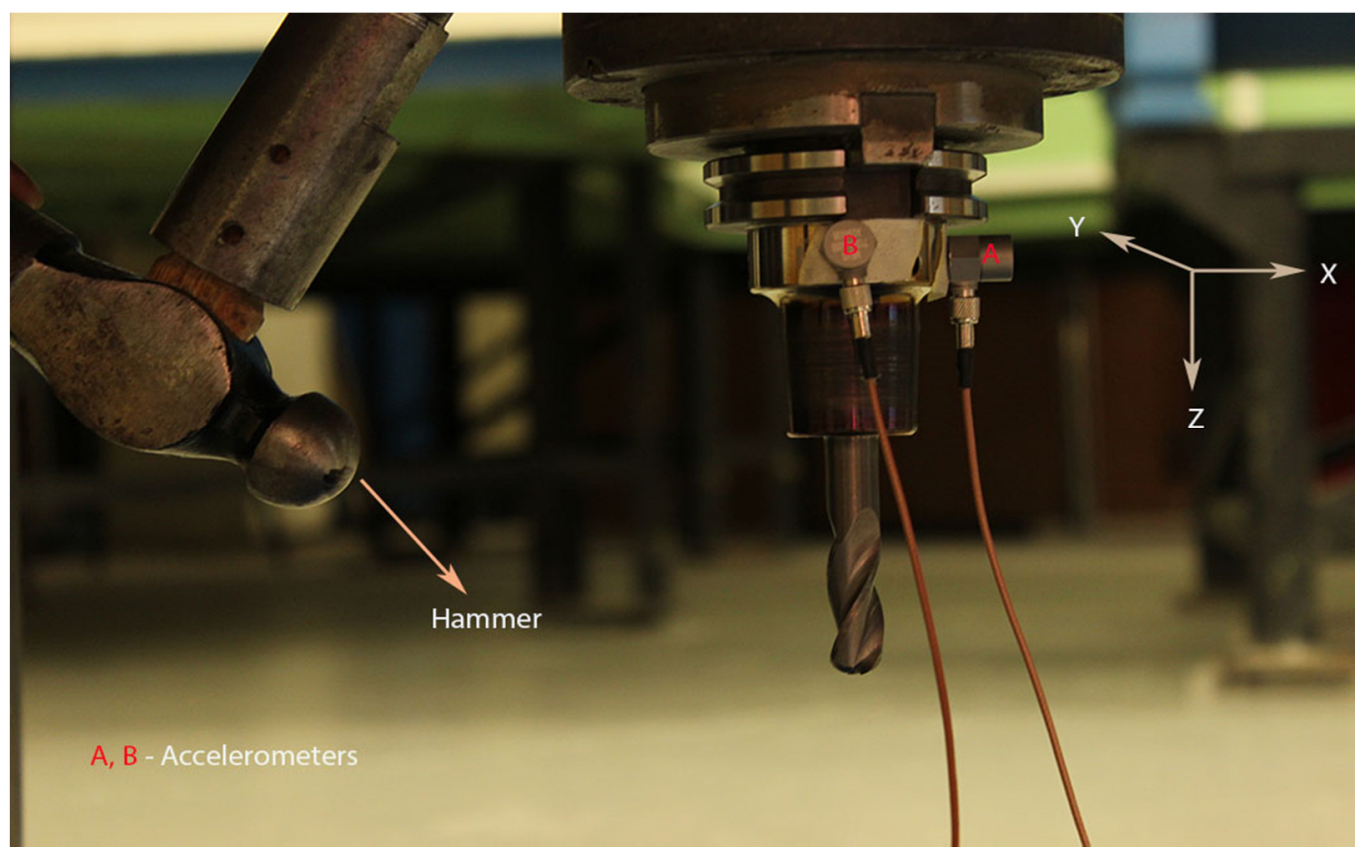

Figure 33: Location of accelerometers for impact testing on the spindle setup 


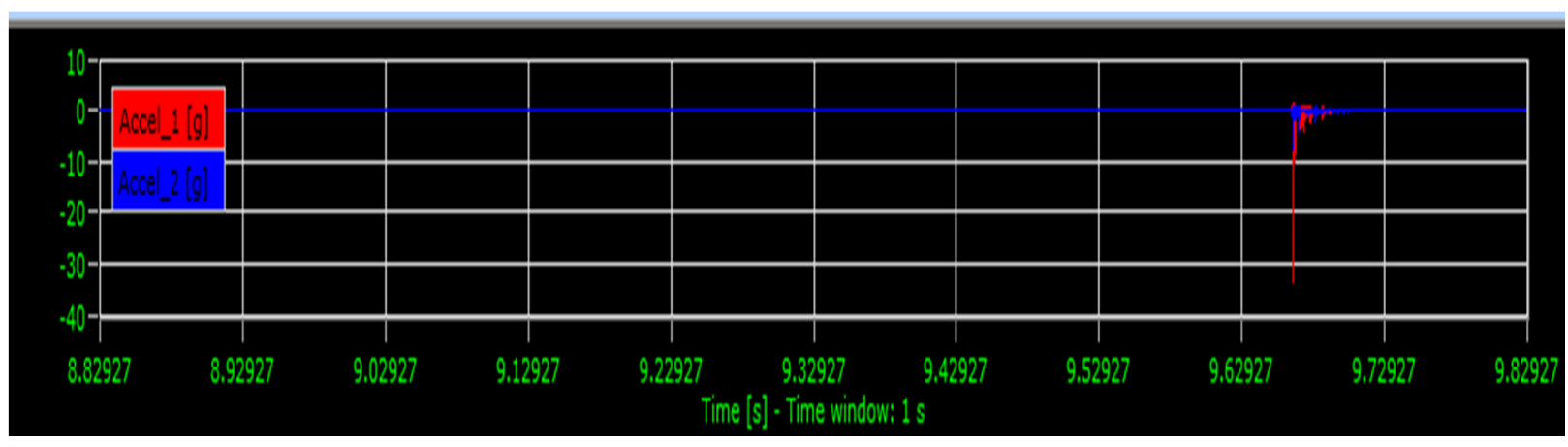

Figure 34: Time domain plot of spindle setup

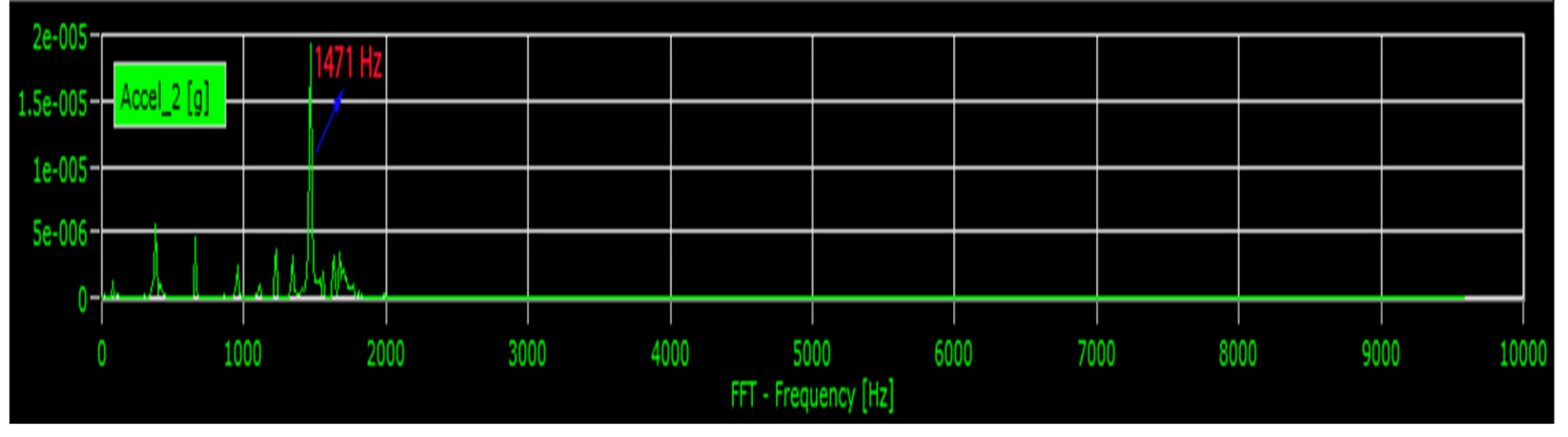

Figure 35: FFT plot at tool head in X-direction

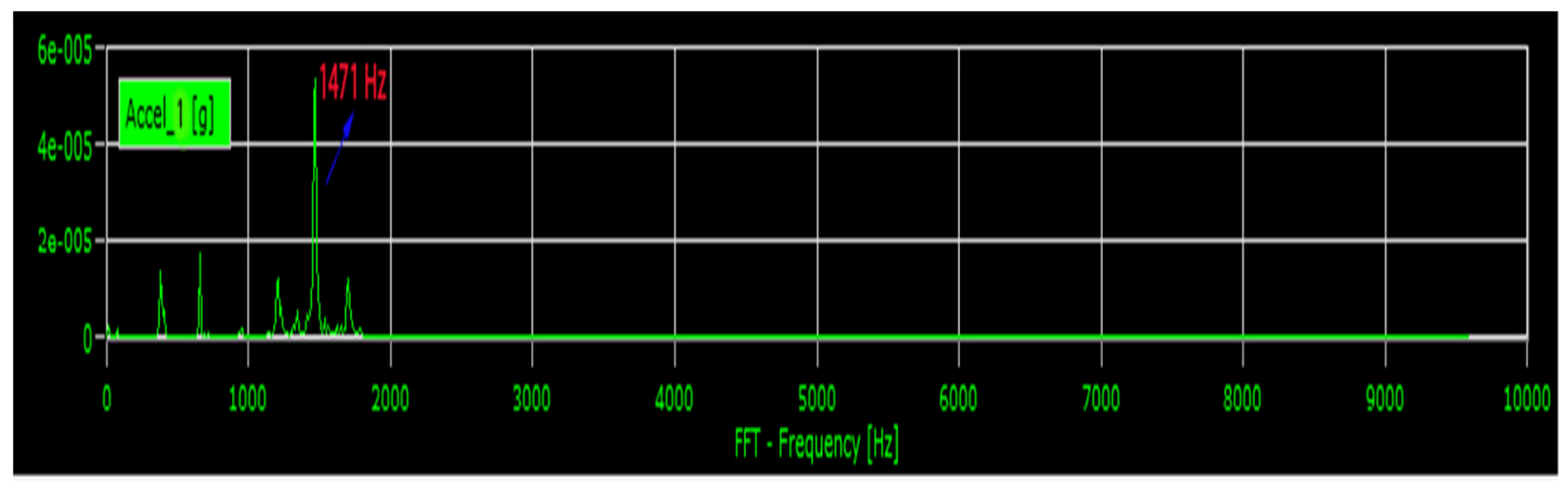

Figure 36: FFT plot at tool head in Y-direction 


\subsection{Discussion}

The experimental setup designed and fabricated to validate the numerical spindle model developed in chapter 3, was discussed. The setup consists of a table, designed specially to hold the spindle in the manner similar to the actual setup. Hollow steel structures were used to prevent bending and provide stiffness to the structure with minimal weight.

The dynamics of the spindle and table were observed experimentally in section 4.3.1 and 4.3.2. The tool was excited using a hammer and the responses were captured using an accelerometer. This type of impulse test technique is well suited for non-rotating spindle and tool. From the experimental impact tests, the natural frequency of the table-setup was measured to be $32.5 \mathrm{~Hz}$ and the natural frequency of spindle was observed to be $1453.5 \mathrm{~Hz}$.

Table 8: Comparison of impact test and simulation results

\begin{tabular}{|c|l|l|l|l|}
\hline Structure & Element type & \multicolumn{1}{|c|}{ Simulation } & $\begin{array}{c}\text { Impact test } \\
\text { (Average) }\end{array}$ & Variation \\
\hline Spindle & BEAM188 & $1482 \mathrm{~Hz}$ & $1453.5 \mathrm{~Hz}$ & $\sim 3 \%$ \\
\hline Spindle & SOLID187 & $1485.7 \mathrm{~Hz}$ & $1453.5 \mathrm{~Hz}$ & $\sim 3 \%$ \\
\hline Table-setup & SOLID187 & $35.2 \mathrm{~Hz}$ & $32.58 \mathrm{~Hz}$ & $\sim 8 \%$ \\
\hline
\end{tabular}

A difference of about 3\% observed in Table 8, between the simulation and the experimental results of the spindle setup. The actual bearings were replaced by bearing blocks; this also has a mild effect on the experimental result. In actual machining environment, the spindle is housed inside the milling machine, where machine speed adjusting belts from the spindle motor are attached to the spindle. Experimental setup in [24] had the spindle hanging from a support, which might result in inaccuracies during impact testing. This has been overcome in the current setup with the use of side-supports, which provides proper support at the bearing points and closely replicates the actual machine settings. The possibility of vibrations not being captured completely, if the accelerometers are not placed exactly in-line with the point of impact might attribute for the $8 \%$ variation observed for the table. 


\section{Conclusion}

The productivity of aerospace and automotive manufacturing sector is often plagued by the occurrence of the chatter phenomenon. Chatter occurrence has been linked to the natural frequency of the entire system, consisting of the tool, tool-holder, spindle and work piece. In general, chatter is associated with the spindle system and in particular the cutting force generated during machining. Since conducting impact test often to identify the natural frequency of the spindle system is a tedious process, a numerical model of the spindle was developed in this thesis, using commercial software ANSYS ${ }^{\circledR}$. In order to validate the FE results, impact tests were carried out on the spindle in the specially designed experimental test cell. Even though there were minor variations between the experimental and simulated results, they were still within the agreeable limits.

The mathematical model of the spindle system using beam elements was developed using classical finite element method and non-spin condition was applied to the spindle elements. The dynamic equation of the system and development of the equations were explained in chapter 2. The numerical model of the spindle system was developed in ANSYS $^{\circledR}$ software using BEAM188 and SOLID187 elements. COMBIN14 elements were used to model the bearings, by varying the spring constant value of these elements the spindle's natural frequency was tuned to obtain the nominal value reported by the manufacturer. The beam elements converged faster than the solid elements. The frequencies resulting from solid element model were found to be lower than those obtained from the beam element model, which could be associated with the shear/rotary inertia effects present in the former model.

Impact tests were carried out on both the spindle, placed on a designed table-setup and the table-setup. The impact force was provided by the hammer-setup and the displacements were captured using accelerometers. Data acquisition system was used to measure and analyze the output from the accelerometers. The natural frequencies of the system were found from the FFT analysis. Calibration tests were conducted to find the accuracy of the accelerometers and were found to be satisfactory. Impact tests were performed in both $\mathrm{x}$ and $\mathrm{y}$ direction of the spindle and table setup. The natural frequency of $32.58 \mathrm{~Hz}$ was found for the table-setup. The average first natural frequency of the spindle-setup was taken as $1453.5 \mathrm{~Hz}$, after conducting 15 impact tests with the maximum first natural frequency of $1471 \mathrm{~Hz}$ and minimum of $1436 \mathrm{~Hz}$. Thus, the numerical spindle model developed here resembles close to the actual spindle. The natural 
frequency found from the simulations and experimental tests were similar and within acceptable limits.

For future works, the numerical model of the spindle can be developed taking into account the effect of the spindle speed on the natural frequency of the system. Furthermore, the stability lobe diagram (SLD) for the system can be developed based on the results obtained from the numerical model developed for the spindle. Finally, this model can also be extended to study the effects of bearing life and damage on the natural frequency of the spindle. For that purpose, more enhanced bearing models can also be investigated. 


\section{Bibliography}

1. McKinsey \& Company. Manufacturing the future : The next era of global growth and innovation. s.1. : McKinsey \& Company, November 2012.

2. Guillem Quintana, Joaquim Ciurana. Chatter in machining processes: A review. s.1. : Internationla Journal of Machine Tools \& Manufacture, 2011. pp. 363-376. Vol. 51.

3. Taylor. On the art of cutting metals. s.1. : Trans ASME, 1907. pp. 31-350. Vol. 28.

4. R.P.H.Faassen. Chatter prediction and control for high speed milling: modelling and experiments. s.1. : Technische Universiteit Eindhoven;Thesis, 2007.

5. W, Schmidt. Zur Dynamik der Werkzeugmaschine. s.1. : Z.V.D.I, 1941. p. 249. Vol. 85.

6. R.N, Arnold. The mechanism of tool vibration in the cutting of steel. 1946. pp. 261-283. Vol. 154.

7. Freshwich, Tobias SA. The chatter of lathe tools under orthogonal cutting condition. s.1. : Transactions of ASME, 1958. pp. 1079-1088. Vol. 80.

8. F, Eisele. Machine Tool Research at the Technological University of Munich. s.1. : International journal of machine tool design and research, 1961. pp. 249-274. Vol. 1.

9. S.A, Tobias. Machine Tool Vibration. s.1. : International Journal of Maching Tool Design and Research, 1961. pp. 1-14. Vol. 1.

10. Tlusty J, Polacek M. The stability of machine tools against self excited vibrations in machining. Pittsburg : Proceedings of International Research in Production Engineering Conference, 1963. pp. 465-474.

11. Tobias S.A, Gurney J.P. A graphical method for the determination of the dynamic stability of the machine tools. s.l. : International Journal of Machine Tool Design and Research. pp. 148156. Vol. 1.

12. Sridhar R, Hohn R.E, Long G.W. A general formulation of the milling process equation, contribution to the machine tool chatter research- 5. s.1. : ASME Journal of Engineering for Industry, 1968. pp. 317-324. Vol. 90.

13. Optiz H, Bernardi F. Investigation and Calculationof the Chatter Behaviour of Lathes and Milling Machines. s.l. : Annals of the CIRP, 1970. pp. 335-343. Vol. 18.

14. Ioannis Minis, Rafael Yanushevsky, Abel Tembo and Robert Hocken. Analysis of Linear and Nonlinear Chatter. s.1. : CIRP Annals Manufacturing Technology, 1990. pp. 459-462. Vol. 39. 
15. Tlustly J, Ismail F. Basic Non-Linearity in Machining Chatter. s.l. : CIRP AnnalsManufacturing Technology, 1981. pp. 299-304. Vol. 30(1).

16. Yoshitaka K, Osame K, Hisayoshi S. Behaviour of Self-Excited Chatter due to Multiple Regenerative Effect. s.1. : Journal of Engineering for Industry, 1981. pp. 324-329. Vol. 103(4).

17. Tlusty T, Ismail F. Special Aspects of Chatter in Milling. s.l. : Journal of Vibration, Acoustics, Stress and Reliability in Design, 1983. pp. 24-32. Vol. 105(1).

18. Altintas Y, Budak E. Analytical Prediction of Stability Lobes in Milling. s.1. : CIRP AnnalsManufacturing Technology, 1995. pp. 357-362. Vol. 44(1).

19. Chiou R.Y, Liang S.Y. Chatter stability of a slender cutting tool in turning with tool wear effect. s.l. : International Journal of Machine Tools and Manufacture, 1998. pp. 315-327. Vol. $38(4)$.

20. Clancy B.E, Shin Y.C. A Comprehensive Chatter Predicition Model for Face Turning Operation including Tool Wear. s.l. : International Journal of Macine Tools and Manufacture, 2002. pp. 1035-1044. Vol. 42(9).

21. Mackerle, Jaroslav. Fininte Element Analysis and Simulation of Machining: a bibiliography (1976-1996). s.1. : Journal of Materials Processing Technology, 1999. pp. 17-44. Vol. 86.

22. W.L, Wang Z.C,Cleghorn. Stability analysis of spinning stepped-shaft workpieces in a turning process. s.1. : Journal of Sound and Vibration, 2002. pp. 356-367. Vol. 250.

23. K.E, Baker J.R and Rouch. Use of finite element structural models in analyzing machine tool chatter. s.l. : Finite Elements in Analysis and Design, 2002. pp. 1029-1046. Vol. 38.

24. Budak.E, Erturk.A ,Ozuguven .H.N. A Modeling Approach for Analysis and Improvement of Spindle-Holder-Tool Assembly Dynamics. s.1. : CIRP Annals - Manufacturing Technology, 2006. pp. 369-372. Vol. 55(1).

25. Budak.E, Erturk.A, Ozuguven .H.N. Analytical modeling of spindle-tool dynamics on machine tools using Timoshenko beam model and receptance coupling for the prediction of tool point FRF. s.1. : International Journal of Machine Tools and Manufacture, 2006. pp. 1901-1912. Vol. 46.

26. Budak.E, Erturk.A, Ozuguven .H.N. Selection of design and operational parameters in spindle-holder-tool assemblies for maximum chatter stability by using a new analytical model. s.l. : International Journal of Machine Tools and Manufacture, 2007. pp. 1401-1409. Vol. 47.

27. Budak.E, Erturk.A, Ozuguven .H.N. Effect analysis of bearing and interface dynamics on tool point FRF for chatter stability in machine tools by using a new analytical model for spindle- 
tool assemblies. s.1. : International Journal of Machine Tools and Manufacture, 2007. pp. 23-32. Vol. 47.

28. Zhang Xin-Yun, Wang Min, Zan Tao, Hu Jian Zhong. The static and dynamic analysis of high-speed electric spindle based on ANSYS. s.1. : 2011 Second International Conference on Digital Manufacturing and Automation, 2011.

29. Weiguang Li, Hongbin Pu, Quanquan Liu, Gang Chen, Song Zhang. Ansys-based dynamic analysis of high-speed motorized spindle. s.1. : 2009 International Conference on Computer Engineering and Technology, 2009.

30. Deping Liu, Hang Zhang, Zheng Tao, Yufeng Su. Finite element analysis of high-speed motorized spindle based on ANSYS. s.1. : The Open Mechanical Engineering Journal, 2011. pp. 1-10. Vol. 5.

31. R.S, Hahn. Metal cutting chatter and its elimination. s.1. : Trans ASME, 1953. p. 1075. Vol. 75.

32. Grabec I, Gradisek J and Govekar E. A new method for chatter detection in turning. s.l. : CIRP Annals - Manufacturing Technology, 1999. pp. 29-32. Vol. 48.

33. Dimla Sr D.E, Lister P.M. On-line metal cutting tool condition monitoring. I: force and vibration analyses. s.1. : International Journal of Machine Tools and Manufacture, 2000. pp. 739768. Vol. 40.

34. Liao Y.S, Young Y.C. A new on-line spindle speed regulation strategy for chatter control. s.1. : International Journal of Machine Tools and Manufacture, 1996. pp. 651-660. Vol. 36(5).

35. Chiou Y.S, Chung E.S, Liang S.Y. Analysis of tool wear effect on chatter stability in turning. s.1. : International Journal of Mechanical Science, 1995. pp. 391-404. Vol. 37(4).

36. Leskovar.P, Grabec.I and. Acoustic emission of cutting process. s.1. : Ultrasonics, 1977. pp. 17-20.

37. Liang S, Dornfeld D. Tool wear detection using time series analysis of acoustic emission. s.1. : Journal of Engineering for Industry- Transactions of ASME, 1989. pp. 199-205. Vol. 111.

38. Taylor C.M, Turner S, Sims N.D. Chatter, process damping and chip segmentation in turning: a signal processing approach. s.1. : Journal of Sound and Vibration, 2010. pp. 49224935. Vol. 329.

39. Y, Thomas M, Beauchamp. Statistical investigation of modal parameters of cutting tools in dry turning. s.1. : International Journal of Machine Tools and Manufacture, 2003. pp. 1093-1106. Vol. 43(11). 
40. Liang, Richard Y. Chiou, Steven Y. Chatter stability of a slender cutting tool in turning with tool wear effect. s.l. : International Journal of Machine Tools and Manufacture. pp. 315-327. Vol. 38(4).

41. Sekar.M, Srinivas.J, Kotaiah.K, Yang.S. Stability analysis of turning process with tailstock-supported workpiece. s.l. : The International Journal of Advanced Manufacturing Technology, 2009. pp. 862-871. Vol. 43.

42. Paurobally R, Siddhpura M. Experimental investigation of chatter vibrations in facing and turning processes. s.1. : World Academy of Science, Engineering and Technology, 2013. pp. 6065. Vol. 78.

43. Cao.Y, Altintas.Y. Modeling of spindle-bearing and machine tool systems for virtual simulation of milling operations. s.l. : International Journal of Machine Tools and Manufacture, 2007. pp. 1342-1350. Vol. 47.

44. Banerjee J.R, Su H. Development of a dynamic stiffness formulation and free vibration analysis of a spinning composite beam. s.1. : Computers and Structures, 2006. pp. 1208-1214. Vol. 84 .

45. Marciniak, Martin. Modal analysis of a tool holder system for a five axis milling machine. Toronto : BEng Thesis, Department of Aerospace Eng., Ryerson University, 2012.

46. L.Logan, Daryl. A first course in the Finite Element Method. s.1. : Wadsworth Group, 2002. pp. 29-32.

47. OKADA VM500 FANUC 6MB. Maintenance Manual.

48. ANSYS Inc. ANSYS Help and Element Reference. 2013.

49. Simulation of dynamic properties of a spindle and tool system coupled with a machine tool frame. Petr Kolar, Matej Sulitka, Miroslav Janota. s.l. : International Journal of Advanced Manufacturing Technology, 2011, Vol. 54, pp. 11-20. 


\section{Appendix A: Application of Galerkin's method}

The integration of the equation (37) is performed,

$$
\int_{0}^{L}\left(E I_{y y} U^{\prime \prime \prime}\right)\left[N_{u}\right] d z=0
$$

Integrating by parts is applied to this term and it results in

$$
\int_{0}^{L}\left[\left[N_{u}\right]^{T}\right]^{\prime \prime} E I_{y y} U^{\prime \prime} d z+E I_{y y}\left(\left[N_{u}\right]^{T} u^{\prime \prime \prime}-\left[\left[N_{u}\right]^{T}\right]^{\prime} u^{\prime \prime}\right)_{0}^{L}=0(\mathrm{~A} 1)
$$

The term on the right side is ignored as the beam is in free vibration. The second derivative of the displacement function is rewritten in terms of shape function derivative and displacement vector.

$$
\begin{gathered}
U^{\prime \prime}=\left(\frac{12}{L^{3}}\left(\hat{d}_{1 x}-\hat{d}_{2 x}\right)+\frac{6}{L^{2}}\left(\hat{\phi}_{1 y}+\hat{\phi}_{2 y}\right)\right) \hat{z}+\left(-\frac{6}{L^{2}}\left(\hat{d}_{1 x}-\hat{d}_{2 x}\right)-\frac{2}{L}\left(2 \hat{\phi}_{1 y}+\hat{\phi}_{2 y}\right)\right) \\
U^{\prime \prime}=\left[N_{u}\right]^{\prime \prime}\left\{d_{u}\right\}(\mathrm{A} 3)
\end{gathered}
$$

The second derivative of the shape function is found

$$
\left[\left[N_{u}\right]^{T}\right]^{\prime \prime}=\left[\begin{array}{c}
\frac{12 z-6 L}{L^{3}} \\
\frac{6 z L-4 L^{2}}{L^{3}} \\
\frac{-12 z+6 L}{L^{3}} \\
\frac{6 z L-2 L^{2}}{L^{3}}
\end{array}\right]
$$

Equation (A1) is can be modified into the following term

$$
\int_{0}^{L}\left[\left[N_{u}\right]^{T}\right]^{\prime \prime} E I_{y y}\left[N_{u}\right]^{\prime \prime} d z\left\{d_{u}\right\}=0(\mathrm{~A} 5)
$$

This will result in the following, in which the square matrix is known as stiffness matrix

$$
\frac{E I_{y y}}{L^{3}}\left[\begin{array}{cccc}
12 & 6 L & -12 & 6 L \\
6 L & 4 L^{2} & -6 L & 2 L^{2} \\
-12 & -6 L & 12 & -6 L \\
6 L & 2 L^{2} & -6 L & 4 L^{2}
\end{array}\right]\left\{\begin{array}{l}
d_{1 x} \\
\phi_{1 y} \\
d_{2 x} \\
\phi_{2 y}
\end{array}\right\}=0
$$




\section{Appendix B: Stiffness, Inertial and Gyroscopic matrix}

The stiffness matrix, $\mathrm{K}$ is given by

$\mathrm{K}=$

\begin{tabular}{|c|c|c|c|c|c|c|c|}
\hline$\frac{12 E I_{y y}}{L^{3}}-\frac{13 L \Omega^{2} \mu}{35}$ & 0 & 0 & $\frac{6 E I_{y y}}{L^{2}}-\frac{11 L^{2} \Omega^{2} \mu}{210}$ & $\frac{12 E I_{y y}}{L^{3}}-\frac{9 L \Omega^{2} \mu}{70}$ & 0 & 0 & $\frac{13 L^{2} \Omega^{2} \mu}{420}+\frac{6 E I_{y y}}{L^{2}}$ \\
\hline 0 & $\frac{12 E I_{x x}}{L^{3}}-\frac{13 L \Omega^{2} \mu}{35}$ & $\frac{6 E I_{x x}}{L^{2}}-\frac{11 L^{2} \Omega^{2} \mu}{210}$ & 0 & 0 & $-\frac{12 E I_{x x}}{L^{3}}-\frac{9 L \Omega^{2} \mu}{70}$ & $\frac{13 L^{2} \Omega^{2} \mu}{420}+\frac{6 E I_{x x}}{L^{2}}$ & 0 \\
\hline 0 & $6 E I_{x x}-11 L^{2} \Omega^{2} \mu$ & $4 E I_{x x}-L^{3} \Omega^{2} \mu$ & 0 & 0 & $-13 L^{2} \Omega^{2} \mu-6 E I_{x x}$ & 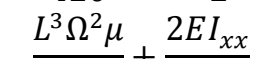 & 0 \\
\hline$G E I \quad 11 I^{2} O^{2} u$ & 210 & $\bar{L}-\overline{105}$ & $I^{2} I^{3} \Omega^{2}$ & $12 I^{2} O^{2}$ & 420 & $\overline{140}^{+}$ & $I^{3} O^{2}$ \\
\hline$\frac{6 E I_{y y}}{L^{2}}-\frac{11 L^{2} \Omega^{2} \mu}{210}$ & 0 & 0 & $\frac{4 E 1_{y y}}{L}-\frac{L^{3} \Omega^{2} \mu}{105}$ & $\frac{13 L^{2} \Omega^{2} \mu}{420}-\frac{6 E I_{y y}}{L^{2}}$ & 0 & 0 & $\frac{L^{3} \Omega^{2} \mu}{140}+\frac{2 E I_{y y}}{L}$ \\
\hline$-12 E I_{y y}-\frac{9 L \Omega^{2} \mu}{}$ & 0 & 0 & $13 L^{2} \Omega^{2} \mu-6 E I_{y y}$ & $\underline{12 E I_{y y}}-\underline{13 L \Omega^{2} \mu}$ & 0 & 0 & $11 L^{2} \Omega^{2} \mu \quad 6 E I_{y y}$ \\
\hline 70 & 0 & & 420 & 35 & 0 & 0 & 210 \\
\hline 0 & $-\frac{12 E I_{x x}}{L^{3}}-\frac{9 L \Omega^{2} \mu}{70}$ & $\frac{13 L^{2} \Omega^{2} \mu}{420}-\frac{6 E I_{x x}}{L^{2}}$ & 0 & 0 & $\frac{12 E I_{x x}}{L^{3}}-\frac{13 L \Omega^{2} \mu}{35}$ & $\frac{11 L^{2} \Omega^{2} \mu}{210}-\frac{6 E I_{x x}}{L^{2}}$ & 0 \\
\hline 0 & $\frac{13 L^{2} \Omega^{2} \mu}{420}+\frac{6 E I_{x x}}{L^{2}}$ & $\frac{L^{3} \Omega^{2} \mu}{140}+\frac{2 E I_{x x}}{L}$ & 0 & 0 & $\frac{11 L^{2} \Omega^{2} \mu}{210}-\frac{6 E I_{x x}}{L^{2}}$ & $\frac{4 E I_{x x}}{L}-\frac{L^{3} \Omega^{2} \mu}{105}$ & 0 \\
\hline$\frac{13 L^{2} \Omega^{2} \mu}{420}+\frac{6 E I_{y y}}{L^{2}}$ & 0 & 0 & $\frac{L^{3} \Omega^{2} \mu}{140}+\frac{2 E I_{y y}}{L}$ & $\frac{11 L^{2} \Omega^{2} \mu}{210}-\frac{6 E I_{y y}}{L^{2}}$ & 210 & 105 & $\frac{4 E I_{y y}}{L}-\frac{L^{3} \Omega^{2} \mu}{105}$ \\
\hline
\end{tabular}


The inertial matrix, $\mathrm{M}$ is given by

$$
M=\left[\begin{array}{cccccccc}
-\frac{13 L \mu}{35} & 0 & 0 & -\frac{11 L^{2} \mu}{210} & -\frac{9 L \mu}{70} & 0 & 0 & \frac{13 L^{2} \mu}{420} \\
0 & -\frac{13 L \mu}{35} & -\frac{11 L^{2} \mu}{210} & 0 & 0 & -\frac{9 L \mu}{70} & \frac{13 L^{2} \mu}{420} & 0 \\
0 & -\frac{11 L^{2} \mu}{210} & -\frac{L^{3} \mu}{105} & 0 & 0 & -\frac{13 L^{2} \mu}{420} & \frac{L^{3} \mu}{140} & 0 \\
-\frac{11 L^{2} \mu}{210} & 0 & 0 & -\frac{L^{3} \mu}{105} & -\frac{13 L^{2} \mu}{420} & 0 & 0 & \frac{L^{3} \mu}{140} \\
-\frac{9 L \mu}{70} & 0 & 0 & -\frac{13 L^{2} \mu}{420} & -\frac{13 L \mu}{35} & 0 & 0 & \frac{11 L^{2} \mu}{210} \\
0 & -\frac{9 L \mu}{70} & -\frac{13 L^{2} \mu}{420} & 0 & 0 & -\frac{13 L \mu}{35} & \frac{11 L^{2} \mu}{210} & 0 \\
0 & \frac{13 L^{2} \mu}{420} & \frac{L^{3} \mu}{140} & 0 & 0 & \frac{11 L^{2} \mu}{210} & -\frac{L^{3} \mu}{105} & 0 \\
\frac{13 L^{2} \mu}{420} & 0 & 0 & \frac{L^{3} \mu}{140} & \frac{11 L^{2} \mu}{210} & 0 & 0 & -\frac{L^{3} \mu}{105}
\end{array}\right]
$$


The gyroscopic matrix, $\mathrm{G}$ is given by

$$
\mathrm{G}=\left[\begin{array}{cccccccc}
0 & -\frac{26 L \Omega \mu i}{35} & -\frac{11 L^{2} \Omega \mu i}{105} & 0 & 0 & -\frac{9 L \Omega \mu i}{35} & \frac{13 L^{2} \Omega \mu i}{210} & 0 \\
\frac{26 L \Omega \mu i}{35} & 0 & 0 & \frac{11 L^{2} \Omega \mu i}{105} & \frac{9 L \Omega \mu i}{35} & 0 & 0 & -\frac{13 L^{2} \Omega \mu i}{210} \\
\frac{11 L^{2} \Omega \mu i}{105} & 0 & 0 & \frac{2 L^{3} \Omega \mu i}{105} & \frac{13 L^{2} \Omega \mu i}{210} & 0 & 0 & -\frac{L^{3} \Omega \mu i}{70} \\
0 & -\frac{11 L^{2} \Omega \mu i}{105} & -\frac{2 L^{3} \Omega \mu i}{105} & 0 & 0 & -\frac{13 L^{2} \Omega \mu i}{210} & \frac{L^{3} \Omega \mu i}{70} & 0 \\
0 & -\frac{9 \Omega \mu i}{35} & -\frac{13 L^{2} \Omega \mu i}{210} & 0 & 0 & -\frac{26 L \Omega \mu i}{35} & \frac{11 L^{2} \Omega \mu i}{105} & 0 \\
\frac{9 L \Omega \mu i}{35} & 0 & 0 & \frac{13 L^{2} \Omega \mu i}{210} & \frac{26 L \Omega \mu i}{35} & 0 & 0 & -\frac{11 L^{2} \Omega \mu i}{105} \\
\frac{13 L^{2} \Omega \mu i}{210} & 0 & 0 & -\frac{L^{3} \Omega \mu i}{70} & -\frac{11 L^{2} \Omega \mu i}{105} & 0 & 0 & \frac{2 L^{3} \Omega \mu i}{105} \\
0 & \frac{13 L^{2} \Omega \mu i}{210} & \frac{L^{3} \Omega \mu i}{70} & 0 & 0 & \frac{11 L^{2} \Omega \mu i}{105} & -\frac{2 L^{3} \Omega \mu i}{105} & 0
\end{array}\right]
$$


Appendix C: Dimensional data about the spindle

\begin{tabular}{|c|c|c|c|}
\hline $\begin{array}{l}\text { Length } \\
\times 10^{-3}(\mathrm{~m})\end{array}$ & $\begin{array}{l}\text { Diameter } \\
\times 10^{-3}(\mathrm{~m})\end{array}$ & $\begin{array}{l}\text { Radius } \\
\times 10^{-3}(\mathrm{~m})\end{array}$ & Parts \\
\hline 12.7 & 19.05 & 9.525 & \multirow{21}{*}{ Spindle } \\
\hline 25.4 & 25.4 & 12.7 & \\
\hline 12.7 & 19.05 & 9.525 & \\
\hline 73.216 & 50.038 & 25.019 & \\
\hline 19.05 & 50.038 & 25.019 & \\
\hline 30.823 & 50.038 & 25.019 & \\
\hline 47.752 & 50.038 & 25.019 & \\
\hline 27.318 & 55.294 & 27.647 & \\
\hline 19.05 & 55.294 & 27.647 & \\
\hline 33.566 & 55.294 & 27.647 & \\
\hline 19.05 & 55.294 & 27.647 & \\
\hline 62.065 & 55.294 & 27.647 & \\
\hline 12.7 & 55.294 & 27.647 & \\
\hline 26.784 & 86.821 & 43.4105 & \\
\hline 9.525 & 56.6858 & 28.3429 & \\
\hline 19.05 & 56.6858 & 28.3429 & \\
\hline 107.95 & 56.6858 & 28.3429 & \\
\hline 19.05 & 56.6858 & 28.3429 & \\
\hline 70.041 & 56.6858 & 28.3429 & \\
\hline 19.05 & 56.6858 & 28.3429 & \\
\hline 15.875 & 56.6858 & 28.3429 & \\
\hline 14.554 & 88.9 & 44.45 & \multirow{3}{*}{ tool holder } \\
\hline 15.901 & 63.436 & 31.718 & \\
\hline 15.964 & 44.374 & 22.187 & \\
\hline 34.341 & 30.7086 & 15.3543 & \multirow{2}{*}{ tool } \\
\hline 57.302 & 12.7 & 6.35 & \\
\hline
\end{tabular}


Appendix D: Section data for Beam elements

\begin{tabular}{|l|l|l|l|l|l|}
\hline Section ID & Shape & $\begin{array}{l}\text { Radius } \\
\times 10^{-3}(\mathrm{~m})\end{array}$ & $\begin{array}{l}\text { Length } \\
\times 10^{-3}(\mathrm{~m})\end{array}$ & $\begin{array}{l}\text { Number of cells } \\
\text { around the } \\
\text { circumference, N }\end{array}$ & $\begin{array}{l}\text { Number of } \\
\text { divisions } \\
\text { through the } \\
\text { radius, T }\end{array}$ \\
\hline 1 & circular & 9.525 & 12.7 & 15 & 5 \\
\hline 2 & circular & 12.7 & 25.4 & 15 & 5 \\
\hline 3 & circular & 25.019 & 170.841 & 15 & 5 \\
\hline 4 & circular & 27.647 & 173.749 & 15 & 5 \\
\hline 5 & circular & 43.4105 & 26.784 & 15 & 5 \\
\hline 6 & circular & 28.3429 & 260.541 & 15 & 5 \\
\hline 7 & circular & 44.45 & 14.554 & 15 & 5 \\
\hline 8 & circular & 31.718 & 15.901 & 15 & 5 \\
\hline 9 & circular & 22.187 & 15.964 & 15 & 5 \\
\hline 10 & circular & 15.3543 & 34.341 & 15 & 5 \\
\hline 11 & circular & 6.35 & 57.302 & 15 & 5 \\
\hline
\end{tabular}

